\title{
Understanding the Educational Experiences of Science Teachers in a Five-Year Teacher Education Program: A Phenomenological Study
}

Nitin Srivastava

Follow this and additional works at: https://researchrepository.wvu.edu/etd

\section{Recommended Citation}

Srivastava, Nitin, "Understanding the Educational Experiences of Science Teachers in a Five-Year Teacher Education Program: A Phenomenological Study" (2015). Graduate Theses, Dissertations, and Problem Reports. 6709.

https://researchrepository.wvu.edu/etd/6709

This Dissertation is protected by copyright and/or related rights. It has been brought to you by the The Research Repository @ WVU with permission from the rights-holder(s). You are free to use this Dissertation in any way that is permitted by the copyright and related rights legislation that applies to your use. For other uses you must obtain permission from the rights-holder(s) directly, unless additional rights are indicated by a Creative Commons license in the record and/ or on the work itself. This Dissertation has been accepted for inclusion in WVU Graduate Theses, Dissertations, and Problem Reports collection by an authorized administrator of The Research Repository @ WVU.

For more information, please contact researchrepository@mail.wvu.edu. 


\title{
Understanding the Educational Experiences of Science Teachers in a Five-Year Teacher Education Program: A Phenomenological Study
}

\section{Nitin Srivastava}

\author{
Dissertation submitted to the College of Education and Human Services \\ at West Virginia University \\ in partial fulfillment of the requirements \\ for the degree of
}

Doctor of Education

In

Curriculum and Instruction

\section{Committee of Advisors:}

Patricia Obenauf, Ed.D., Chair

Samuel Stack, Ph.D.

Randall Wiesenmayer, Ph.D.

Debra Hemler, Ed.D.

Charline Barnes Rowland, Ed.D.

\section{Department of Curriculum \& Instruction/ Literacy Studies Morgantown, West Virginia, 2015}

Keywords: Benedum Collaborative, teacher education program, science teachers, in-service teachers, pre-service teachers, professional development schools, phenomenology

Copyright (C) Nitin Srivastava 


\begin{abstract}
This qualitative study provides an overview of educational experiences of six in-service and three pre-service secondary science teachers in the Benedum Collaborative Five-Year Teacher Education Program at a land-grant university. The researcher interviewed secondary science teachers on the experiences they found meaningful in various program components that influenced their teacher identity, beliefs about science pedagogy, and their sense of preparedness for teaching. Document analysis of teachers' journals and lesson plans supplemented the qualitative data in addition to the researcher's role and knowledge as an outsider (non-Benedum graduate) and insider (facilitator and instructor in the technology integration based classes for one year) of the Benedum Collaborative Five-Year Teacher Education Program. Findings also supported the Holmes (1986) and Goodlad (1990) views for extended field experiences and "collaborative culture" in teacher education for well-prepared teachers.
\end{abstract}




\section{Dedication}

This dissertation is dedicated to all individuals who came in my life in the form of parents, mentors, teachers, siblings, advisors, professors, supervisors, colleagues, students, friends, relatives, pets, and all those who directly or indirectly were associated with me during my educational journey. A special thanks to my wife Sugandha, who has always supported me and showed remarkable patience during my educational journey as a doctoral student. I am grateful to all the members of my doctoral committee who supported me and showed immense faith in me toward writing and finishing this dissertation. 


\section{Acknowledgements}

Words fell short to describe the kind of positive influence Professor Patricia Obenauf brought to my educational life. It was her unconditional support and trust that ultimately encouraged me to finish my dissertation. I am very grateful to her for having faith in me and supporting me during times I thought I may not be able to cross the various milestones during my doctoral program. Pat, your care goes beyond the walls of academics for your students and has strongly influenced me as an academic advisor, researcher, and teacher. I entered the program as a scientist hoping to acquire some skills geared toward science education in the form of gaining some academic scholarship, but ultimately ended up learning to be more human. Professor Sam Stack, you have laid a strong social and cultural foundation in terms of various educational philosophies that really pushed me to think about this world out of my comfort zone and usual scientific-deductive way of analyzing things. Professor Randall Wiesenmayer, I am blessed to have taken various science education courses under your guidance, which exposed me to the social and cultural factors related to evolution of the various branches of the sciences. Those courses had profound effect on my understanding and worldview of science and science curriculum. Dr. Debra Hemler, your enthusiasm and optimism shown during our committee meetings were the sources of inspiration for me during my doctoral journey, right from my plan of study meeting to this point of dissertation completion. Dr. Charlene Barnes-Rowland, I am very thankful for your support and encouragement which helped me finish my dissertation.

My special thanks to Dr. Jeffrey Carver and Dr. John Stallings for their help and suggestions during my recruitment for the participants and planning process. Finally, I would like to thank all the participants who agreed to take part in this study despite their busy schedules. Your support has played a very important role in helping me complete my dissertation. 


\section{TABLE OF CONTENTS}

$\begin{array}{lc}\text { Abstract } & \text { ii } \\ \text { Dedication } & \text { iii } \\ \text { Acknowledgements } & \text { iv } \\ \text { Table of contents } & \text { v } \\ \text { Commonly used term } & \text { vi } \\ \text { Table of Figure } & \text { vili } \\ \text { Table of Tables } & \text { ix }\end{array}$

CHAPTER 1: INTRODUCTION

Introduction

My Personal Context 2

Problem Statement $\quad 12$

Purpose of the Research $\quad 15$

Research Questions 16

Theoretical Influences $\quad 17$

Dialogical Pedagogy of Freire $\quad 17$

Developmental Theory of Spiral Dynamics $\quad 19$

Hermeneutic Phenomenology: Being in the World and Understanding 26

Self and Others

Delimitations $\quad 28$

$\begin{array}{ll}\text { Limitation } & 28\end{array}$

CHAPTER 2 : LITERARUTRE REVIEW

$\begin{array}{ll}\text { Introduction } & 29\end{array}$

PART I

Reform Movement in Teacher Education $\quad 29$

Emergence of the Extended Model in Teacher Education Programs 33

Benedum Collaborative Five-Year Teacher Education Program at West Virginia 36

University

Elements of the Benedum Collaborative Five-Year Teacher Education Program 39

Part II

$\begin{array}{ll}\text { Teacher Development } & 42\end{array}$

Beliefs, Culture, Identity $\quad 43$

Beliefs Defined $\quad 43$

$\begin{array}{ll}\text { Culture Defined } & 44\end{array}$

Identity Defined $\quad 45$

Science Teachers' Pedagogical development 446

Interventions and Academic Cultures Within the Teacher Education Program 49

Teacher Identity and Growth in Self-Efficacy $\quad 51$

Intersection of Beliefs, Culture, and Identity as a Developmental Framework 55

$\begin{array}{ll}\text { Conclusion } & 56\end{array}$ 


\section{CHAPTER 3 : METHODOLOGY}

Qualitative Approach $\quad 58$

$\begin{array}{ll}\text { Shift from Positivist to Naturalist Paradigm } & 60\end{array}$

"I" as an Instrument and Validity Issues 61

Selection of Participants $\quad 65$

Participant Background Information 65

$\begin{array}{ll}\text { Data Collection } & 70\end{array}$

Interviews $\quad 70$

$\begin{array}{ll}\text { Documents } & 71\end{array}$

$\begin{array}{ll}\text { Triangulation } & 72\end{array}$

Data Analysis $\quad 73$

$\begin{array}{ll}\text { Conclusion } & 76\end{array}$

CHAPTER 4 : PRESENTATION OF THE FINDINGS

Introduction $\quad 77$

$\begin{array}{lr}\text { Participants' Prior Experiences } & 78\end{array}$

$\begin{array}{lr}\text { Main Research Question } & 80\end{array}$

Experiences in Culture of Science $\quad 82$

Experiences in Culture of Education $\quad 89$

Experiences in Professional Development Schools 103

Emergent Themes of Teaching and Learning 118

$\begin{array}{ll}\text { Conclusion } & 135\end{array}$

CHAPTER 5 : DISCUSSIONS

Introduction 136

Discussion on the Findings 138

Influence of Academic Cultures on Pedagogical Beliefs and Identity 141

Influence of Structured Field Experiences on the Perception of Teaching Preparedness 147

$\begin{array}{lr}\text { Implications } & 150\end{array}$

Future Research 153

Returning Back to My Personal Context 154

$\begin{array}{lc}\text { REFERENCES } & 156\end{array}$

$\begin{array}{lr}\text { APPENDICES } & 168\end{array}$

$\begin{array}{ll}\text { APPENDIX A Interview Invitation } & 169\end{array}$

APPENDIX B Interview Questions 170

APPENDIX C Clinical Experiences And Associated Teacher Education Courses $\quad 172$

APPENDIX D Characteristics of Novice Teachers 173

APPENDIX E Eight Developmental Zones 174

APPENDIX F Value Structures and their associated Learning and Teaching Styles 175 


\section{COMMONLY USED TERMS}

Pre-service secondary science teacher: Teacher enrolled in a teacher education program planning to teach in a middle or high school.

In-service secondary science teacher: Teachers graduated from a teacher education program licensed to teach science in a middle or high school.

Professional Development School (PDS): schools where teachers and administrators work with university faculty in partnership to improve teaching and learning through collaborative research. 


\section{LIST OF FIGURES}

Figure 1: Spiral Zones of Bio-psycho-social Existence and Development 


\section{LIST OF TABLES}

Table 3 Axioms, Positivist, and Naturalist Paradigms 


\section{CHAPTER 1}

\section{Introduction}

Teaching is a complex phenomenon and hence the preparation of teachers (Kagan, 1992). There is growing interest in recent years about how teacher education programs can impact not only teachers' practices and effectiveness, but also their entry and retention in teaching (DarlingHammond, Chung \& Frelow, 2002). A teacher education program is an important social context where pre-service teachers' prior educational beliefs are supposedly challenged to transform into new ideas about education, integrated into their vast knowledge system (Wang, Kao, \& Lin, 2010, p. 528)

Therefore, teacher education programs may be viewed as a powerful intervention process toward reconstructing individuals' prior beliefs about teaching and learning. Pre-service teachers may attribute different meanings to the same educational experiences within the program compared to their peers, based on their own distinct perceptions, beliefs, and world views. Their unique personal histories, sociocultural context and experiences are important components leading to their development as teachers, an integral part of educational inquiry.

It is essential to understand how science teachers participating in the West Virginia University (WVU) Benedum Collaborative Five-Year Teacher Education Program perceive their development and describe their meaningful educational experiences. The information gained will contribute toward the evaluation of programs, policies, and diversity initiatives within the College of Education and Human Services. Understanding the experiences of science teachers during their teacher education program better qualifies researchers and educators to promote change for educational reforms. 
During my doctoral program I had the opportunity to participate in some of the coursework (including a science method course) required for secondary science teacher certification. My progressive exposure to field experiences, working on group projects, preparing lesson plans, and designing curriculum for the secondary sciences based on the Interstate Teacher Assessment and Support Consortium (INTASC) principles afforded considerable professional development and learning. As a graduate assistant, I had the opportunity to facilitate and teach technology integration based seminars and courses to pre-service teachers in the Benedum Collaborative Five-Year Education Program. My interactions with faculty members, host teachers in the community, and students generated a growing interest in me to develop an understanding of how science teachers perceived the program; especially as they tried to make sense of their individual experiences while undertaking coursework and student teaching. This research is an attempt to understand how science teachers make meaning of their educational experiences as learners in the Benedum Collaborative Five-Year Teacher Education Program at West Virginia University.

\section{My Personal Context}

Dewey (1963) maintained the perspective that there is basically no difference between life and education. The learning process is an evolving spiral which links the past to present experiences and provide opportunity for further expansion and growth for the future (Beck \& Cowan, 2006; Dewey, 1963). Since the very basic nature of life is to evolve, education too, can be seen as "an ongoing activity" (Friere, 2000, p. 83). Friere (2000) viewed people as "beings in the act of becoming-an unfinished, [and] uncompleted beings in an... unfinished reality." $\mathrm{He}$ purported that this awareness of incompletion "lies the very roots of education as an exclusively human manifestation" (p. 84). This research, is the outcome of two major events that not only 
transformed my life but also gave me a sense of liberation. First, my participation as a doctoral student and second, my training as an academic advisor, which provided my experiences in teaching an orientation class designed for students with undecided majors at West Virginia University.

Not all educational experiences are educative, according to Dewey (1963). Some may lead towards independence and liberation, opening doors of endless possibilities and development; while others may lead toward static planes where there is no further growth possible. I viewed Dewey’s (1963) perspective in the context of my own high school and undergraduate science education experiences. I found that I had journeyed on a similar 'static plane' which involved the accumulation of information in terms of "independent existing knowledge structures," rather than being transformational in nature at first (Greene, 1984, p.82).

I was born and raised in India for twenty-six years before pursuing my master's degree in Physics eleven years ago in the United States. The academic culture I grew up in promoted and valued the behaviorist approach toward education. I was a passive and obedient learner in those early years. Therefore, it became important for me to share a brief glimpse of my personal history in order for the reader to gain an understanding of my past and how I saw myself in comparison to great educators and sociologists, like Dewey (1938), Freire (2000), and Greene (1984, 1997).

In recalling my high school curriculum, science subjects were divided into three main categories: Physics, Biology, and Chemistry. Physics was described as the study of "non-living objects," Chemistry was related to chemicals and their properties and Biology pertained to "living beings." In college, the only subjects I studied in my highly specialized undergraduate curriculum were Physics, Mathematics, and Electronic Instrumentation. The option of taking a 
Sociology 101 class or registering for Psychology 101 courses were non-existent. This sums up my learning and knowledge base, throughout my journey in education until my acceptance into the Curriculum and Instruction doctorate program.

The extent of information I retained from my science teachers and early learning experiences became the foundation I drew upon, which was later to be reflected in my learning at the doctoral level and as a science instructor. Personally, science was about solving problems and application in experiments, a sort of organized set of knowledge. I found that I had evolved into a pre-imposed fixed set of reality, which was a result of my exposure to those early science teachers who exemplified a fixed pedagogy basis. I reflected upon scientific theories that were based on external observations of experimental processes, laboratory settings and activities, resulting in cause and effect results. It was a reality that emphasized a clear distinction between teacher, student, and scientific knowledge. My identity was linked to my academic work during high school and college. This was the way other people characterized me as. Once I got tagged as a "science student" I felt pressured to continue under this label and developed a goal of becoming one of the highest achievers in the scientific community.

I was unaware at the time that I was in a culture where teaching was supposed to control the student, an educational style which "discouraged any inward-directed and intrapersonal focus" (Brown, 1996, p. 24). This way of being encouraged self - isolation and dependency on others to label cultural and social identities on human beings. I had always naively viewed myself through the lens of my friends, family, teachers, and Indian culture in academics, as a result, I got detached from my self-awareness. Brown (1996) pointed this out: Justifying our actions becomes more important than awareness of our intentions or motivations; reasoning why we feel something becomes more important than 
experiencing what we feel; controlling excitement takes precedence over acknowledging our emotions. We shove self-awareness into the back seat as we split ourselves off and become the way we should be. (p. 21)

As a new doctoral student, I was a product of my cultural upbringing, experiences, beliefs, and world views as a teacher, student, and scientist. I hoped to learn more about theories and professional training in the teaching field that impacted my understanding and knowledge of science and learning. I was initially interested in issues related to science education and was surprised to find that my beliefs about science and education in general was challenged during my doctoral program. My socialization in the program was in the form of course work, teaching practicums, professional development opportunities, and interactions with my advisor and the learning community I was now a part of. I became encouraged to adopt reflective practices based on the work of Freire (2000) and the developmental model of Beck and Cowan (1996), known as Spiral Dynamics. As I started reflecting about my own past experiences, I experienced what Greene (1997) calls "those dislocated moments" which questioned my previous understanding of teaching science, learning and assessment. I wondered, had I correctly perceived the kind of social and political implications that was inherent with learning and teaching science? The formation of other questions quickly came to mind such as: What kind of educational environment had I experienced as a student in India and currently as an international scholar in the United States? How did I relate with the subject areas I used to teach? What was my understanding of how my students learned? What was the nature of interactions with my teachers and professors? What kind of self-understanding did I possess after all?

Prior to starting my doctoral program, I attained two Masters of Science degrees in Physics, the first in India and the second in the United States. Even as a non-native English 
speaking graduate student, I had very little trouble adapting to the new "science culture" that I was already familiar with in my country. I found the culture of teaching and learning in college level Physics courses were almost identical. The understanding I had about teaching science in India continued to be part of my understanding when I taught Physics to undergraduate students in the United States. Even though my Physics background was more experimental in nature, I always had an inclination to teach Physics. I had an opportunity to participate in outreach projects like Saturday Science, which directed my interest toward science education.

However, things began to change when I began my first doctoral course. I soon realized that I was used to writing in terms of equations and mathematical expressions, not long essays and reflection papers that required organizing my ideas to satisfy course assignments and projects. As I progressed in my doctoral coursework, I became conscious of still trying to resolve complex concepts as I had done many times in teaching Physics. Topics such as: matter and consciousness; duality and non-duality; observation and experience; outer and inner reality; subjectivity and objectivity; knower and the known; and scientific and qualitative research were part of my understanding of the culture of education.

My very first course, Curriculum Development, was taught by my doctoral advisor. Her assessment policy required me to draw from my life experiences and personal knowledge and contribute my perspective in the readings, discussions, reflections, and classroom dialogue. This was strange for me because in my roles as a teacher and a student, my understanding of assessment and knowledge was totally different. I was coming from an academic culture where I was not supposed to take control of my own education, as it was very dependent on the guided instruction of teachers and professors. 
For this reason, I discovered that it was difficult believing that my personal perspective was needed as a source of knowledge. During the times when contradictory feedback from other students sometimes occurred, I quickly realized that it was actually what the professor had in mind. My beliefs about teaching science and learning were influenced by the kinds of interaction I had with my teachers, the educational setting, and the learning community that I was part of. Freire (2000) believed one of the aims of education should be in facilitating environments to help students develop reflective thinking, "The way they exist with the world, with which and in which they find themselves." Both teachers and students through 'dialogue' can view this world not as a static reality but as a reality which is "in process, in transformation" (p. 83).

A very important aspect of my doctoral experience were the nature of my interactions with other professors in the College of Education and especially my advisor in the program. Our frequent discussions and continual interactions with one another encouraged me to register for courses I felt would help me to personally develop. Palmer (1993) described this type of relationship as a created space that gives importance to individuals' feelings and emotions. This was a way of being that I would have considered 'alien' in my previous worldview of science education. I had not imagined that feelings and emotions can be even part of teaching science or learning. Aren't feelings and emotions at the base of being human after all? This was a thought I contemplated. I began to grasp Palmer's (1993) perspective that:

Even the feeling of fear that teachers and students bring to class is an obverse sign of our emotional need for community. Our fears arise from the sense that community is not present or possible, that we are not related to each other in a way that allows us to be vulnerable without being damaged. By dealing with those fears we begin to sense the 
mutual need for community that lies behind them, and sensing that need we are better able to open ourselves to the community that is truth. (p.26)

There were moments in my doctoral program when I realized that my naïve understanding of curriculum was also balanced with my arrogance. I believed that I had a better grasp and understanding of scientific knowledge and level of expertise than most people I encountered over the course of my studies. One such moment occurred when my advisor suggested that I take the Science: Native American Views course. All I had ever known throughout my science career was that I had experienced the rigidness of western science-based theories in my learning. It was hard for me to accept an alternate worldview in my understanding of nature and science as my advisor presented to me. I valued her mentorship immensely and decided to take the class.

The course readings about indigenous people and Nature brought me to the realization that they were totally different than the western science I observed all through my academic career. I discovered that unlike modern science, indigenous people did not view Nature in an objective way. The contemporary science perspective that I held was that the vegetables, land, air and water, were commercial commodities. There was no emotional and spiritual bonding between them and human beings. Native people had a way of viewing Nature very differently.

My worldview about science in general was deeply rooted in my understanding of looking at various science disciplines as separate entities or theories that had no connection with each other. Similar to Native people, Alvord (2000) presented this outlook on science, Within the traditional cosmos, much of the vast natural world, including vegetation, is steeped in spiritual power. Not only the animals, but also the plants, the Earth and landforms, the air, weather, and sky are spiritually invested. This constellation of spirits 
animates the universe, connects elements to one another and to the past, and provides eyes that tirelessly scrutinize human attitudes and activities. (p. 142)

There was a spiritual intelligence about Native Americans that amazed me. Their understanding of nature is now recognized in the science world, like Scott (2007) believed that the universe is, “.... a web of connections...[that] the whole is contained in each and every component" (p.1). Kuhn (1996) and Snow (1993) instilled an awareness in me of the various branches of the science, and the impact of social and cultural factors responsible for their advancement. I began to view science from both social and cultural perspectives. I had spent five years teaching physical sciences to students having a different sociocultural background compared to those in the United States. However, I never thought students in context of what they are learning and where they are coming from. In reflection, I had always viewed things in a fragmented manner. This way of thinking strongly influenced my past interactions with students, teaching philosophy and style.

I was introduced to the concepts of curriculum development and theories in my doctoral program. Learning this information motivated me to enroll in the core courses required in the Master of Arts in Secondary Science (a post-Baccalaureate initial certification program), including a secondary science method course. I participated in group projects such as designing science lesson plans, and developing a personal educational philosophy. This was based on the state content standards and objectives (CSO) and the Interstate Teacher Assessment and Support Consortium (INTASC) standards. I had the opportunity to work with host science teachers at Morgantown High School. I taught few classes in Physics and Algebra during my field experience in one of the courses. 
My professional development expanded when I was presented with the opportunity to have frequent interactions with pre-service secondary science teachers enrolled in the Benedum Collaborative Five-Year Teacher Education Program, at West Virginia University (WVU). I attended their presentations at the West Virginia Science Teacher Association (WVSTA) and various other events. Also, I served as a Graduate Assistant in the Benedum Collaborative FiveYear Teacher Education Program for the year 2014-2015. I worked closely with pre-service teachers enrolled in the program as a facilitator of EDUC-311: Practicum I/Technology Application and as an Instructor of EDUC-400: Instructional Design/Evaluation (see appendix C). The purpose of those courses was to be effective designers of instruction which included writing appropriate learning objectives, developing authentic assessment methods, planning engaging learning tasks, implementing effective instructional methods, and identifying means of differentiating instruction. I provided them guidance and feedback in their efforts to integrate technology in their inquiry-based lesson plan which they ultimately taught in their PDS (Professional Development School).

Having these experiences, allowed me to reflect over time on how the secondary science teachers perceived their experiences. I rationalized that students were immersed in three different aspects of Culture: science, education, and school. With this in mind, I decided to conduct a literature review which provided a lot of insight about the issues related to learning and teaching science education. Importantly, I determined the information that was missing from the discourse in the field. This process inspired the topic for my dissertation which evolved from the narrative of past research and information found at the time.

The second event that led to my transformation during my doctoral program was my training and experience as an academic advisor in the University College Advising department 
(under Academic Affairs) at WVU for more than five years. I taught a student orientation course in addition to advising General Studies, Undecided-Majors student population. I participated in developing and designing the curriculum, which included individualized assignments and class activities, based on students' individual values, interests, and skills in order to help them to decide on a major. My observations of their successful evolvement as students in a major they preferred and then graduating gave me immense satisfaction and accomplishment as their teacher and advisor (Godfrey and Srivastava, 2009) because I also grew with them. This is a perspective keeping in line with Freire's (2000) theory that collectively, the students and I had undergone a personal growth process; we had basically learned from each other.

This position helped to further my understanding of the student experience in college, in ways that I did not have in my previous teaching career. My interactions with students from different backgrounds and nationalities expanded my awareness of inter-subjectivity, relationships, and the uniqueness of individuals' educational paths and experiences. The added value of my role was gaining a strong foundation in higher education leadership and refining my interpersonal skills from the interactions and dialogue with a diversity of students. This multicultural perspective easily translated into useful knowledge in my doctoral research and education.

Working with students to choose a major as an advisor changed the way I had previously assessed and evaluated students throughout my academic career. My way of advising and teaching was also influenced by the way I got advised in my doctoral program where a meaningful dialogue leads to meaningful conversation which is translated into decision making steps. The frequent discussions with my doctoral program advisor led to my own coursework 
design and helped to tailor my professional development specifically to my interests. These were unanticipated freedoms and rewards of my doctoral program.

I had some moments of frustration and fear too, stemming from my previous educational experiences. My doctoral faculty had faith and patience with me when I needed it, giving me space to grow. Palmer (1993, p. 72) indicated that, "Not knowing is simply the first step toward truth, that the anxiety created by our ignorance calls not for instant answers but for an adventure into the unknown." The way my socialization and professional development progressed during completing of my doctoral curriculum is due mainly to the ongoing channels of dialogue my advisor used as supportive measures. I no longer questioned the interpretation of my existence and the world around me. I discovered my inner self. This was a validation that Palmer (1993) referred to,

The view that truth is personal leads neither to objective imperialism nor subjective relativism. Instead, truth is found as we are obedient to a pluralistic reality, as we engage in that patient process of dialogue, consensus seeking, and personal transformation in which all parties subject themselves to the bonds of communal troth. Such a way of knowing is more likely to bridge our gaps and divisions than drive us farther apart. Such a way of knowing can help heal us and our broken world. (p. 68)

\section{Problem Statement}

There is a call to further the goal of scientific literacy for all by the National Science Education Standards (NRC) (1996). Current educational reforms promote inquiry-based teaching, encouraging science teachers and educators to become lifelong learners (NRC, 1996). President Keeley, of the National Science Teachers Association (NSTA) (2008), emphasized the need to acknowledge the diverse cultural, economic, and social background of students in order 
to promote science literacy for every segment of society (Journal of College Science Teaching, 2008, p. 11). Therefore, science teachers needed to think about the shifts (or modifications) needed in their teaching and learning styles. These shifts are required to improve their practice, implement new learning styles, and reflect on the difference it made in their teaching; also important, was determining the kind of impact made on students' learning styles.

High attrition rates of beginning science teachers, is a signal to science educators to improve teacher training and learning. By doing so, teachers are apt to be better prepared in the classroom and successful in their careers as they relate to a 'noble profession' (Hong \& Greene, 2011). Ferguson (2008) pointed out:

As the makeup of the U.S. student population changes, so should the practices of science teacher education programs. Because students entering the science classroom have different perspectives, worldviews, cultures, and experiences than the teacher, these differences, if left unanalyzed, work against an equitable and inclusive science for all. Different student worldviews will operate, regardless of the teachers' backgrounds. (p.549)

Teacher education programs play a vital role in science teachers' practice, effectiveness and retention in their field (Darling-Hammond, Chung, \& Frelow, 2002). It is an important social context whereby pre-service science teachers may develop or refine former beliefs about teaching based on their experiences, interactions, and learning in the program (Hong \& Greene, 2011). Zembylas and Barker (2002) shared the opinion that science teacher education programs allow pre-service teachers a space to, "Create understanding for themselves, to make the new a part of their own prior knowledge, and to create a way for new ideas to become their own" (p.332). Knight et al. (2012) pointed out that science teachers' beliefs before and after program 
participation are important to assess. Little has been found in the literature about the different phases within the teacher education programs that students must contend with such as: science content, method courses, field experiences, and teaching practicums. These are important considerations as they are influential aspects of retention in the program, and provides a lens to gauge students' conception of science in general and of the expectations and routines that effective teachers adhere to (Arbaugh et al., 2013).

The experiences of pre-service teachers may inform policy makers of the daily realities of practice and the complex phenomena of teaching and learning. Therefore, a growing need to understand how pre-service science teachers cultivate meaningful experiences during their immersion in the program, will assist in promoting future reform requirements and the effectiveness of teacher training programs (Monet \& Etkina, 2008). According to Kagan (1992) examining the processes by which teachers' awareness develops in the program can be a valuable tool for educators to promote professionalism. Their learning experiences instills new knowledge which she described as the "increase in meta cognition" (p. 156).

It is also important to understand how teachers view themselves as learners. Their experiences and perceptions gained in a teaching program is not evaluated in isolation. It is important to keep in mind that the knowledge they possess upon entering the program is continually expanding due to society's influences, their cultural backgrounds, personal histories, and unique life situations. Hence, investigating teachers' educational experiences using a phenomenological approach is valuable because the diversity of the information collected in the data introduces new insights pertaining to the transformational process of individuals becoming teachers. 
Freire's Dialogical Pedagogy, the Developmental Theory of Spiral Dynamics and Hermeneutical Phenomenology are the three theories I used to guide my understanding of secondary science teachers' perceptions, experiences, and development in the Benedum Collaborative Five-Year Teacher Education Program at West Virginia University. The researcher's role is an extremely important consideration of this study both in description and interpretation of individuals' experiences; which in turn depends substantially on the researcher's own reflections and philosophical standing (Callejo, 2008, p. 22). Therefore, my personal concepts, experiences as a student, an educator, and a researcher influences this investigation to an extent. Discernment of the information collected is also enriched due to my background in higher education and the personal experiences that shape the experiences I've personally found meaningful.

\section{Purpose of the Research}

The purpose of this research was to investigate how secondary science teachers make sense of their overall educational experiences in the Five-Year Teacher Education Program. Their personal narratives are reflections of their educational journeys and significant 'learning and teachable moments' they encountered over the course of five years that impacted their understanding of themselves as learners and teachers. It is those experiences they found meaningful in the program that this research is focused upon.

Educational researchers and educators have always been interested in acquiring information about how pre-service science teachers perceived their educational experiences, and how they internalized the practices learned in their programs (Darling-Hammond, Chung, \& Frelow, 2002; Pajares, 1992). It is also important to have an understanding of how they facilitate their students' comprehension of the sciences. This information is useful toward future 
modifications of outdated policies and program structure within the College of Education. Merely understanding teachers' experiences is not sufficient. Therefore, understanding what is meaningful to these teachers encourages continuous renewal of science education programs and preparation of future science teachers entering the field. The information contributes to the literature and ongoing discourse in the field of higher education.

A qualitative approach was chosen for this study which included: (1) Nine interviews, comprised of three pre-service secondary science teachers enrolled in the Benedum Collaborative Five-Year Teacher Education Program and six in-service secondary science teachers who had graduated from the program; (2) Participants' written works like lesson plans and inquiry journals; and (3) Program documents like student handbook, program web site and syllabus of secondary science methods course (voluntarily shared by faculty). The qualitative data were triangulated in order to increase understanding and clarity of teachers' experiences that addressed the research questions in this investigation. In addition to that, my own unique cultural and educational background as an advisor, student, teacher and researcher in higher education shall be reflected upon.

\section{Research Questions}

The primary guiding question: How do science teachers describe their academic experiences during their participation in the Benedum Collaborative Five-Year Teacher Education Program?

The Sub-Questions are:

a) What do science teachers focus upon when they describe what they have learned from the program? 
b) What are the emerging themes of teaching and learning before and during science teachers' participation in the program?

\section{Theoretical Influences}

Three theories guided this qualitative inquiry: Friere's Dialogical Pedagogy, Developmental Theory of Spiral Dynamics and Hermeneutic Phenomenology.

\section{Dialogical Pedagogy of Freire}

Freire's (2000) theory helped me to reflect on my previous educational training and understanding. It informed me of the broader picture that education presents, in terms of personal and sociopolitical implications. This theoretical approach redefined the nature of the relationship between the teacher's role and the student's meaningful learning in higher education.

My perception of Freire's (2000) work lies in my own experiences within the doctoral program through interactions with my advisor and the educational community. He viewed education as a form of liberation where, "Education consists in acts of cognition, not transferals of information. It is a learning situation in which the cognizable object intermediates the cognitive actors-teacher on one hand and students on the other" (p. 60).

A student-teacher relationship is one where teaching and learning are considered human experiences. McLaren and Leonard (1993) found that, "Teachers pose problems derived from students' life, social issues and academic subjects in a mutually created dialogue" (p. 24). Education begins with the, "Solution of teacher-student contradiction by reconciling the poles of the contradiction so that both are simultaneously teachers and students" (Freire, 2000, p.72). The value of teachers' and students' act of knowing in education are basically grounded in their unique experiences and backgrounds. The interactions with my advisor and the educational community gave me hope through our dialogue with each other, and in this process my 
knowledge was also co-constructed. This ultimately paved the way for me to have more control over my learning, and of how I perceived the personal, social, and academic value of my higher education experiences. In the same context, Freire (2000) provided the following outlook:

The problem-posing method does not dichotomize the activity of teacher-student..... does not regard objects as his private property, but as the object of reflection by himself and his students. In this way, the problem-posing educator constantly re-forms his reflections in the reflection of the students. The students...no longer docile listeners... are now--critical co-investigators in dialogue with the teacher. The teacher presents the material to the students for their consideration, and re-considers her earlier considerations as the students express their own. The role of the problem-posing educator is to create, together with the students, the conditions under which knowledge at the level of the doxa is superseded by true knowledge at the level of the logos. (p.54)

It is important to keep in mind that educators should not only engage with teachers through dialogue and reflection. They are also challenged to create learning environments that are conducive to students having positive meaning from these experiences. In this instance, learning can be seen as a shared reality between teachers and students.

Through dialogue and reflection educators and pre-service teachers grow and undergo powerful transformations within the teacher education program. Educators need to encourage pre-service teachers to become reflective thinkers. Thereby helping them to develop their own praxis and become a "reflected practitioner" giving them the freedom to think about, "What they teach, how they are to teach and what are the larger goals that they are serving" (Giroux, 1988, p. 126). 
Freire (2000) believed that meaningful dialogue between people won't happen if hope, love, humility, and faith are absent in the relationship. Hope signifies the incompletion of human beings, while love and faith fosters mutual trust between dialoguers (p. 70). Palmer (1993) stated, "Thinking can be taught as a mode of citizen participation, and tolerance of ambiguity can be taught as a way of listening to others without losing one's voice" (p. xvii). Any form of arrogance should not be present in this relationship because both people are involved in the cocreation of knowledge. This idea corresponded with Palmer's view of truthful knowing:

The knower becomes co-participant in a community of faithful relationships with other persons and creatures and things, with whatever our knowledge makes known. We find truth by pledging our troth, and knowing becomes a reunion of separated beings whose primary bond is not of logic but of love (p. 32).

\section{Developmental Theory of Spiral Dynamics}

This model informs us about an adult structural development where individual shifts between different zones of what is called as value structures (or zones of belief structures), which also oscillate between the themes of Express-Self (what one thinks is right) and Sacrifice-Self (what other people think is right) which are dialectic motions between the internal and external self. However those shifts are embedded in one's own uniqueness and complexities of experiences as one develops new ways of thinking and knowing. According to the Spiral Dynamics Model, neither life conditions, nor human capacities are fixed and therefore this model can be best understood in terms of a moving picture and not a fixed discrete snapshot (Beck \& Cowan, 1996). Human beings and societies have the potential to evolve and exist in terms of developmental zones which are known as value structures (belief structures /worldviews). These 
value structures replicate, spread or compete for dominance in human consciousness in terms of themes related to Expressive self (ego centric, modern) and Sacrificial self (traditional and postmodern). The progression of these value structures or zones are in the Spiral form and transcend to the next level not eliminating the previous value structures. According to Beck and Cowan (1996) these value structures are attracted and repelled by the individual's mind and societies at a different level of psychological existence based on the cultural fit. This developmental model may inform subjective complexity in individuals and cultures, in terms of 'ways of thinking,' representing diverse worldviews, beliefs, and identities within those value structures or zones.

An individual/society can move between these values structures/zones depending on the context that arise due to life situations. Each zone of developments is related to cultural, psychological and cognitive realities. The culture/ individual/society/ organization may operate in different value zones and it is possible that an individual may adjust himself or herself according the value structure of the organization.

There are eight development zones according to Spiral Dynamics, with no final zone present in this model, as the system is open to evolve further (see Figure 1). Beck and Cowan (1996) used colors as codes to define the complex system as a means of communication which include: Survival Self, a Clannish Us, My Powerful Self, Traditional, Materialist/Achiever (modern), Relativistic/Socio-Centric (postmodern), Systemic/Integrative, Globalist/Renewalist, and Unknown (Please refer Appendix E for detailed explanation). The first seven zones may be in competition with each other and each zone will think that their worldview is right. Beck and Cowan (1996) indicated: 
Value [structures] reproduce themselves; they interact with their surroundings and adapt to them; they mutate; they persist; and they defend themselves against each other. Memes evolve to fill the empty niches in their local environments, which are, in this case, the surrounding belief systems and cultures of their natural hosts, namely, us (p. 6).

Figure 1

Spiral Zones of Bio-psycho-social Existence and Development

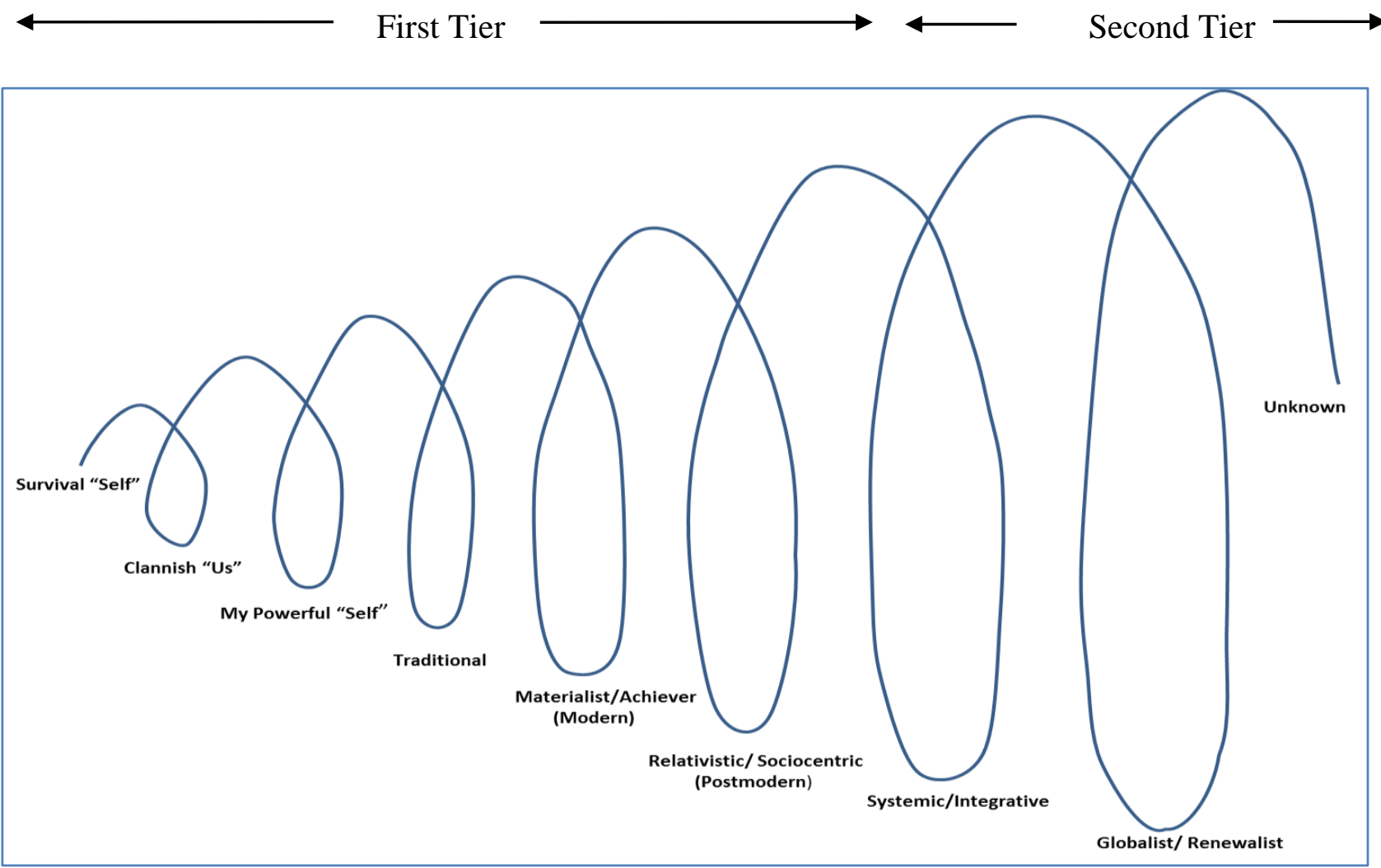

Note: Adapted from Beck and Cowan (1996) "Spiral Dynamics"

Each of these value structures reflect a valuing system, a level of psychological existence, an organizing principle, a way of thinking or a mode of adjustment. In other words, "The values 
memes encode instructions for our worldviews, assumptions about how everything works, and the rationale for decisions we make" (Beck \& Cowan, 1996, p. 32). These zones are nested in the people, and not types of people. Beck and Cowan (1996) believe that since we think about so many things (like work, family, politics, sports etc.) it follows that, "We can also host several ways of thinking which may mix-and-match to the subject areas" (1996, p. 63). Even though these value structures are formed over time, they can be changed whenever any life situation occurs because they are not rigid. Each zone is a dynamic structure representing thinking of various complexities (Beck \& Cowan, 1996, p. 4):

1. Value structures can be seen as decision-making thinking which are discrete structure for thinking, not just a set of ideas, values or causes.

2. Value structures can brighten and dim as the Life Conditions (consisting of historic times, geographic place, existential problems and societal circumstances) change.

Values structures conflict with each other whenever there is a potential for change. Beck and Cowan (1996) explained that six conditions exist in which a change in peoples' value structures may happen (and movement along spiral may occur) depending on whether the intended direction of change has been evaluated from "what to what" (pp.76, 85):

a. Potential: The potential for change for a person or a group varies along the continuum from open to arrested, to closed, and it depends on the kind of barrier that needs to be overcome for the change. Closed potential rejects the alternate perspectives.

b. Solutions: One may not expect for a change to happen unless his/her immediate problems or threats still exist in the present state. 
c. Dissonance within the value zones: Inconsistency between beliefs, expectations, and experiences and the uncertainty that comes with it are the driving forces for the change.

d. Identification of the barriers (such as, physical context, time, available resources, lack of knowledge etc.) and then eliminating neutralizing and reframing them to something else.

e. Insight: For change to happen there has to be an understanding of what went wrong that caused dissonance and what sources are available for handling the problems better.

f. Consolidation: Support during the change process.

Based the developmental model of Spiral Dynamics, it can be argued that teacher education programs can be seen as a dynamic complex system rather than just an event. The ways these dynamics combine in different ways may vary for different people and even for the same person in different contexts (Opfer \& Pedder, 2011, p. 377). Zembylas (2002) views teaching science and learning as a social relationship between the teacher and student, influenced by the individual's way of looking at reality. The individual's reality is not just personal construct but also social-cultural and political.

The dynamics of the science teacher education involves several events within the program which involves experiences in the College of Arts and Sciences and the College of Education, in addition to student teaching. Understanding these dynamics may help us find the emergent themes that may be beneficial for the improvement of science teacher education programs. Educators who follow the one size fits all policy get stuck in one value structure, 
reflected in their fixed methods courses and assessment of their students' learning (Rosado, 2004). This model encourages educators to be in the second tier value zone, so that they would see the bigger picture and be able to operate at any zone of the spiral, since each zone has its own context (Rosado, 2004). I discerned that this developmental theory to be consistent with Identity Theory and Belief Development Theory, in the teacher education literature (Chapter 2). Themes related to teaching and learning based on value structures of Spiral Dynamics are listed under Appendix F.

Based on the developmental model of Spiral dynamics, I contend that any new educational experience can be organized and interpreted to the existing value structures and therefore is accepted or rejected accordingly. Teachers' beliefs and experience should not be seen without valuing their emotions, as emotions are psycho-social constructs and can play an important role in teaching science. It is important to know how science teachers reflect and interpret their experiences and educational beliefs during the different stages within the program when they interact with the educational community and during their student teaching assignments. They can be encouraged to value the internal thought process as external experimental facts required for science education at any level. It is only through this realization they would be able to incorporate their unique experiences into the curriculum and create learning situations in the program; which is beyond the established practices of pedagogical content knowledge (PCK).

Spiral dynamics was the first adult social-psychological developmental theory introduced to me by my advisor, which I studied in-depth during my academic career, becoming a part of my professional development as a doctoral student. I had the opportunity to attend the workshop hosted by one of its creators, Don Beck. The information I learned brought me to the realization 
that my feelings, beliefs and identity were influenced in three ways: as an individual, at an interpersonal level (social interaction), and sociopolitical.

As I studied this model, I reflected how my own conditioning and life experiences influenced my ways of thinking at different stages of my life. How I prioritized them in the society and culture that I was a part of in India and later in the United States during my

experiences in higher education. My educational beliefs were actually associated with the sum of my experiences aligned with educational pedagogy and the curriculum that I had taken as a student. My social expectations also evolved that ultimately decided my career choice and decisions in life. This was a dominant kind of educational and environmental social culture that especially defined my identities as a teacher and student. No doubt, it affected me tremendously as an individual. My worldviews may not be reflective of most people nor understood by others due to my own, personal uniqueness as a complex being; a result of life experiences and of being human.

When I reflected upon my development as a doctoral student, I determined that the dynamics of my experiences were different at various stages mainly due to: the kind of coursework I took, my teaching practicum, and interactions with professors and science host teachers. The roles I had as a graduate student, teacher and advisor provided unique experiences. There were times when I was resistant to changing my existing outlook on a certain topic in the curriculum and even felt moments of confusion in the process of assimilating the new viewpoints. It was due to the consistent support of my professors and advisor that helped me to go through the transformation needed to successfully adapt to my doctoral program and progress.

\section{Hermeneutic Phenomenology: Being in the World and Understanding Self and Others}


Consciousness plays a very important role to human beings. The concept of being in the world and experiencing phenomena is due to our consciousness. A phenomena is nothing but the essence of structures of experiences that are formed within our consciousness. Hence, consciousness is not separate from the world we experience and live in. According to Laverty (2003) phenomenological research is, "Descriptive and focuses on the structure of experience, the organizing principles that give form and meaning to the life world" (p. 27).

Phenomenology helps us understand the importance of lived experiences as an essential component of knowing and interpreting the world we live in. This theory rejects the mind-body dualism. It suggests that thoughts and objects both occur within experience. Hence, the individual cannot be separate from the world as he/she sees the world and interprets it. Consciousness plays an important part in making sense of reality.

Life is all about relationships. The reality we perceive or understand is neither objective (what we see out there) nor subjective (how we see ourselves). We don't have experiences entirely in isolation. Our identity is influenced by the kinds of social and cultural environmental impact we grow up in. Ionnane (1997) pointed out,

We speak of the phenomenological perspective; we generally speak of the uniqueness of the individual, the inner voice of the individual, and the subjectivity of the individual. It seems to me that we are ignoring the external objects, the community, and the external worlds and that phenomenology has always included the idea that we are also part of this world. (p. 360)

Human beings are not independently existing entities. It is through the process of gaining experience (phenomenology) and interpretation (hermeneutics) individuals are able to understand their reality of the world. Ozmon and Craver (2008) pointed out, 
People must try to sort things out through existentialist critique, phenomenological description and hermeneutical interpretation. People must try to be as reasonable as possible, not in the sense of objective and removed rationalism, but a reasonableness that is ever cognizant of the human condition. And this will only happen if we become self-aware and wide awake. (p. 238)

Understanding and interpretation go hand in hand whether it includes self-understanding as well as understanding of other conscious beings. Laverty (2003) indicated that hermeneutic can be seen as a process of co-creation between the researcher and participant in which, "The very production of meaning occurs through a circle of readings, reflective writing and interpretations." This is an interpretive process that is continual one has reached "sensible meanings of the experience, free from inner contradictions" (p.30).

In reference to modern empiricists who demand "unbiased uncertainty and scientific proof," Slattery(2006) points out that postmodern hermeneutics "celebrates the irony of interpretation by recognizing that ambiguity is integral to the human condition and the natural world" (p. 130). Laverty (2009, p. 25) and Gadamer (1960/1998) indicated:

Understanding is always more than merely re-creating someone else's meaning. Questioning opens up possibilities of meaning, and thus what is meaningful passes into one's own thinking on the subject....To reach an understanding in a dialogue is not merely a matter of putting oneself forward and successfully asserting one's own point of view, but being transformed into a communion in which we do not remain what we were.

Gadamer (1960/1998) describes hermeneutic phenomenology as a "fusion of horizons." It is a dialectical interaction between the expectation of the interpreter and the meaning of the 
text (Laverty, 2009, p.25). Based on a interpretative framework, hermeneutic phenomenology demands, "Self-reflexivity, an ongoing conversation about the experience while simultaneously living in the moment, actively constructing interpretations of the experience and questioning how those interpretations came about" (Laverty, 2009, p.30).

The hermeneutic phenomenology framework was ideal for the purposes of this research, because it offered a lens and understanding of my participants' backgrounds, beliefs, and lived experiences. Their reflections bring to light information about how they evolved during their participation in the Benedum Collaborative Five-Year Teacher Education Program.

\section{Delimitations}

The participants in this study were secondary in-service science teachers graduated from the College of Education and Human Services in the Benedum Collaborative Five-Year Teacher Education Program, at West Virginia University (WVU). Pre-service secondary science teachers who were enrolled in the program during the start of this study, were also participants.

\section{Limitations}

Due to limited sample size the results were not generalizable to the population of teachers enrolled in the Benedum Collaborative Five-Year Teacher Education Program at WVU. Participants involved in the program may only describe positive experiences within the program. 


\section{CHAPTER 2}

\section{Literature Review}

\section{Introduction}

This chapter is divided into two main parts. The first part presents a brief overview of the PDS reform movement in teacher education programs and the Benedum Collaborative Five-Year Teacher Education Program at WVU, the site for this study. Students in the Five-Year Program attain both a bachelor's and master's degree at the end of five years. The literature review will outline the program's history, description of the structural and policy reforms over time, and the value of the program to the university and the state of West Virginia. The second part of this chapter provides salient findings and relevant issues pertaining to science teachers' development found in contemporary literature.

\section{Part I}

\section{Reform Movement in Teacher Education}

The reform movement in teacher education gained prominence in the 1980s following publication of A Nation at Risk, a report presented by the National Commission on Excellence (Teitel, 1999). Published in 1983, A Nation at Risk elucidated a crisis in education, creating concerns about the quality of teacher education programs and accountability of schools in general (Teitel, 1999). This led to the formation of the Holmes Group (also known as the Holmes Partnership), named for the former dean of the Harvard Graduate School of Education, Henry Holmes. The Holmes Group was comprised of ninety-six research universities that offered professional education programs. Their mission was to reform teacher education and the teaching profession. Therefore, the need to establish and strengthen a connection between the College of Education, K-12 education, and the College of Arts and Sciences was recommended. It would 
also encourage teachers, university faculty, and administrators to support this undertaking (Teitel, 1999).

At the time when the A Nation at Risk report was released, four-year undergraduate teacher education programs were dominate in the country. The curriculum included components of general education courses, pedagogy, general and subject-specific methods courses, field experience, and student teaching (Lucas, 1992). However, there were ongoing debates about the quality of entrance requirements, structure (and interrelation among its components), duration and placement, or sequencing (p. 104). The Holmes Group (1986) urged universities to take three steps to strengthen education: a) sharply revise the undergraduate curriculum to provide strong academic concentration, while observing model teaching; b) organize academic course requirements and courses in a way that study will be structured rather than disjointed; c) devise a coherent program that will support the advanced studies in pedagogy required for solid professional education (p.16-17).

The training site for the teacher education program become the most important element of debate. Lucas (1992) noted that while some people maintained that the university should be the only home for the preparation for teachers, others claimed that teacher programs should be "moved wholly or in part out of academe and into schools where they allegedly belong" (p. 105). Realizing the interdependence of teaching and teacher education, The Holmes Group (1986) released the Tomorrow's Teachers report in which a Professional Development School (PDS) was proposed as a clinical site, an alternative to the traditional offering of teacher education on campus. It was expected that this, "Would bring practicing teachers, administrators, and university faculty into a partnership that would improve teaching and learning on the part of their respective students" (p 56). 
The Holmes Group (1986) advocated for PDS as a step toward professionalization of teaching, which was seen as the connecting link between universities and schools. Student teaching became a very important component of teacher education (Teitel, 1999). The expectation existed that PDS would, "Help to strengthen the profession by serving as the models of promising and productive structural relations among instructors, professional teachers, careerprofessional teachers, and administrators" (Holmes Group, 1986, p. 57).

The concept of "professionalization of teaching" can be traced back to the progressive education movement and John Dewey's concept of lab schools (Levine, 1992). The function of lab schools were to conduct investigations into problems related to the curriculum, teaching, and learning. This would improve the knowledge base of education especially with regard to methods, psychology, and subject matter. The Homes Group (1986) believed that a site like PDS would provide teachers, administrators, and university faculty with an increase in the professional relevance of their work through: a) mutual deliberation on problems with student learning, and their possible solutions; b) shared teachings in universities and college; c) collaborative research on the problems of educational practice; d) cooperative supervision of prospective teachers and administrators (p.56).

The Holmes Group (1990) second report of Tomorrow's Schools outlined their vision about procedures to design PDS:

By Professional Development schools, we do not mean just a laboratory school for university research, nor a demonstration school. Nor do we mean just a clinical setting for preparing student and intern teachers. Rather, we mean all of these together: a school for the development of novice professionals, and for the research and development of the teaching profession (p.1). 
The emergence of Professional Development Schools (PDS) elevated the standard and delivery of teacher education programs in which field-based experiences also gained prominence (Teitel, 1999). The concept of the PDS was supported by national organizations like the American Association of Colleges for Teacher Education (AACTE), the National Council for Accreditation of Teacher Education (now known as Council for the Accreditation of Educator Preparation), and the National Center for Restructuring Education, Schools, and Teaching (NCREST).

PDS institutions are K-12 schools and colleges for teachers that promote a mission of, "Professional preparation of candidates, faculty development, and inquiry directed at the improvement of practice, and enhanced student learning" (p.1). The standard for PDS partnership describes it as being a learning-centered community, supporting the integrated learning and development of students, teachers, faculty, and PDS partners through inquiry-based teaching (NCATE, 2001). Additional standards were implemented by PDS partners that would emphasize the uniqueness of this type of program (NCATE, 2001):

1. Learning community - inquiry-based practice toward integrated learning and development for all involved.

2. Accountability - increasing professionalism by incorporating various local, state, and national standards in the partnership for continual refinement of practices, making everyone accountable to themselves and to the community and engage the policy makers.

3. Collaboration - commitment towards shared work and responsibilities among partners in designing roles and structures of the partnership. 
4. Diversity and Equity - examination of how the curricula, instructional approaches, and assessment strategies affect outcomes for diverse students and candidates.

5. Structures, Resources, and Roles - establishing governing structures that support learning and development of students, candidates, faculty, and other professionals integral to the operation of both school and university.

The Interstate Teacher Assessment and Support Consortium (INTASC) established the standards and assessment for initial licensing of beginning teachers. The standards defined the criteria for teacher licensure which describes the kind of knowledge, skills, and dispositions required for teacher preparation. While the performance based assessment, based on standards, continues to be an essential part of the most teacher education programs, Zeichner (2006) believed that regardless of design or structure, the teacher education program must have a social justice agenda for the, "Development of sociocultural consciousness and intercultural teaching competence," in order to prepare teachers for the diversity of students at public schools. Zeichner (2006) stated that, "Good enough teachers should not be good enough for everyone's children, and we need to move beyond the current territorial debates about where teacher preparation should occur and instead focus on what is achieved by different forms of preparation" (p. 337). He also explained that the standards related to multicultural education is an important concept of the reform movement. It was conceived with the aim of preparing teachers for social justice initiatives in schools and society at large.

\section{Emergence of the Extended Model in Teacher Education Programs}

Lucas (1997) reported there were many advocating for the extension of four-year teacher education programs throughout the first half of the century. There was a general consensus that 
"it was impossible to offer satisfactory teacher preparation within the limits imposed by fouryear programs" (p.139). Students interested in teaching were given the option of attaining Masters of Arts degrees in Teaching (M.A.T.), the program was first introduced in the late 1950s to Liberal Arts graduates as an alternate route toward accomplishing this professional goal. However, the M.A.T. was never institutionalized, and costly to operate over time, the program could not continue during the 1960s and eventually ended when external funding was withdrawn (Lucas, 1997).

Extending graduate teacher preparation programs were raised again in the early 1980s, by Henrick Gideonse, Education Dean of the University of Cincinnati (Lucas, 1992, p. 141). He believed that an entry level teacher should extended years of training in their field, this would include the completion of the four-year requirement for achieving undergraduate degrees in addition to a progressive series of undergoing field observations and on site experiences. He proposed that the curriculum should cover elements from education policies, foundations and societal issues as an integral part of the training beside content area ( p.141). Many supporters of four-year traditional teacher education programs saw cost and management constraints related to maintaining extended programs and felt that Gideonse's outlook were unrealistic. This was due mainly to the perception that quality students may not be attracted to extended programs given the low status of teachers in the education field and the low salaries of those working in public schools ( p.144).

A report released by the Holmes Group in the 1980s raised the issue of teacher education again in regard to increased funding for teacher education programs, expansion of curriculum and rigorous standards for teacher preparation (Lucas, 1990, p.148). John Goodlad (1990), believed that the new extended five-year programs have the capacity to improve the standards of 
teacher retention and development. He proposed having a Center of Pedagogy, comprised of a) education faculty; b) science and arts faculty; and; c) K-12 professional teachers. Under this model, pre-service teachers would take content courses from the College of Arts and Science faculty, educational theories and methods classes from the College of Education faculty, and work with K-12 schools under the guidance of professional teachers. Similar to the PDS, Goodlad (1990) proposed Partner Schools, a school that works collaboratively with the university in a partnership that provides professional development and clinical experiences to pre-service teachers, with a goal in mind that "join theory and practice in every component of a future teacher's program" (p. 300).

The Holmes Group recommended extended integrated learning programs (five years or more) offering an internship that should be intensively supervised while at the same time providing students with opportunities to reflect upon their practical experiences. Universities were at liberty to interpret the Group's proposal and suggestions at the time even without an official 'blueprint' of the plans. The Five-Year Integrated Model of Teacher Education Programs was the outcome of a collective effort.

West Virginia University became one of the first universities that promoted a vision of strong collaborative relationships with local public schools and the College of Education and Human Services. The concepts of inquiry and reflection were infused in the Benedum Collaborative Five-Year Teacher Education Program. The rationale of the program was derived from the recommendations of the Homes Group and John Goodlad's vision to provide preservice teachers in K-12 classrooms with exposure to early clinical experiences which have been "limited and late" in traditional programs ( "History of the PK/20 Collaborative," 2012). 


\section{The Benedum Collaborative Five-Year Teacher Education Program at West Virginia University}

West Virginia became one of the first states to join the Holmes Group in 1986, due to the teacher reform movement impacting the nation. The initial goals of the Holmes Group included restructuring academic curriculums, establishing the PDS and collaborative structures, to sustain the reform efforts of the university in teacher education ("The Benedum Collaborative Five-Year Teacher Education Program Student Handbook," 2014). For practical reading purposes in this research, the handbook will be referred to as "The Benedum Collaborative Student Handbook."

Faculty and administrators in the College of Education and Human Services and the Eberly College of Arts and Sciences at West Virginia University, collaborated on a major grant proposal to redesign the teacher education program and establish a PDS. Funding was received in 1989 from the Claude Worthington Benedum Foundation, of Pittsburgh, Pennsylvania. This eventful occasion led to the formation of eight multidisciplinary teams based on the Tyler model of curriculum development, comprised of higher education and public school representatives (Steel and Hoffman, 1997, p. 52). The teams were: society, pedagogy, students, liberal studies, teaching disciplines, philosophy of education, psychology of learning, and PDS. The PDS team initiated a discussion to create a viable definition for PDS as it was not clearly defined at the time (Steele \& Hoffman, 1997).

Following collective reflections, discussions, and consultations by the stakeholders and all interested parties, the team came up with the following "PDS Belief Statements," reform initiatives to guide and develop PDS such as: a) All in a Professional Development School are learners; b) All in a Professional development school have the opportunity for success; c) The organization of the Professional School encourages all to be empowered; d) A PDS fosters an 
environment of mutual respect; e) A PDS promotes curriculum and instruction that evolves from continual review that reflects the school's vision ("Benedum Collaborative Student Handbook," 2014, p. 6; Steel \& Hoffman, 1997).

Initially, all public schools in five counties in West Virginia were invited to apply for the PDS. After reviewing the applications, faculty at the university and public school administrators selected six schools to become PDS within the Benedum Collaborative. The listing of schools included three elementary schools, one middle school, and two high schools. By 2003, the PDS network had expanded to fifteen elementary schools, six middle schools, and nine high schools.

The Benedum Collaborative is an organization that provides for "simultaneous renewal" of education in the public school system and teacher preparation in the form of inquiry-based PDSs. These "best practices sites" would ultimately create a new culture, that "crosses the traditionally closed borders of public schools and universities," resulting in the professional development of the education community impacting teachers, students, and faculty members ("History of the PK/20 Collaborative," 2012). The Five Year Teacher Education Program was designed specifically to link the school and university.

It is an integrated five-year dual degree program for secondary science teachers that provides an undergraduate degree in multidisciplinary studies and a master's in education simultaneously, at the end of the fifth year. The present study is located in a five-year integrated education program where students' clinical experiences start early in the program and intensifies as they progress to more complex teaching assignments ("Benedum Collaborative Student Handbook," 2014). They gain more than one thousand hours of experience when working in a PDS classroom. 
In light of reform, the Benedum Collaborative Five-Year Program ensures teachers are well prepared to meet the national standards upheld by the Interstate Teacher Assessment and Support Consortium (INTASC), the National Council for Accreditation of Teacher education (NCATE), and local standards as well, such as the Characteristics of Novice Teachers and Benedum Collaborative belief statements ("Benedum Collaborative Student Handbook," 2014). The Characteristics of Novice Teachers were developed by both university and public school faculty members, which serves as the conceptual framework of the Benedum Collaborative FiveYear Teacher Education Program. Evaluation was guided by ten performance-based rubrics for assessing students' teaching abilities and skills during the clinical years.

The evaluation design is aligned with the standards established by the INTASC (1992) for the student evaluation in the program. While content knowledge remains the main criteria of for science teachers they need to understand the, "tools of inquiry, application, structure of science and of science disciplines," thereby students are immersed in learning activities that are meaningful. Science teachers should also have a thorough understanding of the nine standards set by the INTASC (1992):

- Students' individual learning and development

- Different approaches for learning and instruction for diverse students

- Instructional strategies to encourage the development of critical thinking and problem solving

- Individual and group motivation to create positive learning environment

- Communication techniques to foster active inquiry and supportive interaction

- Instructions based on individual situation and curriculum goals

- Formal and informal assessment strategies to assess the development of each learner 
- Reflective practitioner capabilities to evaluate the experiences and actions of teacher and student

- Relationships that promote learning in the larger community of the society

\section{Elements of the Benedum Collaborative Five-Year Teacher Education Program}

The organizational structure of the Benedum Collaborative Five-Year Teacher Education Program is very rigorous, the courses and clinical experiences are arranged sequentially, which is an outcome of the systematic planning process to integrate theory with practice. The aim is to provide a link between teaching and learning. The program's curriculum is built upon three pillars: 1) Liberal Arts; 2) Pedagogy; 3) Clinical/Field Experience ("Benedum Collaborative Student Handbook," 2014).

The three pillars introduce students to the various forms of acquiring knowledge and meeting objectives related to General Education Curriculum. They are provided with a social foundation of public education, curriculum development, teaching strategies, learning theories, and classroom management ("Benedum Collaborative Student Handbook," 2014, p. 3-4). Students have the flexibility to enroll in courses at the College of Arts and Science, and the College of Education. They have early exposure in the program to the "culture" of school and apply their content and pedagogy knowledge in "extensive sequenced" teaching experiences within a PDS classroom as they progress.

In addition to the three pillars, the curriculum is specified in three ways: 1) Inquiry, 2) technology, and 3) diversity. These are interwoven in the form of academic courses and teaching practicum. Inquiry, reflection and research as core elements are recommended by Holmes group (Tomorrow teachers, 1986) and also adapted by INTASC (\#9) and Characteristic of Novice 
teacher (number 8) which are essential part of professional development at Benedum Collaborative Five- year Teacher Education Program. The development of inquiry as a stance is based on the belief that teachers should be considered as reflected practitioners; deepening their understanding of learning as well as impacting students' experiences in terms of their teaching styles and philosophies. At the same time, they should be able to consciously explore their underlying assumptions, biases and ideologies related to the curriculum, policies, and practices that are acceptable and promoted in the workplace ("Benedum Collaborative Student Handbook," 2014, p. 4).

Students have opportunities to learn techniques of integrating instructional technology into their pedagogy courses and PDS classroom. The diversity strand provides pre-service teachers with the knowledge and methods to accommodate the different ways of learning and instruction pertaining to exceptional students. Importantly, they become skillful in creating classrooms that were "socially just and meet the needs of all learners" (p.4).

The Benedum Collaborative Five-Year Teacher Education Program maintains very selective admission standards and high student retention. Students are evaluated at multiple points within the program ("History of the PK/20 Collaborative," 2012). The Benedum Collaborative Student Handbook (2014) indicates that [the] “...program is rigorous and demanding, students entering the program are expected to exceed the academic expectations of a typical undergraduate student enrolled in WVU ...[and] is expected to demonstrate a high level of commitment in becoming a professional educator" (p.2)

Students are admitted into the program following completion of all approved universitybased coursework and must have an overall GPA of 2.75 . They are required to pass the preprofessional skills test and accumulate sixty hours of volunteer experience with student groups 
they plan to teach. The first two years consist of taking core educational classes and science content classes in order to fulfill the undergraduate degree requirements for general science. From the third year (Tutor year) onward, student should begin volunteering in a PDS setting for two hours a week.

They also become immersed in the PDS experience by tutoring students two hours per week in one-on-one, small-group settings. Coursework is focused primarily on: learning and instructional design, technology applications, and developing an understanding of the different learning styles of students they tutor. By the end of fourth year, students are required to complete all the content courses required for their Bachelor's degree. Students working toward secondary science certifications must complete requirements for the Multidisciplinary Studies (MDS) degree in which they have the option of enrolling in Biology, Chemistry, or Physics courses.

During the fifth year (Intern year), clinical experiences intensify substantially due to students' full time teaching workloads in PDS under the guidance of a host teacher mentor during fall semester. The coursework includes leadership skills development requiring students to work in school based activities. They work with a faculty mentor in the College of Education in order to complete an action research inquiry project. Collaboration between the two will require: designing the project, having a plan of action, collecting and analyzing the data, writing up the results, and presenting the conclusions. This information is presented at professional meetings to peers, colleagues, and faculty. The final semester includes 135 hours of professional service in PDS. Interns must have approval of their final exit portfolios which should be reflective of their understanding pertaining to the Characteristics of Novice Teachers and those defined in the INTASC principles.

In addition to the Five-Year Plan, teachers were required to pass various certification 
Benchmarks, in the third, fourth and fifth year of program participation. They are administered tests in a specialized subject area that includes the Principles of Learning and Teaching (PLT) in order to become fully certified in West Virginia. Furthermore, students involved in the Teacher Education Programs are expected to become part of the public school community. They benefit from having a close relationship with the university and the opportunity to cultivate their schoolbased experiences. Importantly, they have developed an understanding of "theory to practice." Therefore, each practicum year is closely associated with professional education courses designed as sequence-based learning experiences. This process builds upon the increasing level of inherent complexities they confront while successfully progressing in the program ("Benedum Collaborative Student Handbook,” 2014 ).

\section{Part II}

\section{Teacher Development}

As I was reflecting on the theoretical framework for my study, I recalled how my unique past educational experiences (interactions with social and educational communities) shaped me as an individual, teacher, and student. During my doctoral coursework, my understanding and insight increased substantially about curriculum development and theories. The information helped me to realize the complexities that a person confronts in pursuing a profession such as teaching. In working with pre-service science teachers, this opportunity motivated my interest to investigate their experiences in the Benedum Collaborative Five-Year Teacher Education Program.

I turned to the literature in the field to help me discover issues related to the development of science teachers in teacher education programs. The following important aspects defined their experiences: 
1. Science teachers' beliefs and experiences and their pedagogical development.

2. The academic culture in which they participate and interact with the community.

3. Their identity and role as a science teacher.

4. Their sense of preparedness towards teaching science.

\section{Beliefs, Culture, Identity}

I present three terms: Beliefs, Culture, and Identity, that are relevant to teacher education programs and found to be consistent with the developmental theory of Spiral Dynamics this research investigated.

\section{Beliefs Defined}

Beliefs are defined as psychological constructs derived from one's personal history that influences the structure of a person's thinking and interpretation (Kagan, 1992; Nespor, 1987; Pajares, 1992). Pajares (1992) has the outlook that, "beliefs are created through a process of enculturation and social construction" (p. 316). They are unlikely to be replaced, "unless they prove unsatisfactory, and they are unlikely to prove unsatisfactory unless they are challenged and one is unable to assimilate them into existing conceptions" (p. 321). There should always be a distinction between knowledge and beliefs. One distinction between knowledge and beliefs that Pajares (1992) found is that knowledge is something which is fixed and may not have any emotion associated with it, while belief is more personalized in nature, influencing behavior more than the knowledge. He pointed out that educational beliefs play an important role toward influencing one's perception, judgment, and behaviors, as in teaching. According to Pajares (1992), "Belief is based on evaluation and judgment; knowledge is based on objective fact" 
(p.313). For example, two teachers may have the same knowledge but may teach in different classroom styles.

\section{Culture Defined}

Sewell (1999) described culture as, "the concrete and bounded world of beliefs and practices" (p.39). My cultural background has played an important role in defining my experiences at different points in time. The academic settings of the Eberly College of Arts and Sciences and the College of Education and Human Services at WVU, specifically impacted my identity as a teacher, student, scientist, and human being. At the institutional level, the Academic Culture, is influenced by external factors like economic and political conditions; and by the internal dynamics responsible for the decisions, actions and flow of communication within the units of the organization. In all likelihood, the administrators, faculty, staff, and students within that campus culture are impacted in some way.

I viewed the Academic Culture in terms of my experiences, interactions, and expectations related to the education community (professors, supervisors, colleagues, teachers, students, and doctoral peers) in this research. The relationships I formed within the institutional framework, was significant in many positive ways for me as a human being. The Culture of Academic Advising was a major learning experience that strongly influenced my identity formation in the advisor and teacher roles. My participation in the Academic Culture (India and the United States) involved academic experiences working with host teachers, faculties, and students in the community. It is my belief and experience that an individual is unable to totally separate from a culture they have been a part of. Geertz (1973) shared this perspective: 
Man is an animal suspended in webs of significance he himself has spun. I take culture to be those webs, and the analysis of it to be therefore not an experimental science in search of law, but an interpretive one in search of meaning. (p. 5)

\section{Identity Defined}

Identity is usually associated with one's understanding of the past, present and future. It is socially constituted (the individual and others), and open to one's own interpretations and narratives of experience (Luehmann, 2007). Brickhouse and Potter (2001) referred to identity as the "ways in which one participates in the world and the ways in which others interpret that participation" (p. 966). Holland (1998) pointed out:

People tell others who they are, but even more importantly, they tell themselves and they try to act as though they are who they say they are. These self-understandings, especially those with strong emotional resonance for the teller, are what we refer to as identities. (as cited in Enyedy, Goldberg \& Welsh, 2005, p. 3)

Identity can be seen as a complex construct related to one's own personal history (personal identity developed through beliefs and experiences), it is multiple, it is negotiated, and depends on the various situations one goes through in life. For example, in addition to my cultural and social identities, I have an identity within the academic setting. I view myself as a member of multiple communities in higher education linking to various roles, such as teacher, graduate assistant, researcher, doctoral student, colleague, doctoral peer, advisor, and scientist. The subject matter that I taught or practiced aligned with my identity as well. There were instances when my scientist and advisor identities interacted, conflicted, or negotiated. The outcome was ultimately reflected in my practice and decision making processes, and the expectations the educational community had of me. 


\section{Science Teachers' Pedagogical Development}

The desire to change their educational belief system is one purpose that science teachers seek out professional development experiences (Leonard, 2011). By the time students enter college they have preconceived ideas about learning and teaching science. This is often rooted in their previous learning experiences in school and the image they have of science teachers when they participate in the teacher education (Kagan, 1992; Pajares, 1992). Their beliefs originated in their lived experiences and interpretations. Research has found that individuals' beliefs continually influence teaching practices and are resistant to change (Pajares, 1996). Essentially, they have a professional image of self as a teacher in mind, created from past experiences as a student (Eick \& Reed, 2002; Kagan, 1992). Tsai (1999) explored students' epistemological views about how science can influence their actions and reasoning during laboratory or project work, "If they perceive science as a collection of proven facts, they will focus on memorizing these truths and will attempt to prove them through codified procedures provided by the scientific method" (p. 655).

Pajares (1992) pointed out that understanding students' prior experiences they bring to the teacher education program and the nature of their belief systems in general, will help educators and faculty gain a perception of how students internalize and practice what they learn in their programs (p.322). Driel, Beijard and Verloop (2001) maintained that the reasons for failure of some reform efforts in teacher education are attributed to not being aware of preservice teachers' incoming and existing beliefs and experiences. Teachers can be effective guides

for students' learning science only if they have the opportunity to examine their own educational beliefs (NSTA, 2003, p.29). 
As science and technology progressively advanced, it has become important that teachers be prepared and ready to accept the anticipated changes in how science is taught. NSTA (2000) indicated that "The current reform effort requires a substantive change in how science is taught; an equally substantive change is needed in professional development practices" (p.56). Pre-service teachers will need to learn new theories about teaching and the application of various scientific information. Wideen, Mayer-Smith, and Moon (1998) suggested that teacher education programs assist beginning science teachers to examine prior pedagogical beliefs, structures, and ethos in order to understand and support new practices being introduced and be consistent with changing their beliefs (p. 169).

However, one cannot overlook the fact that beliefs are constructed individually and socially. While most of the dominant research topics for past several years were based on the beliefs related to pedagogical content knowledge and views about nature of science (Backhus and Thompson, 2006; Davis et al., 2006), there is a wider range of problems and challenges that needs to be addressed in preparing science teachers for diverse learners (Davis et al., 2006; Ferguson, 2008; Sadler, 2006; Rodrigues, 1998) in today’s society. Anderson and Stillman (2013) inform the researchers that the term "diverse learners" has been used vaguely in the science teacher education literature and interpreted in a variety of ways which may include culturally, racially, linguistically, and even contextually (urban and rural locations) diverse learners. In a study done by Sadler (2006), some pre-service secondary and middle science teachers reported that they struggled teaching students whom they called "diverse learners" and "felt ill-prepared by the university to do so" (p. 229). Though the term "diverse learners" was not clearly defined by the science teachers, they viewed the diverse student learners in several ways 
that included students with less motivation, students with different learning styles as compared to their own, students with English as a second language, and special needs students (p. 228).

In a study, Rodrigues (1998) found that pre-service secondary science teachers showed two types of resistance: ideological (beliefs and value system) and pedagogical (perception about what constitutes an effective teacher). Dialogic conversation, authentic activity, metacognition and reflexivity encouraged teachers and learners to examine their prior beliefs about what constitutes effective teachers (p. 616). Rodrigues (1998) believed a socially constructed process as "science for all" has to be implemented in order to learn and teach science. This is important in assisting pre-service science teachers who have shown to be resistant to new information and practices in the field. There is a gap in the literature about the perception of secondary science teachers and their approach toward student diversity (Davis et al., 2006; Rodrigues, 1998; Larkin, 2010; Sadler 2006). Wideen, Mayer-Smith, and Moon (1998), in a comprehensive literaure review considered those teacher education programs successful which "feature systematic and long term support in a collaborative setting"(p. 130) inorder to address the preservice teachers' prior beliefs about pedagogy and student diversity.

More particularly, the research studies where secondary pre-service secondary science teachers' views and perceptions about student diverse learners are influenced as the outcome of their participation in a teacher education program. In some qualitative studies (Sadler, 2006; Larkin, 2010) pre-service secondary science teachers described how their interactions with cooperating host teachers, when confronted to diverse teaching sites/environments and diverse learners helped them revise their beliefs about student learning and diversity. In order to address their beliefs about the diverse learners, per-service teachers first must understand their unique belief structures. The experiences they gain during different phases 
of the program will interact with the beliefs they bring into the teacher education programs (Lumpe, Haney \& Czerniak, 2000). This process determines their effectiveness as science teachers (Hancok \& Gallard, 2004). In this way they move toward a "personalized teacher education," which places value on the experiences they currently have (Fletcher \& Luft, 2011).

\section{Interventions and Academic Cultures within Teacher Education Programs}

Wideen, Mayer-Smith and Moon (1998) indicated that the different cultures of the university and K-12 schools impact the priorities of teacher educators and pre-service teachers. The differences may be found in the lack of communication between science educators and scientists, as they are housed separately in academic units within the university (Zitzewitz, Moyer, Otto, \& Everett, 2010; Kohlhaas Labuda, 2002). Collaboration is needed between academic units in order to gain mutual understanding and effect a balanced curriculum (Kohlhaas Labuda, 2002; Fletcher 2006; Rock and Levin, 2002). Talanquer, Morgan, Maeyer, and Young (2007) discussed a similar kind of conflict that existed in which pre-service teachers complained they were not able to effectively implement scientific inquiry and science methods coursework during their pre-teaching due to miscommunication between the university and public schools. Lederman (2006) found pre-service teachers indicated their understanding of teaching science and learning was dependent on the kinds of experiences they have in the teacher education program, coursework, and participant involvement. Discussing the results of educational research on teacher education done by NRC (2001), Talanquer et al. (2007) states : one of the central challenges in the preparation of prospective science teachers is ensuring that their college coursework is infused with realistic opportunities for them to plan, implement, and assess student-centered lessons that promote meaningful learning (p. 18). 
The disconnect between theory and practice not only leads to one of the most common teaching dilemmas like classroom management (Enyedy, Goldberg, \& Welsh, 2005; Sadler, 2006; Kagan, 1992;Wideen et al., 1998) but also the lack of self-confidence to implement inquiry-based science classroom (Fletcher 2006; Luehmann, 2007; Sadler, 2006). Wideen, Mayer-Smith and Moon (1998) examined teacher education program elements designed to counter the beliefs of pre-service teachers about teaching and their roles in the teaching process. It was found that short term interventions (single course based interventions) have limited effect on the beliefs of teachers. The data did not show a relationship between a single course intervention and the overall program (p. 148). For example, Akerson, Morrison and McDuffie (2006) found that most pre-service science teachers improved their views about scientific inquiry after one semester of instruction in the science methods course. Interviews conducted five months following graduation indicated that several pre-service teachers had reverted back to their earlier views (p.194). It implied that teaching a single course is not a guarantee that pre-service teachers will retain the inquiry-based teaching after they start working as in-service teachers. One of the reason could be the lack of connection between a single course and its relationship with overall program structure of teacher education (Kohlhaas Labuda, 2002; Fletcher, 2006; Mason, 2009; Wideen et al., 1998). Several studies show that beginning teachers do not feel adequately prepared to meet the classroom realities after they graduate (Shen 1997; Quartz and TEP Research Group; Kagan 1992; Wideen et al. 1998). Improvements are required for the overall program structure in which such interventions are taking place.

On the other hand, focused long term interventions were found effective when there is continuous dialogue and a close collaboration exists between the university faculty, cooperating host teachers and pre-service teachers, particularly in a PDS setting (Snow-Gerono, 
2009, Davis et al., 2006; Sadler 2006). Interventions like including early classroom experience combined with meaningful coursework also led to awareness in -terms the emotional needs of students ultimately leading to the growth of teachers (Rushton, 2000). Another long term intervention is collaborative action research through school-university partnership which is often viewed as an important contributor to address teachers' belief and impacting their pupils' learning. Rock and Levin (2003) define action research as "systemic inquiry by teachers with the goals of improving their teaching practices" (p.8) consisting of several cycles of inquiry in a structured manner. As Rock and Levin (2002) state "through the struggle of conducting collaborative action research projects, meaningful learning emerges that has the potential to bring out change and development in teachers (page 19). However, the role of cooperating host teachers becomes very crucial in making sure that there is a willingness to cooperate and support in this whole process of action research.

Past research studies (Davis et al., 2006; Sadler, 2006; Kohlhaas Labuda, 2002) have shown that extended field experiences and collaborative culture based on the philosophy of research based teaching in the teacher education programs have been perceived positively by the pre-service secondary science teachers. The positive cooperation from host teachers with meaningful feedback and effective inquiry-based approaches toward science teaching in classroom, were viewed as the most important factors in increasing confidence in teaching. These factors played important role in gaining the confidence in teaching and facing the unfavorable situation in classroom management.

\section{Teacher Identity and Growth in Self-Efficacy}


The way pre-service science teachers identify themselves is an important aspect in understanding the way they learn and practice teaching science. Meijer, Graaf and Meirink (2011) revealed pre-service teachers have two kinds of professional identities, the one they want to be and what is expected because of societal demands and theoretical notions (p. 116). Science teachers have a sense of professionalism and a dominant identity (Helms, 1998). Teaching dilemmas occur when there are conflicts between teachers' personal and professional identities (Enyedy, Goldberg, \& Welsh, 2005). Dilemmas are often related to their beliefs that stem from teaching and learning science in addition to the expectations they have of the education community. Other pertinent factors include: lack of communication between pre-service science teachers, lack of resources within the school, lack of exposure to diverse classroom experiences, the realities of the classroom, and the gap found in educational theories (Greene, 2011). Luehmann (2007) viewed teachers' identity development in the teacher education program as something beyond basic scientific knowledge and teaching skills. Helms (2011) described the teacher education program as being a community similar to a bridge between newer communities (pupils), older communities (host teachers and educators), the science and educational communities, and the pre-service teachers' community. Studies have shown that inquiry oriented teaching benefits in developing inquiry role identity in teacher education program when applied in student teaching (Eick and Reed, 2002; Davis et al., 2006; Kagan 1992). Teacher education program should help science teacher envision themselves as inquiry oriented teachers to better help retain this identity as they start their career as beginning teachers (Eick and Reed, 2002). Emphasizing the role of cooperating host teachers in developing science teacher identity through inquiry-based lessons in classroom and through action research, Eick and Reed (2002) 
concludes: "Preparing student teachers to effectively utilize structured inquiry in their classrooms is a goal of science teacher education" (p. 413).

Bandura (1997, p. 277) defined self-efficacy as "beliefs in one's capabilities to organize and execute the courses of action required to produce given attainments" (cited in Lumpe, Haney \& Czerniak, 2000). Zembylas (2002), emphasized that science pre-service teachers" view of their "selves" impacted the way they make decisions about what they should teach. Within teacher education programs, the methods courses integrating scientific knowledge and pedagogical knowledge have been considered as one of the source of increased teaching selfefficacy (Appleton \& Kindt, 2002). Like Rushton (2000), I would define efficacy growth as "the positive change in attitude toward self, teaching, and working with others"(p. 371).The relationships fostered within the communities of various academic cultures are important in developing teachers' sense of preparedness (self-efficacy) to teach. However, Zembylas (2002) believed that teaching science requires more than subject knowledge and technical teaching skills. Pre-service science teachers should not be viewed just as transmitters of scientific knowledge. Their human experiences and feelings are to be valued, "The emotions that teachers experience and express, for example, are not just matters of personal dispositions but are constructed in social relationships and systems of values in their families, cultures, and school situations" (p. 81). Backhus and Thompson (2006) suggested that the perception of science as a human enterprise should extend beyond viewing "science as a body of knowledge and teaching as a profession" (p. 78).

Teachers' perceptions and feelings are important because there needs to be a balance between their internal and external 'self.' Darling-Hammond, Chung and Frelow (2002) indicated that teacher's feelings and perceptions are relevant to issues that impact teacher retention. Wideen, Mayer-Smith and Moon (1998) believe that teacher education programs, course works, and field experiences must be seen as interconnected with each other and regarded 
as "examinable and problematic in both research and practice" (p. 169). They also emphasize the growing needs of the role of not only content and methods educators but also of hosts (supervising) teacher to help shaping up the beliefs of teaching and learning of science. Therefore it can be asserted that teacher education programs can play an important role in teacher self-efficacy (teaching confidence) as well as teacher retention. In a study, DarlingHammond, Chung and Frelow (2002) found that the teachers' perception about their preparation varied depending on individual and contextual differences (depending on the kind of school where they started teaching and the kind of support they receive). It was found that the teachers' sense of preparedness in teacher education program was the strongest predictor of teaching efficacy (p. 94).

Studies have also shown that there is a strong relationship between the positive selfefficacy growth and five-year teacher education programs with extended field experiences, which can play an important role in teacher retention and commitment to teaching (Darling et al. 2002; Mulready, 2005; Suranna 2000). In a survey done on 3000 beginning teachers, DarlingHammond, Chung and Frelow (2002) found that their sense of preparedness was the strongest predictor of self-efficacy, even though it varied depending on the kind of programs they were enrolled in, and were highly correlated with their sense of responsibility toward student learning and their confidence to remain in the teaching profession in future (p.286). The study also found that the students enrolled in five-year teacher education plan felt better sense of preparedness and plan to stay in teaching profession for a longer period of time. This was attributed to the intensive training and the collaborative culture of the program and participating PDS (p.287).Teacher efficacy is not only associated with positive teaching behavior and student outcome but also dependent on variables related to school experiences like classroom 
management strategies (Savran and Cakiroglu, 2003), positive attitude towards low performing students (Midgley, Feldlaufer, \& Eccles, 1989), and specific subjects of teaching (TschannenMoran, Hoy and Hoy, 1998). Limited research on efficacy studies has been done on the preservice secondary science teachers (Azar, 2010) and from measurement perspective, most of them are very quantitative in nature. Stating the limitation of the quantitative measurements of efficacy studies, Tschannen-Moran, Hoy and Hoy (1998) state:

Quantitative measures typically contributes to our understanding with a snapshot of the efficacy beliefs of a large number of teachers at a particular point in time. However qualitative studies of teacher efficacy are overwhelmingly neglected. .. Interpretative case studies and qualitative investigations are needed to define our understanding of the process of developing efficacy. (p.242)

According to Tschannen-Moran et al. (1998) the self-efficacy of in-service teachers is connected to the kind of experiences they had during their participation during the teacher education program. Rushton (2000) relied on on the qualitative description to tap the authentic feelings and perceptions about self-efficacy growth of pre-service teachers using open ended questions, where pre-service teachers described how their confidence increased in-terms of their ability to cope with different scenarios and make changes accordingly as they were made more aware about school dynamics and classroom dilemmas. When faced with the conflict in their belief system and confronted with real classroom situation, their growth in self-efficacy occurred when they worked collaboratively with the cooperating host teachers to sort out the classroom management issues and that ultimately boosted their confidence as a teacher. Another qualitative study done by Levin and Rock (2003) showed that collaborative research inquiry in PDS setting in the form of action research also helped pre-service science teachers in gaining an increased understanding of not only about themselves as teachers but also about their responsibilities toward students. This collaborative stance relied on the mentor-mentee relationship and therefore shared dialogue became critical despite constraint like limited timeframe for research implementation. Therefore the study recommended to support structures within the teacher education programs should encourage and facilitate such collaboration (p. 148). 


\section{Intersection of Beliefs, Culture, and Identity as a developmental framework}

Zembylas (2002) viewed teaching and learning as a social relationship between teachers and students. Their relationship is influenced by the individual's way of looking at reality, which are fusions of personal, social and political constructs. Teacher education can be viewed as a socialization process where continuous interaction of factors like personal beliefs and academic culture (and community) influence the perception of teacher identity and teaching self-efficacy within the framework of institutional norms. This encourages researchers to view teacher education as a dynamic and complex system, rather than just an event. The properties combine in different ways, varies to the individual, and affect the same person in different contexts (Opfer \& Pedder, 2011, p. 377). The development of an individual in such system due to socialization may or may not lead to the shift in consciousness which may be structural (like spiral dynamics model), where one may stuck to a level or move and transform to next more inclusive level while retaining the elements of previous structures of what can also be called as "the ways of thinking". The development in such system is influenced by academic cultures that may also be based on modelling and observing the behavior and attitude of the educational community within the cultures of institution (Vygostky, 1978). This may influence the pedagogical beliefs and perception of self and teaching self-efficacy. The constructs like culture, beliefs, identity, and perceived teacher self-efficacy retrieved from the literature on teacher education programs may be used as a reference to better understand the complexity of teachers' experiences and their perceptions of training in a teacher education program.

\section{Conclusion}


The professional development of science teachers require they master content knowledge and effectively translate and communicate science information to their students. They are expected to successfully qualify for their teaching license and certifications. However, science teachers are usually not part of the decision making process in teacher education programs. They are dictated to and treated like technicians. Therefore, it is essential for educators to value and allow science teachers a voice in the program. Their perceptions over the course of five years provides a general overview of the personal and academic issues that are crucial in their retention, their role as a teacher and the kinds of relationships they have with the education community as a whole.

Teachers are the bridge in the partnership between the university and public schools and can be effective representatives of the knowledge and training acquired in teacher education programs as the Benedum Collaborative Five-Year Teacher Education Program offered at West Virginia University. Past research indicated that Five-Year Teacher Education Programs in general result in students' retention and graduate satisfaction compared to alternate route programs (Andrew, 1990; Darling-Hammond et al., 2002; Mulready, 2005; Suranna, 2005). Little information has been forthcoming concerning participants' in-depth perceptions about the way they viewed themselves in this program, or their overall perceptions before and during participation as a result of their participation. As a researcher, I believe that understanding the dynamics of teachers' experiences is very helpful for those expanding educational inquiry in the future. Importantly, science teachers have a key role in furthering students' understanding of the sciences that ultimately impact society at large. 


\section{CHAPTER 3}

\section{Methodology}

\section{Qualitative Methods}

Qualitative research methods were used to investigate human or social issues. It has been used concurrently with case studies, grounded theory, ethnography, phenomenology, heuristics and naturalistic inquiry (Agostinho, 2004; Patton 2004). This methodology gives the researcher the freedom to understand the opinions and feelings of participants in-depth without having any preconceived notions (as compared to the hypothesis element of quantitative research). It provides multiple approaches toward understanding human phenomena.

The purpose of this research was to investigate how science teachers make sense of their overall educational experiences in the Benedum Collaborative Five-Year Teacher Education Program. The personal narratives were reflections of their educational journeys related to the self and the academic cultures that one is part of, mainly the culture of science, culture of education, and culture of PDS. Therefore, a phenomenological approach was chosen to understand the lived experiences of the research participants in the program that this research was focused upon. This also included the kind of meaningful experiences related to teaching and learning as perceived by them over the course of five years influencing their understanding of themselves as learners and teachers.

The Primary Guiding Question:

How do science teachers describe their academic experiences during their participation in the Benedum Collaborative Five-Year Teacher Education Program?

The Sub-Questions are: 
a) What do science teachers focus upon when they describe what they have learned from the program?

b) What are the emerging themes of teaching and learning before and during science teachers' participation in the program?

In order to explore and illuminate the lived experiences of pre-service and in-service secondary science teachers, qualitative methods were selected as being best suited for this research. Qualitative researchers have the option of using one or a combination of approaches to develop clarity and understanding of human reality. Patton (2004) described qualitative research as being a complex and evolving field that includes a wide variety of approaches for different studies in the human sciences field. It is not a single, monolithic approach to research and evaluation. It conveys different meanings for different people. Qualitative inquiry emphasizes understanding of divergent theoretical and philosophical traditions. The qualitative outlook is a "Weaving together [of] theory-based inquiry traditions and qualitative methods will reveal a rich tapestry with many threads of differing texture, color, length, and purpose” (Patton, 2004, p. 78).

Qualitative data best describes the essence of human experience. Patton (2004) advised that open-ended responses, "permit one to understand the world as seen by the respondents..[and] understand and capture the points of view of other people without predetermining those points of view through prior selection of questionnaire" (p.21). With this in mind, my data collection involved open ended, semi-structured interviews, document analysis of teachers' written artifacts (like inquiry reports and lesson plans) and program documents. My unique role as researcher (insider-outsider), educational background discussed in the following section provided additional insight to the richness of the data.

My personal values and beliefs about the nature of reality and knowledge about the program will enrich my role as a researcher. This study is guided by the ontology (the form and 
nature of reality) and epistemology (the nature of knowledge, known and acquired) of the qualitative lens and preservation of individuals' reality. The methodology (the researcher discovers the unknown) promotes the essential components needed in critiquing and conducting qualitative research (Lincoln and Guba, 1985).

\section{Shift from Positivist to Naturalist Paradigm}

I reflected how the positivist approach has guided me prior to joining the doctoral program in education, through my academic career, and how the coursework in education has led to the nature of knowledge I acquired so far. Palmer (1993) held the perspective that, "We become manipulators when our knowledge leaves the inner self unexamined, for it is there that the drive for dominance arises" (p.37). The new information presented in this research demonstrates a qualitative approach that was heavily influenced by the naturalistic paradigm defined by Lincoln and Guba (1985). They differentiated between the positivist and naturalist paradigms and that of epistemology and ontology in qualitative research methods (Table 3).

I actually experienced a shift in perspectives when I viewed my reality as a master's degree student in the College of Arts and Sciences, and later as a doctoral student in the College of Education and Human Services. Before joining my doctoral program my worldview as a researcher was heavily dominated by the quantitative nature of research which was also reflected in my master's thesis. As a researcher and teacher, I found that anything logical was in terms of numbers, as in conducting assessments of my science students. I learned the complexities of qualitative research during my doctoral program, when I conducted an interpretative study (Keopuhiwa, Srivastava, Oonge, \& Maundu, 2011) to understand how an online space can provide voice to minority graduate students. The insight I gained from the data was invaluable as a qualitative researcher. 
Table 3

Axioms, Positivist, and Naturalist Paradigms

\begin{tabular}{|c|c|c|}
\hline $\begin{array}{l}\text { Axioms (basic beliefs) } \\
\text { about }\end{array}$ & Positivist Paradigm & Naturalist Paradigm \\
\hline $\begin{array}{l}\text { The nature of reality } \\
\text { (ontology) }\end{array}$ & $\begin{array}{l}\text { Reality is single, tangible, } \\
\text { and fragmentable. }\end{array}$ & $\begin{array}{l}\text { Realities are multiple, } \\
\text { constructed, and holistic. }\end{array}$ \\
\hline $\begin{array}{l}\text { The relationship of } \\
\text { knower to the known }\end{array}$ & $\begin{array}{l}\text { Knower and known are } \\
\text { independent, a dualism. }\end{array}$ & $\begin{array}{l}\text { Knower and known are } \\
\text { interactive, inseparable, }\end{array}$ \\
\hline $\begin{array}{l}\text { The possibility of } \\
\text { generalization }\end{array}$ & $\begin{array}{l}\text { Time- and context-free } \\
\text { generalizations } \\
\text { (nomothetic statements) are } \\
\text { possible. }\end{array}$ & $\begin{array}{l}\text { Only time- and context } \\
\text { bound working hypotheses } \\
\text { (idiographic statements) } \\
\text { are possible. }\end{array}$ \\
\hline $\begin{array}{l}\text { The possibility of } \\
\text { causal linkages }\end{array}$ & $\begin{array}{l}\text { There are real causes, } \\
\text { temporally precedent to or } \\
\text { simultaneous with their } \\
\text { effects. }\end{array}$ & $\begin{array}{l}\text { All entities are in a state of } \\
\text { mutual simultaneous } \\
\text { shaping, so that it is } \\
\text { impossible to distinguish } \\
\text { causes from effects. }\end{array}$ \\
\hline The role of values & Inquiry is value-free. & Inquiry is value-bound. \\
\hline
\end{tabular}

Note: Contrasting Positivist and Naturalist Axioms (Lincoln \& Guba, 1985, p.37)

\section{The role of Researcher and Validity Issues}

In using a purposeful sampling of participants, I did not expect generalization of the results in this qualitative study. Validity in qualitative research is totally dependent on the 
paradigm assumption and theoretical perspective of the researcher: "The credibility of qualitative methods, therefore, hinges to a great extent on the skill, competence, and rigor of the person doing the fieldwork" (Patton, 2014, p. 14). There are no absolute validity and reliability tests in using the qualitative method: "In short, no absolute rule exists except perhaps this: Do your very best with your full intellect to fairly represent the data and communicate what the data reveal given the purpose of the study" (Patton, 2004, p. 433). This makes the role of researcher complex, as the researcher should be viewed as being the instrument that enhances selfawareness. Brown (1996) referred to "sharpening the instrument" (p. 42) in order to draw out beneficial and novel information. I am reflective in my role as a researcher and understand that self- reflection and self- awareness are important to overcoming one's biases and helpful in interpretation of the data.

Interpretation is viewed in the proper context that made sense to me and produced meaningful understanding of what I found. And while interpretation and subjectivity are seen as an important characteristics of a qualitative researcher, the same sources can also be seen as the sources of personal bias and raise questions about trustworthiness of a study influenced by naturalistic paradigm (Lincoln and Guba, 1985). As a qualitative researcher I made sure to do my best in order to minimize my personal bias and maximize the holistic picture of this study. In keeping with these issues as suggested by Lincoln and Guba (1985) I addressed the following: 1) internal validity: by using more than one method of data collection and analysis (discussed in later sections of this chapter); and 2) external validity: enhancing the transferability of the research findings by providing thick rich description of the relevant themes to represent participants' voices in great detail and then leaving up to the reader to decide if the results are transferable to other circumstances or not (p. 316). 
As discussed in chapter 1, my unique-insider-outsider perspective made me felt capable of providing a critical lens of inquiry. My past conversations with students, PDS host teachers, advising staff and faculty mentors at various platforms like the West Virginia Science Teacher Association (WVSTA) conferences and field experiences helped me to appreciate the rigor hard work pre-service science teachers go through in the Benedum Collaborative Five-Year Teacher Education Program. In content analysis of the data, my experiences as a researcher, academic advisor, instructor, and student were important, in comprehending the relevant information found in the documents I collected in the study. I followed the narrative style throughout this work and believe my interviews with participants produced a suitable format to easily communicate their experiences with me. Palmer (1993) referred to interviews as Inter-View, "a way of looking into other people's behaviors and attitudes that opens our own lives to view" (p.62). Interpretation is an evolving process. All understandings and interpretations were connected to individuals' background or pre-understanding. Hence, the individual needs to become aware of his/her interpretative influences. Interpretation according to (Alevesson, 2004) is a process achieved through a "hermeneutic circle which moves from the parts of experience, to the whole of experience and back and forth again and again to increase the depth of engagement with and the understanding of texts" (p. 24).

Inter-subjectivity between the researcher and the participant play a vital role in having a qualitative frame of mind in research. Brown (1996) pointed out that researchers needed to be receptive to the diversity of participants, their ideas, and way of being. This openness is an important aspect of mutual trust during the research:

This implies feeling secure about one's emotional reactions and being able to tolerate emotions expressed by others. The abilities to identify with another's experience - even 
when that experience is different from one's own - and to get beyond judgments of inferiority and superiority involve temporarily dispensing with guardedness and moving with the process of the interaction, engaging in the natural unfolding of a sequence of events. It means coming, not to the truth, but to the truth of oneself, the other person, and the relationship in the moment (p.23).

In quantum physics, when two or more quantum particles interact their wave functions entangles in such a way that some properties of each are now dependent on what happens to any one of the particle. I realized that the principle true not only for microscopic particles but also for human beings. My interaction with participants had given me a chance to find myself as a teacher, student and conscious human being. Patton (2004) found that conducting qualitative inquiry makes a strong impression on the researcher, "prepare to be changed. Looking deeply at other people's lives will force you to look deeply at yourself' (p. 34).

In trying to understand participants' experiences and feelings I drew on my personal experiences and interpretation as "I am the knower" and "I am the known" because they both cannot be separated from each other. Palmer (1993) pointed out:

The way we interact with the world in knowing it becomes the way we interact with the world as we live in it. To put it in somewhat different terms, our epistemology is quietly transformed into our ethic. The images of self and world that are found at the heart of our knowledge will also be found in the values by which we live our lives (p. 21).

My own hermeneutic circle of my interpretations developed the information I found in the data. In other words, analysis was based on what I found meaningful from my personal understanding of the statements and the exact words the participants chose to use in describing their experiences and perceptions. It leaves the question open as to whether another researcher 
wanting to replicate my research has a similar lens due to my cultural background. The data was enriched nevertheless due to the uniqueness of diversity that I as a researcher brought to this investigation. This is part of the nature of qualitative research in my opinion that makes it interesting; it is how I interpreted in my mind the stories people tell me. My task was to study their lived experience and hence it's important that my subjectivity as a researcher combined with our inter-subjectivity is taken into account to establish mutual influence. The results were not generalizable to the population of teachers that participated in the Benedum Collaborative Five-Year Teacher Education Program. I used my skills and made best attempts as researcher to understand their experiences as it was important to me and to the purpose of this research that I highly valued the participants' point of view.

\section{Selection of the Participants}

Nine teachers were purposefully selected for this study from the Benedum Collaborative Five-Year Teacher Education Program (Benedum Program). Teachers were contacted through mass email sent to student cohorts in the following years: 2009, 2010, 2011, 2012, 2013.

Teachers were identified in two ways:

- Three participants in their Intern Year who had completed the Secondary Science Methods course at the time of this study.

- Six participants who had graduated from the Benedum Five-Year Teacher Education Program within the last five years at the time of this study.

\section{Participant Background Information}


Information on each participant's general background is provided. Pseudonyms were assigned to each teacher for anonymity and confidentiality purposes. Participants in this study are identified as: (1) Joe, (2) Ted, (3) Rhea, (4) Cory, (5) Adam, (6) Sylvia, (7) Ella, (8) Tami, (9) Amber. Six of the nine research participants were certified (or working toward certification) in General Science (Biology 9- Adult). Three of the nine participants were certified (or working toward certification) in General Science (Chemistry 9-Adult).

Joe. Joe is an in-service teacher who works as a science teacher in a school. He grew up in rural West Virginia. I have known Joe as being an active participant in a college affiliated student organization. I also had several interactions with him while attending annual conferences such as the West Virginia Science Teacher Association (WVSTA). During our many conversations, he reflected his enthusiasm for teaching science that would ultimately make him a valuable participant for this study. He attributed his early interest in science to the experiences he had with his science teachers in middle school and high school. He mentioned science modeling and hands on activities both in and outside of the classroom as some of his earlier memories. Noticing Joe's growing interest in applied science, his high-school teacher suggested that he pursue a career in engineering which led him to his journey as an Engineering major at WVU. However, he soon realized that he was not enjoying engineering and wanted something which was more people oriented. This realization came about because of his involvement in tutoring students who were preparing to enroll in college. Eventually, Joe learned of the Benedum Program during his sophomore year.

Ted. Ted is an in-service teacher working in a high school. He spent his early childhood years living in a diverse, suburb of a metropolitan city in California. After spending his first three years of elementary school in California, he moved to West Virginia. 
Academically, his parents and three siblings have science backgrounds. As a young child, Ted enjoyed science and hoped to achieve his dream of becoming a scientist one day. He felt that his science teachers, family, and interest in science motivated his decision toward a career in this field. It did not occur to him to even consider becoming a teacher one day. He began college as a chemistry major and later entered the Benedum Program at the end of his sophomore year. Ted attributes this change of career direction to a summer job working as a resident assistant with high school students. He realized that he could easily relate his knowledge of science to people closer to his own age group and shared this perspective, "I like young people and I like science, so why not become a science teacher? It allows me to combine two things [interests] and that's what made me want to go to the Five-Year Benedum Program."

Rhea. Rhea, a pre-service teacher, grew up in very rural community about thirty miles outside a metropolitan city in Pennsylvania. She has a sister who is two years younger than her. Since both parents were West Virginia University alumni, she considers herself as being "born and raised as Mountaineer." As a child, she was always interested in science, due to her middle school and high school science teachers. They allowed her to use scientific methods to solve real world problems. Rhea feels that she is a "born teacher," and fondly recalls, "My mom told me a story that when my sister and I were growing up we use to play school and I would never let her be the teacher. Looking back on it [experience] I realized that I wanted to be the leader in charge." Her greatest inspiration for becoming a science teacher was triggered when she encountered a student teacher who was the first female science teacher in high school she ever had. The image of a female teaching a science class made a huge impact on her. Although none of Rhea's immediate family members were teachers, her parents were very enthusiastic about her decision to become a teacher. 
Cory. Cory, a pre-service teacher, grew up near the border of a neighboring state to West Virginia. She has one older brother. Both of her parents graduated from West Virginia University and have careers in the medical field. Due to her parents' influence she initially opted to pursue a career in dentistry. As a young girl, she was drawn toward science because of very "relatable teachers" in middle school, and having a supportive relationship with her science teachers. Cory chose a teaching career because she loved studying Biology, and was also inspired by her experiences with science teachers in middle school and high school. Despite her parent's desire for Cory to seek out a medical career, they responded positively and supported her decision to become science teacher.

Adam. Adam, an in-service science teacher was raised in a suburb of a metropolitan city in Maryland, and attended public schools through high school. He credits his interest in science to the teachers in middle school and high school. The idea of teaching science in the future was developed when he was a high school student. His high school science teachers encouraged him to volunteer in science activities and helped him acquire an internship in a science museum due to his strong interest in the subject. He found that his experiences working with people and teaching them in the internship helped to confirm his decision to pursue a teaching career in science. His mother, a high school teacher, greatly influenced his outlook toward teaching. Adam stated, "She is a great teacher [the] person who inspired me [and] she was very supportive." He did experienced some opposition from his father who wanted him to choose a profession which would yield more money. Therefore, he began as a pre-pharmacy major in college. He soon realized that teaching was what he wanted to do after all. His father eventually accepted and supported this decision. 
Sylvia. Sylvia, a pre-service teacher, grew up in a small town in Connecticut, attending public schools. Education has always been very important to her family because both parents were college graduates. She attributed her interest in teaching science to her science teachers in middle school and high school that helped to spark her interest in Biology and Genetics. Her curiosity in science activities especially in completing hands-on activities helped to tilt her career focus in favor of the teaching profession, "I just love science and I kind of like to share that with people." She first participated in the Science Olympiad and other science competitions in middle school, and continued to do so in high school. As a high achieving student, her parents wanted her to enter a helping profession, preferably a career as a Biologist or Neurosurgeon. Sylvia on the other hand assessed that teaching was something that came naturally to her, deciding to enroll in the Benedum Program and pursue a career in teaching science.

Ella. Ella, a pre-service teacher, attended Catholic school from seven to twelfth grade. Her interest in science began in Forensic class her junior year in high school. Activities like investigating crime scenes and the crime solving process itself made her to be more inclined natured toward studying Biology and Forensics. Although her parents have careers in business, she was never interested in becoming a business major in college. It was mainly due to her teachers' influences that she wanted to go into a helping profession related to science. She initially started as a pre-nursing major, soon realizing that teaching was something she could feel comfortable doing; entering the Benedum Program as a sophomore. Ella's parents welcomed this news and supported her decision to be a teacher.

Tami. Tami, an in-service teacher, grew up in a small town in Ohio. She comes from a family of four siblings, and is the youngest and only biological child of her parents, as others 
were adopted. She attended public schools through high school. She attributes her interest in science to her high school chemistry teacher who had encouraged her to pursue science as a career. Tami initially considered studying Forensics or Nutritional Science, opting for teaching in the end. Her mother was a high school teacher and was the role model that influenced Tami. Her mother was ecstatic about her decision to pursue a teaching career.

Amber. Amber, an in-service teacher grew up in the northern part of West Virginia. She attended public school throughout high school. Both of her parents were graduates from West Virginia University. Her involvement in science projects in high school sparked her interest in science. She wanted to be a teacher at a very young age, even though she wasn't sure what subject she would teach. Amber's interest in Anatomy and Genetics began in high school science classes with a teacher that developed her enthusiasm in these two areas. Her close family members advised her that the teaching profession would not earn her a lot of money. Amber did not change her mind about her chosen career path because she felt that teaching would be best for her.

\section{Data Collection}

\section{Interviews}

Interview data were collected through telephone and face-to-face interviews. Two face to face interviews were conducted at Allen Hall where the Benedum Office is located. I met individually with each participant in one of the unoccupied offices. Seven phone interviews were completed due to participants' teaching commitments outside the area. Open-ended, semistructured interview questions were used in the interview protocol to study the lived experiences of the participants to reflect on tier journeys during their participation in the Benedum 
Collaborative Five-Year Teacher Education Program. I used question prompts when necessary to increase discussion. This gave participants enough room to reflect on their academic journey and training during their participation in Benedum Collaborative Five-Year Teacher Education Program. The questions used in the interviews are based on past qualitative research studies (Fletcher, 2006; Larkin, 2010; Mason, 2010; Pease, 2010; Sadler, 2006; Suranna, 2000; Selmer, 2008) and the program components of Benedum Collaborative Five -Year Techer education program.

\section{Documents}

The second set of data collection method was through the participant's written documents, which were requested at the end of interview. The participants voluntarily shared the lesson plans and inquiry journal reports made during their participation in the program. These written work were emailed to me by the participants after the interview was over. Six out of nine participants shared the lesson plans they developed during their participation in the program. Four out of nine participants shared their selected inquiry journal reports under various contexts during their participation in the program. Two out of nine participants also shared their electronic teaching portfolios.

The documents provided by the participants served as an added method to address the research questions to capture an essence of their narrative account toward inquiry-based learning and lesson plan development during their participation in the program. The lesson plans reflected their understanding of their way of implementing the inquiry-based teaching strategies, addressing students' diverse learning styles, and assessments to meet educational objectives in a science lesson. The lessons revealed their action plan of what they actually implemented as a 
teacher in their PDS classroom during their clinical experience in their program. The written documents, like inquiry reports, revealed what the participants actually reflected or viewed regarding their learning during their participation in the program. Inquiry reports were analyzed in the context of participants' growth as learners in their inquiry-based seminars.

In addition to the above documents, a second set of documents related to the program of this study were also used for data analysis. These included the Benedum Collaborative Five-Year Teacher Education Program Student Handbook (obtained through the program website), the program website, and the syllabus of the secondary science methods course (C \& I 644) voluntarily shared by the faculty. The syllabus for secondary science methods was used because this was the one course that all participants attended during the time of interviews.

\section{Triangulation}

I drew my definition of triangulation from Creswell and Miller (2000): “a validity procedure where researchers search for convergence among multiple or different sources of information to form themes or categories in a study" (p.126). However, this does not mean that this was looked at as a deliberate attempt to converge on a single reality or same result (Patton, 2002). Instead, the meaningful combination of methods and analysis provides researchers with diverse ways of looking at the research problem to minimize the personal biases in understanding and giving meaning to participants' experiences. Also, the diversity that I bring to this research as a student and teacher working in the academic cultures of science, education, and PDS brings another dimension of richness to the data collection, interpretation, and analysis.

In a qualitative research paradigm, besides being self-reflexive, a researcher should also work to increase the trustworthiness of the methods and findings to address the research question 
of the study. This can be achieved by using more than one method of data collection, also called triangulation in a qualitative research paradigm. I found in-depth interviews and written documents by the research participants, along with program documents, as reliable sources of data collection to understand and interpret the meaningful experiences of my research participants. While interviews were the main source of data collection technique to address the research question, document analysis were used to supplement information collection through the interviews (Mogalakwe, 2006).

The above three sets were triangulated to supplement and corroborate the findings from interview data, written document analysis, and analysis of the program documents. Specifically, the data analysis consisted of interview data and document analysis. An additional researcher, trained in the qualitative research, coded the data to establish themes and patterns to check against my bias and to increase the consistency of the results pertaining to the research questions (Patton, 2002, p.558).

\section{Data Analysis}

Data analysis included case by case studies of the participants used in the study. In qualitative research, the inductive outlook involves "discovering patterns, themes and categories in one's data" (Patton, 2004, p.453). Patton (2004) pointed out that, "Findings emerge out of data through the analyst's interactions with the data" (p.453).

Emergent paradigm signifies the interactive character of human inquiry as it retains the humanness of respondents (Lincoln \& Guba, 1985, p. 46). Brown (1996) indicated:

People and their interactions are more than a collection of objective, measurable facts; they are seen and interpreted through the researcher's frame - that is, how she or he organizes the details of an interaction, attributes meaning to them, and decides 
(consciously or unconsciously) what is important and what is of secondary importance or irrelevant. The researcher's disposition, inclinations, sensibilities, and expectations all come into play, influenced by psychological factors, cultural background, her or his interests, and the relationship between the researcher and the participator(s) in the investigation. (p.16)

The nine interviews were transcribed and the raw data were categorized after providing pseudonyms to all the participants. I read and re-read the transcript several times, completely immersing myself within the data to highlight the common responses to interview questions in order to identify categories that aligned with my research questions. The categories were determined and each one was labeled with a specific code. The data in each category was further reviewed for emergent themes. I looked at the data on a case by case basis at first, before assigning categories. In this way I was able to draw conclusions as to how the information linked to my sample, taking in consideration all nine participants to find patterns of relationships.

I contacted participants to confirm the raw data as needed. It was vital that I had clarity of participants' words and statements. I also drew from my own experiences and familiarity with the mission, structure, and delivery of the WVU Benedum Collaborative Program and the interactions I had with students, teachers, and faculty. This also included my own experiences in the academic culture of science, education, and PDS - areas that the participants in the study were part of. My level of expertise as a teacher, advisor, and doctoral candidate allowed me the liberty to make judgment calls regarding the data used during analysis. This is the nature of having insight (before and after) conducting inquiry of phenomena. I determined the themes and patterns I found that were applicable to my research questions. To check if the emergent themes were biased a second researcher trained in qualitative research methods also coded the 
data. For document analysis, I scanned through both sets of documents (written works provided to me by research participants and the program documents). Here, too, themes and patterns were established as they emerged from the data, in order to answer the research questions. To verify if the emergent themes from the document analysis were biased, the secondary researcher that checked the emergent themes from interview data, also coded the data from the documents. Any variations amongst the codes were discussed until an agreement was made between the principle researcher and secondary researcher.

The similarities and differences were the connections I was looking for. The cross analysis provided emerging themes and some broad overarching themes. According to Patton (2002):

Once those themes and patterns are emerged, then the final or confirmatory stage of analysis may be deductive in nature in order to test and affirm the authenticity and appropriateness of the inductive content analysis, including carefully examining deviate cases or data that don't fit the categories developed. (p.454).

This confirmatory process is deductive in nature because it is appropriate following the process of inductive content analysis of the raw data that examined information that didn't fit or was developed that Thomas (2003) stipulated:

The purposes for using an inductive approach are to (1) to condense extensive and varied raw text data into a brief, summary format; (2) to establish clear links between the research objectives and the summary findings derived from the raw data and (3) to develop of model or theory about the underlying structure of experiences or processes which are evident in the raw data. The inductive approach reflects frequently reported patterns used in qualitative data analysis. Most inductive studies report a model that has 
between three and eight main categories in the findings. (p. 1)

Lastly, for qualitative reporting, Patton (2002) suggests that the researcher needs to make sure to maintain a balance between description, quotation and interpretation:

Description and quotation provide the foundation of qualitative reporting. Sufficient description and direct quotations should be included to allow the reader to enter into a situation and thoughts of the people represented in the report... The reader does not have to know everything that was done or said. Focus comes from having determined what's substantively significant and providing enough detail and evidence to illuminate and make that case. (p.503)

\section{Conclusion}

This study used a qualitative approach to analyze the kinds of experiences participants shared in interviews and document analysis of their written work. The nine Pre-Service and InService teachers who were enrolled in the Benedum Collaborative Five-Year Teacher Education Program at West Virginia University were purposely selected for this study. Additionally, within the themes of culture, beliefs and teacher identity in a teacher education program, as identified in the literature review, as well as the framework of the Benedum Collaborative Five-Year Teacher Education Program (see Chapter 2), this research will address what kinds of meaningful experiences lead participants to grow in the program. 


\section{CHAPTER 4}

\section{Presentation of the Findings}

\section{Introduction}

The aim of this qualitative research was to explore the experiences perceived by secondary science teachers who had participated in the Benedum Collaborative Five-Year Teacher Education Program at West Virginia University. The participants were nine secondary science teachers, six in-service teachers who had graduated from the Benedum Collaborative Five -Year Program, and three pre-service teachers enrolled in the program. Their experiences and development over the course of five years are presented in this chapter. Interview questions were based on the participants' prior experiences before and during their involvement in the three main components of the teacher education program: content, education, and field experience. The questions were designed to explore the notions of participants' interpretation of their education within the learning environments that impacted their participation and learning.in academic cultures.

The main guiding research question was: How do science teachers describe their academic experiences during their participation in the Benedum Collaborative Five-Year Teacher Education Program?

The Sub-Questions are:

a) What do science teachers focus upon when they describe what they have learned from the program?

b) What are the emerging themes of teaching and learning before and during science teachers' participation in the program? 
This chapter is organized in five main sections: Participants' prior experiences before joining the program, main research question, experiences in the culture of science, experience in the culture of education, and experience in the culture of PDS. In order to distinguish the quotes from pre-service and in-service participants, I will use the suffixes P and I respectively next to their pseudonyms. Also, because the participants have used the word "Benedum" all through their narrative, I will be using "Benedum Collaborative Program" in place of "Benedum FiveYear Teacher Education Program" throughout this chapter for consistency.

\section{Participants' Prior Experiences}

As the participants started reflecting on their prior experiences, it was important to know what cultural and ideological backgrounds may have influenced their answers. From the participants' responses, two main themes were identified: image of science teacher and family's support and perception of science teaching as a profession.

Image of a science teacher: All nine participants attributed their interest in science primarily to the relationship they shared with their middle/high school science teachers and the way they were taught sciences in their schools. Also, some described their experience in summer camp, tutoring, and working as resident assistants as motivating factors that influenced their decision to consider teaching the correct career option. All participants visualized teaching as their future career prior to deciding to become a science teacher. None of the participants recalled any parental involvement towards learning sciences, though some participants had relatives in the teaching profession, yet who did not influence their decision to become science teachers. Therefore, it would not be an understatement to say that a science teacher played a very 
important role in creating each participant's interest in pursuing a career in science. However, in the case of Rhea, she saw a "hope" when she saw her first female science teacher (in the form of student teacher) in her high-school chemistry class. As she states, "It made me excited to see a female standing in front of me.... I wanted to show both males and females, especially females - that you can be in there and you can enjoy science, and you can love it." (Rhea-I)

Family's support and perception of science teaching as a profession. Most of the participants were in pre-science/engineering majors in their first couple of semesters before applying/entering the Benedum Collaborative Program. They already had good GPAs, as most of those pre-science majors require high GPAs in their programs. All participants already had support from their family to pursue a career as a "science professional," and the descriptors that emerged from participants were "supportive" and "enthusiastic." However, when the parents learned about their decision to choose a teaching career in science, not all were initially convinced that this was a good career choice for them. For some participants, their family's perception of a "career in science " and "career in science teaching" were different, especially in terms of monetary compensation.

However, those participants were able to convince their family members of the validity of their choice and ultimately were supported in their decision to become science teachers. Some of those examples are presented below:

Working in a pharmacy would make me more money, so I didn't know how he [my father] would take it but [ultimately] he was very supportive of the change and I think ultimately everybody realized what I was meant to do. (Adam-I)

Some people thought I am not going to make that much money in my teaching career-I still am today financially okay, but other than the financial situation not being paid a ton like you are doctor or something else - everyone is supportive of me being a teacher. (Amber-I) 
They were surprised because they knew I was a good math and science student and engineering would be a very secure and well-paying career. ... my dad had no negative attitude or directions from either my friends or my family about me becoming a teacher and especially think one of the reasons for that is a lot of my friends were already education major[s]. (Joe-I)

... and she [mom] was like you could become like a biologist or neurosurgeon. . . . I just wanted to be a science teacher. ... my family has been really supportive of that [decision]. (Sylvia-P)

Based on the descriptions of participants, it is clear that a supportive family environment helped them pursue a teaching career with confidence. It also shows the kind of strong dedication they bring with them when they apply for the Benedum Collaborative Program. The parents trusted the enthusiasm and passion that these participants showed before deciding to go for a science teaching career. All the participants I interviewed had either graduated or are at advanced stages of their program; therefore, their support from family only had positive impact on their success as a science teacher. They all brought a passion into the program and their success is evidence of this.

As an academic advisor, I had encountered many pre-education students considering applying for the Benedum Collaborative Program. I was asked questions regarding their change of major from pre-science to pre-education and the kind of concerns their parents had about their decision to change their major. In my advising experience it was not uncommon that students would tell me the parental and societal pressures that dictate their choice of major, especially when they decide to switch from science to pursue a career in teaching. I clearly advised those students about the rigor of Benedum Collaborative Program and the kind of dedication needed to become a teacher.

\section{Main Research Question}


The main guiding research question was: How do science teachers describe their academic experiences during their science teacher education program?

My sub questions were:

a) What do science teachers focus upon when they describe what they have learned from the program?

b) What are the emerging themes of teaching and learning before and during their participation in the program?

Research question 1 and 1a) seem to overlap with each other and are interwoven in terms of understanding meaningful experiences. Both questions 1 and 1a) cover the same topic which is geared toward understanding the kind of experiences participants find meaningful during the program; therefore, I presented the results in the same section instead of presenting them separately. The findings are summarized based on the descriptions of their educational journey during the program. The main themes identified were experiences related to meaningful courses, meaningful relationships, and meaningful learning. Subthemes that emerged were inquiry-based learning, program structure, perceived barriers, professional development opportunities, support, sense of community, scientist identity, teacher identity, and theory to praxis connections. For the sake of presenting my results as a narrative, I have split their experiences from the Benedum Collaborative Program into three academic cultures: experience in the culture of science-where participants talk about their experiences taking content classes from the College of Arts and Sciences; experience in the culture of education — where they take pedagogy classes from the College of Education and Human Services; and experience in the culture of a PDS (school participating under the collaborative structure of Benedum Collaborative Program)—where they do their clinical practice. 
The second sub question $1 \mathrm{~b}$ ) related to emergent themes of teaching and learning will be discussed in the last section of this chapter.

\section{Experience in the Culture of Science}

The main themes that were found were meaningful science-content courses, meaningful relationships, and meaningful learning experiences, which included subthemes like scientist identity, support, and large lecture classrooms. The discussion presented below is in narrative form and is grouped by in-service and pre-service teachers:

Meaningful science-content courses. In the Benedum Collaborative Program the content classes are taken in the Eberly College of Arts and Sciences, while courses related to pedagogy are taken in the College of Education and Human Services. Most in-service and preservice teacher participants described their science-content classes as helpful when learning science concepts and gaining practical hands on lab experience, but their "extent of benefit" differed depending on the perceived usefulness of the course content. Their discernment of the level of importance of science-content courses varied. For Joe, Ted, Rhea, and Tami their experience with their science-content courses was positive because they believed the scientific knowledge gained in the courses was applicable to their chosen career path. On the other hand, in-service teacher participants like Adam and Amber described their experiences as mixed, as they were not able to relate to some advanced upper level science-content courses which they thought were not required for their high school and middle school science teaching.

While Tami felt that she was probably "overly prepared in terms of content knowledge," Rhea found the science-content courses engaging and helpful in terms of creating science-based 
activities for her high school students. Joe describes his learning experience with science courses as "satisfactory," attesting to a balanced and comprehensive curriculum with a good combination of lecture- and lab-based courses. He believed that the curriculum was comprehensive but "not far enough to overwhelm or confuse you." Joe also said that because the science-content professors were so knowledgeable, he benefitted a lot from them in terms of scientific ideas and applications:

A lot of these professors talk about real life application of their science-content courses and also gave us opportunities to do things that were hands on. So I felt like I was really putting worth in my science-content knowledge based on my content class. (Joe-I)

Ted, who was initially a chemistry major before applying to the Benedum Collaborative Program, also felt that the science-content courses had helped him in terms of knowledge gained through both lecture and labs that made him confident to answer content-related questions posed by his students:

... because I was initially in the [science] major and because of the nature of the Benedum Collaborative Five-Year Program I have a lot of content knowledge and I was able to answer those [high school] students' questions, so I think my content classes gave me more knowledge than I would ever need to teach at a high school level. I have two or three years more knowledge from the class that I was required to take in college and that helps a lot. (Ted-I)

For Amber it was more in-depth knowledge that built on her high school science classes:

Overall it wasn't much of the difference between science in high school and science in college other than the fact that it was much more [in-]depth, but one thing that I did really like about my science-content classes in college was that we had the mandatory labs that we had to go to and a lot of stuff that we did there kind of stayed with me and helps me teach kids. . . the content class I had I think they were good I got a lot of information to kids that I teach. (Amber-I)

Pre-service teachers Cory, Sylvia, and Ella believed that science-content courses helped them in understanding science contents but not all content courses were useful in their teaching. 
They believed that some advanced science courses they took would not be very useful never be utilized in their school teaching. For example, Ella states:

I think some of them are little just over the top and weren't necessary. ... I was like I am never going to teach those [advanced science classes] and so why I am getting distracted over them ... and some of the classes were I would say a little strenuous for being a science education teacher [course]. (Ella-P)

INTASC principle one focuses on science-content knowledge based on the National Science Education Standards [NSES] which is broadly organized into three categories: ideas, inquiry, and application related to science disciplines as well as learning to create activities that make the content meaningful to the students. Of all the in-service teachers, none of the participants used the term "inquiry-based science" while talking about their experiences in their content classroom. Most believed that if they had not taken good pedagogy courses they wouldn't have learned to teach those contents because they merely taught deriving formulas, learning concepts, and applying them to the labs. However, none of them mentioned if their science-content courses helped them learn inquiry-based learning/teaching, which would help them as teachers. As an in-service teacher participant Amber puts forth, "my classes were good but I wouldn't say that they helped me teach science, but we did labs and it was good for that." This theme is summarized in Joe's narrative:

... had I just taken the science-content courses alone without any educational or pedagogy courses, it would have been more difficult to teach science at the secondary level because I don't have any strategy or technique to relate the information to my high school students. (Joe-I)

Meaningful relationships. While a majority of the in-service teacher participants like Adam, Rhea, and Tami were not able to connect with their professors in large introductory science-content classes, in-service participants like Joe and Ted saw closer connections with science-content professors from smaller, advanced courses. Large class sizes created a sense of 
isolation for some participants. For Rhea, the feeling of being alone in the class made her doubt her ability to receive help: "is this teacher gonna relate to me? Am I able to get help I needed? Are there study groups? Are there any tutoring sessions?"

For Joe, the dynamics of relationships with his science-content professors varied depending on the level of science-content classes he took. Joe had two sets of experiences with his science-content professors. The relationship with the professors teaching large classes of roughly 200 students (like freshmen general chemistry and sophomore organic chemistry) were totally different than the relationship he shared with upper level advanced small-sized content classes. In case of large sized content classes, Joe "rarely saw those professors outside their lecture times" because he found that "they were busy doing research or since they taught lot of students they often didn't have enough time to see individual students because of their demand of research responsibilities." However, he shared meaningful relationships with his upper level advanced science-content professors of smaller-sized courses; he perceived a higher level of dedication from upper level science-content professors:

I was in his office several times during the semester asking him questions about lecture material or lab material and he would actually have time dedicated specifically to seeing students every week to provide them assistance and offer them help. ... so I think the type of relationship that changed to more personal and more of one on one attention was given with smaller upper-level chemistry content courses. ... I got to know him really well, like he was a big hockey fan. He talked about his family with me ... we talked about different things beyond chemistry so I got to know him on a more personal level . . . even after I graduated from WVU I was able to go back to him ... he had remembered me coming to his office and getting extra help from him ... he remembered me well enough to write me a letter of recommendation. So those types of relationships were able to flourish when we had those smaller-size chemistry courses, where the professors can actually give more individual attention. (Joe-I)

On the other hand, Tami saw a better relationship with her teaching assistant in one of her large chemistry classes, as he had big influence through helping her out in labs. Rhea never felt 
connected to any of her science professors, but she shared a personal story with one of her sciencecontent-professors during a very emotionally challenged time for her:

It was not the easiest week of my life and I was taking instrumental chemistry, which is a very difficult class. My professor was very strict . . . you did the work and there was no leeway with her. I was very hesitant to email her and tell her that I didn't want to take the test next day because my friend had passed away and all of this going on with my life and she emailed me back and said, "Rhea take all the time you need-if you want to come next week and make up the test, I understand. I am here for you if there is anything I can do and just [let me know]" ... she had compassion and she was understanding that all these things that were going on in my life had made me want to learn more and made me be in her class even more. So it's not really necessarily a learning experience but WVU professors as much as strict and discipline they are on outside, they are really willing to work with you under any circumstance that you come across in college. (Rhea-I)

For other in-service teacher participants like Amber, it was more sort of an "information type relationship." Amber describes she never felt any connection with her science-content professors: "I won't say that I really had a close relationship with my science-content teachers. They were people I go to when I need help or something, but I definitely gained a good knowledge from them" (Amber-I).

For pre-service teachers, large lecture-based classrooms were seen as a barrier to prevent them from establishing meaningful relationships with science-content professors. Says Sylvia, ... in my [science] core classes ... when it was a giant lecture hall there was like no [connection] between you and professor ... you didn't get to know them and I think there is no such relationship between you and the teacher ... you don't feel safe and comfortable to ask questions or to go to their office hours.(Sylvia-P)

Meaningful learning experiences. Except Joe, Ted, and Tami, none of the in-service and pre-service teacher participants were able to recall the breadth of the experiences that they considered meaningful in their science-content classes, as most of them described science classes as helpful only in terms of science knowledge and application of that scientific knowledge in 
labs. For Joe, Ted, and Tami, it was their learning experience as a "scientist" that they recalled as most meaningful experience in their content classes.

Joe defined science-content courses helpful in terms of practical hands on experiences which excited the "scientist" within him, so he was not bothered with the large size lecture-based classroom because he was able to not only connect to the scientific concepts but also found it fascinating to see a connection between theory and lab classes:

My experiences with chemistry classes were great, even during large lectures. I felt very comfortable in that environment because the professors had a very good way of explaining things in a way that a freshman could understand...It was the same way with Organic Chemistry in my sophomore year. I still felt [I had a good] grasp [of the] material very easily because professors had very good way of explaining it.(Joe-I)

.. in the labs of Physics we got to do experiments with magnets and electricity ... the other science courses I took was astronomy which I found very fascinating and it took place in the observatory at the top of Hodges Hall [physics department, WVU]. (Joe-I)

Joe found some teaching strategies of science-content professors very innovative. When asked about any learning experiences that stood out in science-content classes, Joe recalls how one of his chemistry class professors utilized computer technology in his class while teaching chemistry:

I remember one of my organic chemistry professors had an online-learning system ... where we did several practice problem[s] of organic chemistry through the computer program as many times we needed in order to understand the concept for ... I think that was the really good because my generation we grew up on computers and technology and by learning chemistry with a computer program ... worked well for a lot of students. (Joe-I)

Joe also praised the science-content curriculum and how the science courses are designed in such a way that they build on each other and connect the scientific concepts into a bigger picture. This ultimately helped him while preparing contents for lesson plans where he can design his lesson plans such that the contents can build on each other: 
The sequence of science - content courses helped me understand from where the equations and formulas are coming from and having a different perspectives on them like more intensive mathematical perspective... and I think what is a neat thing about science courses is that after you have taken all of them you understand the big picture like how everything fits together and I think you are able to pass it on to students when you teach the big picture. I can explain how one topic in chemistry is related to another topic in chemistry based on the prior study that I have. (Joe-I)

For Ted it was his science research project in his advanced content area courses that he found meaningful and exciting as a science student. Ted recalls taking an advanced class in chemistry where he did an actual research project which involved critical thinking as a scientist. This class required coming up with a project and methods to analyze various concentrations of chemical components of an acid mine drainage coming out of the abandoned mine that flows into Decker Creek mine near Morgantown. He defined his science research experience different than a typical "cookie cutter" science lab and attributed his success to the unstructured but helpful guidance provided to him by his professor.

Tami attributes her research experience in forensic chemistry labs and an advance course in biology where she had to design and conduct her labs. This experience also involved writing a proposal and her own paper that would be published, or potentially published, in national science foundation.

Preservice teacher participants described their learning experiences more in-terms of the hands on learning experiences that they found meaningful, which they intends to use in their future classrooms. For example, Cory described the learning activities she found interesting: ... actually in immunology class we took blood samples and we lifted the blood and figure[d] out what blood type we are and all that stuff and I think that's really cool because I like hands on learning. [It is] something I want to use in my own classroom, so the fact that she involved us instead of just lecturing on how to find blood type that was really cool. (Cory-P) 


\section{Experience in Culture of Education}

The College of Education plays an important role in pedagogy classes and in the Benedum Collaborative Program, pre-service teachers usually start taking pedagogy courses as they start their clinical experiences during the tutor year. This goes along with the parallel structure of combination of pedagogy and clinical experiences; developing the identity of teachers as they take specific courses related to pedagogy, for example, secondary science methods, classroom management, special education, and inquiry-based seminars included in a Teacher As A Researcher class (see Appendix C-Benedum Clinical Experience and Course List). The main themes that were found in the culture of education were: Meaningful Pedagogy Courses, Meaningful Relationships and Meaningful Learning Experience. They are categorized and presented below:

Meaningful pedagogy courses. All participants recalled that pedagogy courses like secondary-science methods course and small-group seminars (focused on educational inquiry) were most helpful in developing and revising their beliefs. In-service participants found the application of those courses helpful in applying their learning action research, which they consider as most beneficial in effective teaching. Science methods courses play a very important role in combining science content and pedagogy, which is offered in the Participant Year [see Appendix C]. By the time pre-service teachers take their science-methods class, they would have some experience in practicum and completed the content courses equivalent to their bachelor's program. All participants described the experience in their methods class as very crucial for their application of knowledge when learning how to apply the inquiry-based science lesson plan in an actual classroom. Inquiry and reflection is one of the main strands in the Benedum Collaborative Program, with a "focused intervention" as teachers get involved in educational inquiry-based on 
seminars that are distributed over several semesters. As they proceed in their program from Tutor Year to Intern Year, the teachers work in PDS where they do their educational inquiry. These educational inquiry-based seminars are counted towards the course known as Teacher As A Researcher (please refer to Appendix C).

However, in-service teachers also valued those courses where they saw more theory to practical applications. Joe liked most of his education classes but there were some classes where he could not see any practical application to student teaching or professional teaching situation. For example Joe states:

I didn't get very much out of [an education course] as that course was taught in a way where it was very dry and not very interesting. We weren't given many application-based activities it was more like learning the definitions: learn the vocabulary words and then repeat them later on in a test. (Joe-I)

Regarding pedagogy courses, all in-service participants described their science-methods class as one of the most rewarding learning experience particularly in terms of inquiry-based methodologies while designing their science lesson plan for microteaching. For some, the most effective, beneficial, and useful class was the science methods course and the inquiry-based seminars, which teach inquiry about students, school, and context. In the seminars they started making mini lesson plans and ultimately worked on an action research project. Joe learned about science instruction using inquiry-based methodologies. He states:

... I remember being able to teach electron configuration in the chemistry class using this inquiry-based lesson that I designed, and I was provided constructive feedback from the [science methods] professor that helped me improve my inquiry-based lesson in chemistry. (Joe-I)

Joe considered science-method courses most beneficial as a science teacher because he learned how to safely implement science instruction using inquiry-based methodologies. Joe describes his science-methods class as the most influential class, as he got constructive feedback 
micro-teaching plan based on inquiry-based methodologies. For Joe, the actual implementation of inquiry-based units created in PDS were most beneficial. They laid a strong foundation in his ability to design his lesson plan implementing science-based inquiry activities in his current practice as a teacher. Joe recalls the field trip and hands on experience that he found meaningful, "in these field trips, hands on learning experiences we were able to kind of directly see the types of activities that we could implement in our own classroom and that's what made his course what I think is so influential in the way I teach now." He further states:

My [science-methods professor] had applied this concept in the class in [a] real situation so that we had projects to implement during our practicum experiences at professional development schools where we are at. So I remember him teaching us about inquiry, and how to teach inquiry-based lessons in the science classroom and then we were instructed to design an inquiry-based unit and then implement that unit in the professional development school where we were teaching at as a part of our practicum. (Joe-I)

For Ted, the pedagogy classes helped him design his lesson plan according to learner differences, which are very context based because as he states: "I truly feel the only way to really become a good teacher is to be in the classroom" and therefore he cites the structure of the Benedum Collaborative Program as the most effective curriculum integration in-terms of science contents and pedagogy:

I think it will never be "one size fits all," as there is a too much variety on how students learn. I think that educational classes gave different approaches that you could use to teach. What I do [for] myself is that I take a little bit of one thing and a little bit of another and I modify it. I don't teach it like I was taught in high school. I pull on variety of ideas or generalizations from my education classes and [then] I apply them when I design my lesson plan based on what I think what would work for my students in my class. (Joe-I)

Adam, Amber, Rhea, and Tami found most of the pedagogy courses very helpful to learn about pedagogy except some courses which they felt were more geared towards elementary school:

Sometimes the courses were not focused on secondary education level. There were a lot of elementary pre-K students ... they were not of the secondary focus students ... most 
are English and social studies ... so I think I ran into difficulties in courses where I had lot of elementary [student] focus. (Adam-I)

Adam names his science methods course as the single most important learning experience he got in the Benedum Collaborative Program as he found a direct connection to his current teaching position. He sees it as a direct theory to practice translation and transformation as a teacher:

I wish there are more opportunities [courses like science methods] like that. What I was doing in his course directly translated into what I needed when I started teaching my science classroom. His course certainly transformed the type of teacher I was ... When we did get into those the science-focus[ed] education courses, those to me were the best experience that I had. And by far they were the most important. (Adam-I)

Adam found his inquiry-based unit plans created in his science methods course to be a very meaningful learning experience. The research experience he got working with his science methods professor is what he found most useful in his current teaching position; therefore, he viewed his science methods course as most valuable:

That [science methods course experience] really helped me at what I am doing now . . . Right now in my school there is [a] focus on collecting data and there are science teacher[s] in science programs and the county is very much focused on inquiry experiences and the program certainly helped me prepare for that through research projects. (Adam-I)

On the other hand, pre-service teachers were more concerned about the practical aspects they are currently learning in their pedagogy courses and how they implement information in the classroom. Most pre-service teachers, besides citing secondary science methods classes and small group inquiry-based seminar classes, also cited other pedagogy classes like classroom management courses and special education courses as addressing the specific needs of their classroom and their student needs. While pre-service teachers consider classroom management as challenge, they also see it as opportunity to better prepare themselves as future teachers.

[There are a lot of teaching strategies that I could use. I am in that classroom management class right now and it is definitely really helpful in ways to know your students, ways to create different type of assessments, whether it is formative or summative, definitely creating lesson plans, understanding by design ... [ [those classes 
are] extremely helpful. I am actually using them now to create that lesson plan, and I am creating units. (Sylvia-P)

I definitely think that education courses are really helpful because you wanted to specifically how to teach science to middle school and high school students. I also had a secondary science methods class that was also very helpful too, focusing on inquirybased science. (Sylvia-P)

The inquiry reports submitted by one of the pre-service participant further validates what Sylvia mentioned as how her field experience helped her explore and learn more about the diversity of students and diverse teaching strategies in context of the PDS. One of the pre-service participants wrote in her inquiry report mentioning about the classroom management related challenges in her PDS:

We do a lot in my classroom management class right now. We do a lot of scenarios and acting out like what to do if a student did this in your classroom or this happened. Those really stand out to me because classroom management is one of the hardest things for an educator, to be able to have control over the classroom to help promote the learning. It is helpful to see this scenario so that we see what we would do, learn what we should do, to be able to compare where we were at and learn effective strategies to handle students. (Excerpts from one of the inquiry)

Another aspect that was considered a challenge was working with students with special needs and pre-service teachers emphasized that they value such courses as it informs about the about students with various learning abilities. Both pre-service and in-service participants valued classes like special education and classroom management because they found them related to their current classroom practice as well as in the PDS classroom experience. For example, Amber finds special education courses most helpful as she works with special education teachers in her present teaching position:

[The focus on] special needs like autism, ADHD disorders [etc.], I thought that was really good it actually helped dealing with kids who need assistance. When I took those special education classes I feel I can understand them better so that I can react differently to them. (Amber-I) 
Cory emphasized courses related to classroom management and special education that were useful to apply those concepts in their lesson plan designs and application:

The SPED [special education] classes are really helpful because I know in my student teaching now there is lot of inclusion going on in my classroom. You have to able to know how to deal with students who are in special education. (Cory-P)

Pre-service teacher participants also attributed small seminar classes based on educational inquiry geared towards teacher-researcher courses that would ultimately lead them to developing an action research project:

I think my education classes have prepared me very well, especially small-group meetings [inquiry-based seminars] that we had every other Friday. Those are great in just getting to talk to someone one on one specifically related to my teachings. (Cory-P)

The research based educational inquiry in PDS, along with technology integration stranded throughout the Benedum Collaborative Program helped pre-service teachers to know more about student learning with teaching strategies like differentiated instruction to address diverse needs of student learning. Ella described her technology-based seminar classes as very resourceful in-terms of using technology to address diverse needs of students. Other pre-service participants also found the technology integration very helpful toward their lesson plan design and classroom instruction. Most of the PDS participating in the Benedum Collaborative Program are well equipped with technology and students are encouraged to integrate the technology with their content pedagogy in their lesson plan. Participants also informed researchers that they are more aware of the usage of technology integration. They considered technology integration seminars very helpful in implementing the class activities to meet the diversity of learners. Says Ella, "With the changing time, new technology is coming out and as a teacher in today's world technology integration is very helpful." Tami talks about how she incorporates the technological 
skills she gained from the program by using clickers, Google Docs, peer-editing Google Docs, etc., frequently in her classroom:

... I feel like technology is playing a huge role in the classroom right now if you have the availability we go through and struggle - now everyone has a computer and so you know when it's available and it kind of takes off some of the pressure of the teacher. [They won't be teaching as much when they kind of make students responsible for their own learning]. (Tami-I)

Meaningful learning experiences. Most in-service teachers found inquiry and action research projects based on their science content as the most important part learning aspect in the program. There are series of three mini educational inquiry instances embedded in the Benedum Collaborative Program: inquiry of self, inquiry of students and school contexts (which is related to students and their experience in school), and inquiry of teaching practices (research-based practices in their subject of specialization). These inquiry instances are distributed in their threeyear duration within the program as a form of "long term intervention," which ultimately leads to an action-research project and counted in a "teacher as researcher" course. This collaborative action research project is based on identifying an issue that needs to be researched and then working out a plan to execute the research. This includes finding an issue of concern and then taking action to address the issue. Joe recalls one of the first events where he tried to implement a research based teaching strategy that he found effective for increasing students' reading fluency, but he found that the results in his class were widely mixed:

Some of the students showed significant improvement, some of them demonstrated no change, and still others showed negative trends in their reading fluency. Because I assumed this "best practice" would be effective with all my learners, it was disappointing to see such wide variability in student performance ... I learned how my students respond differently to a single teaching strategy and how I might differentiate a learning strategy to meet the needs of all my students. (Excerpts from Joe's inquiry report) 
Ted found his action research project, based on collaborative culture of PDS and university as the most meaningful learning experience when he realized that the action research project is very interpretative in nature. Coming from a chemistry background, he found himself a scientifically deductive person. His identity as a scientist clashed with his identity as a science teacher when he had to deal with students, who were much unlike his science experiments and reasoning. However, he finally negotiated both identities; even though he considers himself more comfortable in traditional research, action research helped him grow as a teacher. He believed that engaging in action research was one of the most important professional development in the program that not only revised his previous views about students' perspectives but also an increased awareness about the needs of the students:

I myself am a very logical, deductive person and [in] research in education you have to often make major assumptions and there is a lot of room for interpretation and that was tough for me.... [action research was] pushing me to do something that I wasn't comfortable in.... . I think [that] was one of the large growth opportunities for me and even though I would consider myself more I'm still more comfortable doing traditional research over action research, but I do think it helped me grow. (Ted-I)

In-service teachers also recalled how they successfully implemented inquiry-based science lesson plans in PDS that they created in a science methods course. Adam recalls that the PDS School he was placed in during his participant year was not following a very progressive approach towards high school science teaching. He observed that they mostly followed a very old school of thought in their approach with a traditional type of science teaching with lots of lecturing and worksheets. He saw this contrast to what he was learning about for inquiry-based science lesson plans in his science methods course. He ultimately ended up contributing his lesson plan to his student teaching and was appreciated by his PDS host teachers:

The science methods course showed me the other side of science education. I saw the most progressive inquiry-based project based type of learning experiences that should be 
provided to the students, and from that I was then able to take those experiences in the classroom ... [I] showed my host teachers some of the things that we can do to improve student learning. I . . and the mentor teachers whom I worked with appreciated my approach and the students appreciated having an alternative experience than what they were used to. (Adam-I)

For Rhea, her experience in developing an action research project gave her an edge compared to her colleagues where she is currently teaching. The following statement signifies her confidence:

I start to collect data, and I know how to complete an action research project and a lot of my colleagues had no idea what that was. I as a young teacher actually have to tell them and help them create an action research project. (Rhea-I)

Rhea also credits the importance of knowing her students that made her more aware of trying to connect to her students. Knowing about students is one the most important things that she learned from her inquiry-based seminars that she implements in her current teaching position:

I have them write [an] autobiography about themselves: What was your past school experience like? What are you planning today? Do you have a job? Do you live with your parents? Do you not live your parents? Are you in the drama club? Are you in the chess club? Are you in the science club? What are your goals in schools and how you plan to achieve them? (Rhea-I)

She makes it a point to know her students at the beginning of every semester. She becomes emotional while sharing a recent conversation with one of her students:

One of my students actually wrote back to me today. She emailed me her autobiography and she said: "I just want to thank you for asking us to do this assignment." This is coming from a 16 year old girl and she said to me that there have been very few teachers in my lifetime in school that actually asked what I want to do and where I want to go and what my life is about - and they [the students] said to me that they are more interested in science now because I cared about them and where they want to go. (Rhea-I)

For Amber her meaningful learning experience was knowing more about students and their

problems and backgrounds and creating an awareness of the human aspect of teaching science:

I think it definitely helped me get to know my students. I am more concerned to know their backgrounds going in and I was concerned about where they were coming from, like their home lives. Do they have people in home who are helping them? I am more aware of different types of problems kids have like currently in our society, so I think that 
because a lot of these classes are focused on kids who are going to need maybe extra help in the class and I wasn't really aware of that as a student. (Amber-I)

Tami too considers students as her highest priority that knowing about students is essential and therefore it is important to work collaboratively with special education teachers:

To know my students more I give my students a survey on the very first day. It's important to know so much about them to know what their family life, it's important to know why are they so tired because they have this awful home life - they can't sleep all night whatever be the case so it's important to know a lot and I think being an active member in the school and even in the community you notice students out in the community. So you need to talk to their past teachers. Sometimes I would just talk with their special education teacher to know more about one of my students. You need to ask questions-you need to just try to connect with them and figure out a little bit about them and anyways that can help them learn more in your classes. (Tami-I)

For pre-service teachers, their meaningful experiences were more related to the successful teaching planning like structured inquiry experiences, lesson planning, formulating standards and objectives in lesson plan and making lesson plans relevant to students' interests. For example, they cited 5E model (Engage, Explore, Explain, Elaborate, and Evaluate) for instructional planning as very important in designing their lesson plans. Because they had not completed their program when this study took place, their way of expressing their meaningful experiences were more concerned with relating to how to make contents relevant to students' interest. Pre-service teachers described their educational inquiry-based seminar classes as very important in their development. They felt confident exploring those inquiry-based topics and strategies learned in pedagogy courses and considering what made them very helpful, as they can relate them to their PDS experience.

I learned that through inquiry, one can learn about the classroom, the students, teachers and the environment. By observing and taking data, you can observe contexts that you wouldn't normally notice by just being present in the classroom. For example, taking pictures allows you to study the different aspects of the pictures to make conclusions about what is going on. ... That is why it is important to inquire now, as a pre-service teacher, so that in the future I can implement different strategies within my classroom, 
creating a learning environment that is pleasing to everyone.(Excerpts from Ella's written notes)

Sylvia was concerned about the students learning and accommodations that she was learning in

her inquiry-based seminars:

By being able to differentiate instruction, I will better be able to accommodate the diverse needs or interests of all of the students in my classroom and to maximize the learning of all of my students, meeting as many of their needs as possible. ..so in order to effectively differentiate instruction, and to increase the learning of all students, it is important for me to know about my students. It is crucial to understand that students are cultural beings and that they have talents and strengths that can be used to help them make sense of the curriculum...From the inquiry about what subjects or topics the students enjoy or find frustrating, as well as what they know about subjects, I learned that connecting topics in class to things they like increases learning (Excerpts from Sylvia's written notes)

Cory finds things like "differentiated activities in classrooms" in her special education class as a very meaningful learning experience. She gives examples on how those little activities she learned in her pedagogy courses are so useful in her lesson plans and even replicated by her PDS host teachers:

Tiny little activities like having students write their thoughts and crumbling the piece of paper up like snowball, throwing it in the middle room, and having students pick up the snowball, read what others students wrote, and elaborate on their thoughts. Just [a] little activity like that made my lesson more fun for students. They [are] still learning lessons they learned, but those classes gave me specific ideas for me to learn to twist how I do it. Even my host teachers have stolen some of those activities. (Cory-P)

Meaningful relationships: In-service teacher participants found the relationship between education faculty, particularly science methods and small-group inquiry facilitators most effective because they developed a dialogical relationship with them in which their previous views were challenged and at the same time views were revised by thorough feedback and evaluation from teachers while conducting inquiry within PDS. They value those relationships that influence them in their current teaching positions. 
Joe recalls the advantages of working with his science-content methods professor which involved field trips, presentations at professional development sites like West Virginia Science Teachers Association (WVSTA) conference, and hands on learning experiences where he was able to directly see the types of activities that he could implement on his own classroom. He was influenced by the science methods professor and considered him influential in the way he practices his current teaching responsibilities:

I collaborated with my [science methods professor] in sharing my own ideas about science instruction with science educators from across the state. Besides discussing my work in the classroom with other teachers, I spent the rest of the conference weekend visiting multiple sessions to augment my knowledge of the teaching discipline. My participation in other sessions taught me about the use of chemical demonstrations to capture student interest, science notebooks to record thinking processes, and research experiences for teachers leading to the construction of problem-based learning units. (Excerpts taken from Joe's written journal)

He talks about professional relationships with his science methods professor and discusses how these relationships allowed him to participate in and attend conferences

I spent the rest of the conference weekend visiting multiple sessions to augment my knowledge of the teaching discipline. My participation in other sessions taught me about the use of chemical demonstrations to capture student interest, science notebooks to record thinking processes, and research experiences for teachers, which lead to the construction of problem-based learning units. (Excerpts taken from Joe's written journal)

Joe recalls the advantages of working with his science methods professor which involved field trips, presentations at professional development sites like WVSTA conference, hands on learning experiences where he was able to kind of directly see the types of activities that he could implement on his own classroom. He is influenced by the science methods professor and considers him influential the way he practices his current teaching responsibilities. He gives the reason:

We had a professor that allowed [us] to apply things we learned in the class [and] incorporate them in our lesson at our PDS in our actual classroom where we taught. Also, he always offered specific constructive feedback on our lesson plans and- $n$ the mini- 
lessons that we actually did in class and taught in small groups, and he gave us an opportunity to do our own experiments in his course. (Joe-I)

Compared to his science-content professors, Ted was closer with his science-methods professor but what made Ted value the culture of education was that he was more open to his education professors. He was able to open up and debate with education professors in a respectful manner and therefore had healthy and excellent relationships with his pedagogy professors in general:

I like being able to debate with the professors and getting to have education classes [which are opposite] to raw-science classes where something is either "it is" or "it is not." Education in general is a theory and concept. I think actually it was good about the program, students arguing with the professors strongly saying that "I don't buy that" and "I think" . . that lead to excellent relationships between the professors and the students. I do think that professors did a very good job about being open with the students and most of them very approachable. (Ted-I)

Adam ended up having a very good working relationship with his science-methods professor who he believes has really shaped him to be an educator in his current teaching position. He developed an inquiry-based curriculum with him, which was presented in the WVSTA conference and also published as a research paper:

He [science-method professor] and I went on to co-author a journal article that was published in Science Teacher Journal. Those experiences really stuck with me because going on now, I understand the research part of the teacher and the importance of always analyzing our practices and bettering our practices and trying to find the best approaches provided that we can. (Adam-I)

Adam states that it is his science-methods professor who shaped his present science teacher identity because of the work he did with him and that is the reason he is so confident in his current teaching practice:

He [science-methods professor] was real first professor that really showed me inquirybased [science pedagogy] . . . before that I don't know if I'd even heard about inquirybased science education and it was only due to his effort that really got me going down that road. So I think having to develop lesson plans for his course and teach mock lessons - those experiences really helped me because he was really research based. So 
while I was trying things in schools, my host teachers gave feedback, particularly working with him and he was able to give me really great feedback on how to improve inquiry-based lessons as well as the others in the class were able to help me. (Adam-I)

Compared to her science-content classes, Rhea saw a closer relationship with her peers in her education classes because the Benedum Collaborative Program gives them a sense of community:

I feel that in the Benedum Collaborative Program, you form a bond with the rest of your fellow peers towards taking those education classes we became a plan or a group so to speak - they were mere rock through hard times. When I was student teaching they were student teaching too-we were able to share our differences, share our experiences share in the real world [in terms of] what happens in the classroom. You have the kids who have a bad day and how to discipline them and how to work through their conflict. I really feel the Benedum collaborative is a family on its own and without them and without their support and without my fellow peer support I don't think I will be here today. (Rhea-I)

Tami too recalls the good relationship she shared with her education professors and cohorts who gave her sense of community: "My cohorts, I think probably five or six girls in our education classes I mean without them I probably would not have made [it] through."

Compared to a culture of science, pre-service teachers enjoyed closer relationships with their fellow education students, and they defined their relationship with their education professors with descriptors such as "helpful," "safe," and "open to communication." Cory already had made some friends because they spent lot of time teaching classes together. Sylvia found her education classes very helpful as she found her education professors "always made [an] environment where I feel safe to ask questions.” Ella shared a meaningful relationship with one of her education professors as she finds her very resourceful as she presented at one of the WVSTA conferences and NSTA (National Science Teachers Association) conferences. For Ella such national and regional conferences not only gave her sense of belonging to science teacher 
community as a whole but made her feel that she is not alone in her journey. She therefore valued her relationship that she shared with her peers and teachers:

I have talked about relationships with like everyone is so nice in the education program. We all have the same personalities that everyone is like going to the same thing, so I talked to everybody no matter what their content is, I had some elementary education people as well so and it's pretty good. (Ella-P)

\section{Experience in the Culture of PDS}

Benedum Collaborative Program has sequenced clinical experience for three years that is structured in such a way that students observe, teach and implement their learning in their classroom [see Appendix C]. Teacher identity starts forming when they start their observation in their tutor year and start taking technology and educational inquiry-based seminars. However it was the three-year collaborative structure that all participants including pre-service and inservice teachers credited as their best experiences towards teaching efficacy.

Initial impression of starting PDS clinical experience. Clinical practice is the most important structured experience in the Benedum Collaborative Program and is the foundation to participants developing their identities as teachers. Pre-service teachers find it intertwined with courses they take in pedagogy like classroom management and special education, so they find it more helpful. In-service teachers and pre-service teachers have different ways of describing their emotions simply because they were at different levels when this interview was conducted. Inservice teachers recall how the uncertainty made them nervous when they started their field experiences and what kind of students they may face and what kind of host teachers they will be working with. Joe recalls how he felt when he started his field experience in his tutor year:

I was nervous as with any new situation as you are not sure of what types of students you might get, you are not sure of maybe am I doing good enough job, am I doing things correctly? You are not sure of your host teacher like whether my host teacher will be supportive of me or not, would my host teachers [be] flexible with me or not. Whether 
my host teacher gives me constructive feedback and gives me ideas on ways that I can improve. So those were the things that were making me nervous. (Joe-I)

Ted describes his initial impression "naïve," as he had a strict scientist view of teaching and he thought he would use the same mindset to observe or teach his students in a high school setting:

[I was] honestly naïve, is the only way I can describe [it], when I was in school. I [could] never think of myself potentially being a teacher, so I was not paying attention to things I probably should have at that time that could have made me a better teacher. I was out in my own world doing my own little student things and so going in I really didn't know what to expect. (Ted-I)

Rhea associated clinical field experiences as having a strong influence on her teacher identity: "I think without student teaching you can't fully understand what it means to be a teacher." Amber and Adam shared the same sentiment:

Yes I was very nervous before I actually started with student teaching as I didn't know how kids would react to me or respect me and how I would be viewed as an actual teacher before kids and people, but before that I was very nervous. (Amber-I)

Tami recalls how she was nervous initially but ended up being more a confident teacher and she gives credit for the structured field experiences at PDS to increase her teaching efficacy:

(Laughs) yeah I was nervous. It was extremely nerve wrecking but I also feel as rock ... I felt prepared because of the way the Benedum works you in the classroom starting with the sophomore year [with] two hours a week then the seven hours a week. I really do think a lot of them come from the scaffolding they have in place in terms of getting you in the classroom. I mean they start you off so early, you start tutoring so may hours a week and then so many hours a week and by the time you are student teaching you really are prepared to teach in student teaching. (Tami-I)

For pre-service participant like Ella, she thought that because she looked really young, she may not do well and students may not take her seriously:

I was real nervous before student teaching, like I thought that I was really young and I thought that I looked really young and that the kids would try to be like my friend and they still try do these kind of things but I mean, you got to find the line between teacher and students obviously but before when I started like I was very nervous just like thinking like-are they going to like me? What if they don't like me? What if I go up there 
and I just can't deliver? Doubts came to me like whether I am good at teaching and whether I am good at explaining things. So I was really nervous for sure. (Ella-P)

Ella stated that she is getting more confident about her teaching capabilities as she is progressing towards her final few semesters. Cory recalls her first lesson plan she taught in her participant year. She cried because she was so nervous, yet at the same time found it most beneficial for her teaching career:

Oh that was the most beneficial part of this program. I am coming from the first lesson that I taught. I cried after I finished I was so nervous now I don't even think I just I have got much better. I am so far from the end [of the program] but field experience has greatly benefitted me. (Cory-P)

Sylvia too, found herself nervous when she first interacted with her students during her tutor year but realized and appreciated the structured format of field experience compared to being thrown directly into teaching in a class:

I mean it's really nice when I am not going to be thrown in a classroom [to teach them right away]. I was really excited but also nervous like I definitely wanted that experience but definitely nervous being thrown there and have to deal with the actual students. (Sylvia-P)

Structured clinical experience. All participants described their feelings before field experience as "nervous" and "fearful," but credited the sequenced structure of their teaching experience in PDS for developing their teaching confidence as semesters progressed. This nervousness and emotional need is somewhat addressed by the distribution of the field experiences. For examples, two hours for tutor years, five hours for participant years, and so on [see Appendix C]. Joe finds a good balance of science-content courses, education courses, and the amount of field placement experiences. His teaching confidence developed in the program, so that he could start working in schools and he never felt overwhelmed, especially by the loads of coursework in his tutor year: 
You want to able to find a little bit of coursework and you also want to get a little bit of experience in the classroom in the first year and then I liked that gradual progression of having more hours in the classroom when you went to the Benedum program. I think that the gradual progression allowed me to have a good balance between doing my coursework in college with my education courses and my science-content courses but also being able to get the experience at the same time of being in a real classroom with the real students. So I think there is a good balance and good opportunity there in terms of number of hours of clinical experience by having this three phases of new experiences. (Joe-I)

For Ted, it is through three years of structured field experience that he learned the most as a teacher. Adam too attributes the structured format of field experience, with the increasing number of field hours, with allowing him to go through an easy transition to develop a confidence in teaching. Tami recalls the helpfulness of the structured hours in field experience rather than throwing someone directly into teaching. She identifies the role of PDS teacher combined with the field experience that really makes her confident in student teaching:

So I like that so much rather than throwing in all of a sudden but it's still so nerve wrecking that I don't think that you can actually be able to prepare for that, but I feel they can best prepare you for that. And like I said before there is so much [that] depends on your host teachers too, and I was working to get awesome host teachers and so I think that helped a lot. (Tami-I)

Tami gives credit to her structured field experiences for shaping her teacher identity and she finds herself at higher pedestal compared to her teachers in her school as she shared this story:

It has shaped the teacher I am today and the experiences I had in terms of how much time I spend in classroom. I don't think that other universities can even compare to the Benedum Collaborative Program. It has shaped the teacher I am today and the experiences I had, and how much time I spend in classroom. At my first teaching job [I began with] teacher of the year... there were like 10 new teachers and I got best one, and that definitely wouldn't [have] happened if I had coming from any other school, and now having taught for five years I am no longer the youngest one any more. The new teachers come to our school and I look at them and I don't think they are prepared such as I was, from whatever school they are coming from I don't think they are prepared as I was. (Tami-I) 
Rhea too showed greater confidence while describing her feelings about the importance of field experience in the Benedum Collaborative Program and if given a chance to design her own teacher education program, she would like to keep the structured format of field experiences and the support system within the Benedum Collaborative Program:

I have always wanted to be [a] teacher. I have been very passionate about it and honestly believe that the teachers and the advisors and the support system in the Benedum Collaborative Program allowed [me] to be very successful in my career today. (Rhea-I)

Other pre-service teacher participants like Ella, Cory and Sylvia found it helpful to participate in PDS consistently for every semester:

I mean it's cool that my beliefs have changed since then [after starting PDS field experience] because I am becoming a better teacher and I am learning all the appropriate things to do in order to maximize the learning of my students. (Sylvia-P)

Cory displayed more confidence as a teacher as she is learning what professionalism and outlook towards teaching means. If given a chance to design her own teacher education program, she attested it could not be better than her current Benedum Collaborative Program. Sylvia thought she found her current semester load stressful, she still feels better compared to her counterparts and hopeful of her confidence in teaching. Ella too finds herself in agreement with Tami, Rhea, and Sylvia. She relayed that when she interacted with other teachers from other teacher education programs she found herself in a better position in terms of the structured time she was given for her field experience:

I think that benefitted me tremendously. Even when like I started my I guess it was my sophomore year I have been in school every semester and I think that's just been great and I think it puts me on a higher pedestal and allows the other students coming out of the different education programs is that they don't get that time in school (Ella-P)

Meaningful learning experiences. All participants cited field experience as the most valuable experience because they can directly interact with students and face real life teaching 
situations. They also considered their interaction with PDS teacher and their constructive feedback as important resources for their learning in actual classrooms. Joe recalls that his PDS host teacher helped him apply the inquiry-based unit he developed in his science methods class during his participant year, giving him constructive ideas and feedback on his unit. He also recalls when he was confronted with a disruptive classroom behavior and how his PDS host teacher gave tips of what to do in such situations, and it was one of the topics covered in classroom management:

My host teacher told me what the first things you should do is to call a private conference with them, first speaking with students privately reorient them in the class. Instead of shouting or yelling at them, privately or quietly try to figure out what's going on, what's prompting their behavior. And then you have to arrange their seating in different places in the room where there will be less distractions, maybe closer side of the room, and different ways of handling a situation like that before it escalates and kind of becomes bigger issue. (Joe-I)

Joe explained further why he finds his PDS experience most fruitful:

One of the best things about student teaching is that you learn from your mistakes and get feedback on ways to improve while you are still being observed by an experienced and veteran teacher. So I think that was one of the great advantages being in field experience, that you are able to be get observed all the time and be able to get feedback from teachers who will always been in the classroom. They give ideas on things that you need to change to improve your teaching and I think starting with the participant year where we got more time in the classroom. I was able to get specific feedback from my host teacher who is a chemistry and physics teacher. (Joe-I)

Ted had an assumption that he already had some idea of how to teach in high school students as he thought about his high school science teacher's methods and what he represents. However, when he actually started teaching and was faced with real life class situations, he realized how much he needs to learn if he wants to be a high school teacher. He values the role of his PDS teacher is helping him know the real classroom situation as time progressed, "I tried teaching something be able to approach it with my host teachers and find what went well and what things didn't went well how else we could do this was great." 
Rhea recalls that she was placed in a high school PDS which she describes as "the middle of nowhere" in West Virginia. Her teaching site was located in rural area, and she comes from a big city. She was initially uncertain before staring her student teaching experience in that school, but she cited these teaching experiences as the most gratifying ones, as she realized that it does not matter where students come from. Working with her PDS teacher helped her carry out inquiry labs in her classroom. She realized that "it does not matter what they want to do in life or how they were raised, but there is science in all of us." She states,

I was little bit hesitant to go on the field experience for student teaching because you are just you. You are on stage, you have these kids and the host teachers. You are going to bring them in, it's your job to keep them engaged and assist them as much as you can. Make sure that they are learning the content material but once I got into my classroom with my host teacher I never looked back, and that was one of the best experiences of my life there at West Virginia University. (Rhea-I)

Rhea connects that experience to her present day as a practicing teacher: "without that little experience I don't think I would have been able to carry out inquiry lab with my students today." For Adam, it was more like the kind of relationship they shared with the educational community in the PDS environment that despite of differences they allowed him to do new things:

I think the best thing about it wasn't so much the type of teaching they showed me ... the type of teaching I observed there but to allow me to try new things. They gave me good feedback and they were good observers ... because they give their perspectives on things and gave me back what I needed ... so it was great place for me to take what I was learning in my courses and apply it and see what happens ... they allow me to do that ... really whole heartedly supported my effort. (Adam-I)

Tami values small things related to classroom management that she still finds helpful as a practicing teacher:

You know filing system that I use for my papers I learned from my host teachers ... the hours you spend with your host teachers so valuable ... I don't think I would have been as far as teaching without them ... I just learn so much from them and I gained lot of materials I still use in teaching, my PowerPoints, my labs. I still use lot of stuff I got while student teaching ... I had an awesome teaching experience. (Tami-I) 
For Amber it was the time spent in varied experiences in PDS where she learned the most: "I think first of all in the Benedum Collaborative Program you get so much time in the classroom and you get to go to the variety of schools and its great for you to see." Amber states that she had experiences in diverse and not so diverse PDS courses, but that ultimately opened her eyes to see the kind of diversity students can bring in with them. It was the first time when she worked with students who almost could not speak English, and her first time instructing students with special needs. This ultimately helped her in her current teaching position as it made her more confident working with diverse students:

I was also at a PDS in Morgantown [which had] students [from] all financial background[s] and that was very diverse in [their] cultural background[s]. So that being said I had a really wonderful unique opportunity where I saw kids from all over the world who spoke all kinds of languages and I saw kids who spoke no English which was very unique as well ... I remember in particular one class that had five students with autism . . . I had probably the best experience I could have had teaching kids who at first I didn't know how to teach them. . . . kids don't speak English, kids are non-verbal because of autism so I feel like being challenged to come up with ways of teaching that I never have had to come up with. I had to translate things I had to use the kind of [non]verbal things I was using a lot of pictures that I have not thought of. Now I got kids who have behavior problems, like communication type of issues I feel so prepared because I had such a strange, difficult situation but now I am a natural-it's awesome. (Amber-I)

Pre-service teachers like Cory, Sylvia, and Ella found more meaningful learning experiences as they were exposed to real life teaching experiences in tutor and participant years, and they learned more about managing and planning classrooms, which they would have not considered as challenging before their field experiences:

Before joining the field experience, I didn't think it would be so hard. I didn't think you'd have to think about how to manage and plan and what you are going to do next or how long something is going to take. I guess I didn't expect that all those little things that are important to make a lesson run smoothly. (Cory-P) 
Cory explains that her biggest learning experience was when she taught her first class during her participant year:

Probably the first lesson I taught was biggest shift in my views about teaching because I thought I have planned well enough for 30 minutes, I put in a lesson and that was not really enough to keep anyone engaged and that was specific experience when I realize how much work it requires for each activity. (Cory-P)

Sylvia too was concerned about her teaching strategies as she started:

I have definitely learned a lot from my [participant year] student teaching. My ideas and the way I teach changed strategically. Just because you are able to see what real life teaching is like and I think it's definitely benefitted me a lot. (Sylvia-P)

Ella described her tutor year of field experience as "scary" as well as a learning experience that stands out in her memory:

I remember walking in to my classroom and the teacher said, "okay, we are doing a unit on chemistry" and they [students] are learning about balancing equations and then, "here Miss you take charge, go ahead keep your house." So I was like really thrown into it and I was like mortified. This was the scariest thing ever, just because I wasn't expecting that and like I got up there and I was feeling nervous and the kids can tell that I was nervous, but after I did it and he was like, "I just wanted to ... show them [student teachers] what they need to expect. It was a good learning experience but scary, so that was something I will probably not forget. (Ella-P)

But as Ella progressed through her clinical experience, she developed more confidence working with her PDS teachers in high school settings. She recalled one instance where she worked in a collaborative setting, working towards integrating a problem-based unit which involved integrating content from biology and chemistry and she calls it as one of her most memorable learning experiences:

... they were very good at bouncing ideas off of each other ... because when you are a new teacher you then you have to collaborate with other teachers and you have to ask for help when you need help and that's kind of gave me a tools for that. (Ella-P) 
Meaningful relationship. Most of the in-service teacher participants defined their relationship with host teachers as positive with descriptors like "helpful" and "understanding" because they gave them "space" to implement what they want to. Most PDS host teachers helped them to apply what they learned in class but also provided tips for classroom management. As student-teachers progress in the intern year, they spent full time teaching all periods every day each semester. Joe did a unit plan under his science method professor's guidance but he was later given feedback by his PDS teacher and advised on how to utilize the classroom management strategies while implementing that unit plan, which could also be useful to the success of his class.

Joe described his Intern Year as very tiresome, but what he valued was the kind of flexibility his host teacher showed towards him, helping him move with his pace and always providing constructive feedback. The kind of meaningful relationship he shared with his host teachers during his busy student teaching semester included the teachers giving enough room yet providing positive feedback:

I know there are some host teachers who still want to control the classroom even though the student teacher is supposed to be the one who is in-charge and directing instructions, and I was very fortunate that I had a host teacher who gave me the latitude and responsibility of instructing the classroom and managing the classroom. He was very flexible with me and allowed me to design my own lesson, allowed me to set my own pace for my lesson, he gave me constructive feedback on my lesson. And so I think I got a lot in my intern and my participant year because of the type of host teacher that I hadone that was flexible and the one that would always provide feedback. (Joe-I)

One of the biggest learning experiences that Joe credits to his host teacher from his participant year that he uses as a strategy even today is to engage students "at the beginning of the last period:"

I remember I was observing him in my participant year in a Physics [class] when he did this really neat demonstration about this projectile motion ... it was like a monkey and a barrel, it had some silly name ... what was most important from this demonstration is 
that he did that at the very beginning of the period like before he even talk[ed] and rest of the students [started] working on the worksheet, the students started asking questions how did that work? Or why did this occur? You know they were really excited by what he did but also very curious about how it worked ... He was kind of able to grasp the student's attention with a demonstration that he started ... and I know something I try to do in my teaching chemistry-For example, when I teach my class during last period, I would start with a demonstration to grab students' attention that way, and that kind of got them interested in the topic for lesson. (Joe-I)

Ted, like Joe, also give the credit to the good relationship he shared with his host teachers who had provided an atmosphere of mentorship and acted as "advisors." They facilitated his lesson plan and provided feedback, rather than controlling his ideas and imposing his way:

The majority of my host teachers were very good and they would explain why they are doing what they are doing ... they would give me more freedom and would act more as advisors ... a teacher giving up control on what they are doing in the classroom is something that lot of teachers don't not necessarily enjoy doing ... I had one teacher, and I would bring in new lesson plan and he would say "okay, ya that's look good," "have you thought of doing this and that?" But it wasn't like :you should do this or you should do that, they were just throwing out many possible ideas. (Ted-I)

Like Ted and Joe, Rhea recalled one of her host teachers during her intern year as one of her most memorable learning moments, as she had good communication with her in terms of expectations and meaningful feedback:

... was probably one of best experiences of my life ... I don't keep in contact with her as much as I should ... she let me take over her classes and she supported me and gave me constructive criticism - she suggested things that she knew would work with her kids and also said, "Rhea what do you think? Do you think this will work with the kids or that this won't work? What do you think? - She totally submerged me into her curriculum with her kinds and allowed me to take over and actually do what I was supposed to be doing with student teaching. (Rhea-I)

Tami recalls her host teachers were very resourceful and she still keeps contacts with two of her PDS host teachers:

My host teacher at Morgantown high school, I still keep in touch with him. When I was teaching at the high school after graduating from the Benedum Collaborative program, 
she was still sending me her PowerPoint presentations and stuff like that [which were useful]_ just having those resources were invaluable. (Tami-I)

Amber, describes her PDS host teachers very communicative and easy to talk to:

My host teacher would act as a guide: doing this idea that idea and she was very easy to talk to ... always helpful [in terms of] anything I needed too, but she let me finally took over her class and she would let me make mistakes which probably helped me learn best. (Amber-I)

Amber credits her relationship with her host teachers who she believes what a school teacher really should be. She started seeing herself as a transitioning teacher through her relationships with her PDS host teachers as it made her more aware in terms of real classroom experience and as a current practicing teacher she credits her confidence to her relationship with her host teachers:

...it has given me an improved version of myself at least as a teacher I am much more aware of what really goes on in the school that I had no clue —ok yeah I wanted to be a teacher and you think that it is a fun job but you don't feel the background stuff that teachers do. After working with my host teacher, I realized what it is to be like a teacher as a whole, not just teaching and grading papers, but you are trying to prepare for kids who can't read, and who don't speak English. I mean in that way I fully understand what is to be a teacher now which I think is wonderful and I am so glad that I didn't go anywhere else. (Amber-I)

Pre-service teacher participant mostly described their experiences with their host teachers in their Tutor and Participant Years. For pre-service teacher participant, most of the learning came through their field experience or classroom or observation of their mentor host teachers. Their descriptions were not in depth but they did show a trend of positive learning experiences as they are working with their host teachers. Cory describes her host teachers more as friends than as mentors who shared their experiences about things like classroom management and parent teacher conferences:

My current host teacher is very willing to share any tips she has, especially with how to deal with parents. She taught me specifically how to approach parent teacher conferences bring hard evidence or physical evidence into those meetings and how to try to keep the 
meeting positive even if you are meeting about the negative trait of the student. These were some of the most helpful; you know I didn't get lot of experience in the classroom so it was great to know those [strategies]. (Cory-P)

Sylvia sees a role model in her current host teacher because she found him not only very knowledgeable in terms of content knowledge and classroom management, but also the kind of safe environment he creates for his students,

He is amazing. He is pretty much everything I want to be when I become a teacher. He is really down to earth with his kids and he knows his content and he knows how to go across to the students. He like he makes his students be comfortable to approach him and ask questions. He just creates an awesome learning environment. (Sylvia-P)

Ella too found her host teachers very resourceful and she showed confidence in her host teachers as she progressed to complete her field experiences:

My host teachers have been great. They tried to lead me in right direction and they tried to show me any opportunities that I can better help student teaching . . my relationships with my mentor teachers were awesome - they were so helpful they have given me so many resources. (Ella-P)

She did form an initial impression of one of her host teachers in her participant year when she worked with a $10^{\text {th }}$ grade bio classroom in a PDS but ultimately she found her very helpful:

... a first I think I didn't liked her because she was very traditional -she was old school and she was a lot older than me and she just had her set ways, but once she saw me like doing well with the kids, she kind of became more accepting and was very resourceful as well. (Ella-P)

Time as perceived barrier and support. Pre-service teacher participants like Cory, Ella and Sylvia also see time as an issue in-terms of maintaining a balance between coursework, inquiry-based activities, and field experiences. Time was seen as a barrier in one aspect but also as a support in another aspect. Ted suggested even moving some of the observation hours early in the program: 
We learned a lot of concepts in the classroom, but we couldn't really apply them because we didn't get time and freedom to do so. It would have been helpful to have more time in class with the students. (Ted-I)

Other teachers like Joe, Rhea, and Adam also cited time as a constraint, especially during the last year when they implemented their action research project. In-service teachers like Joe, Rhea, and Tami also cited time as a constraint as barriers especially in the fifth year of the program during their full time student teaching. However, Joe said that due to cooperation of his PDS teacher he was able to overcome such barriers to great extent. Amber regards the program as the structured clinical experience for helping her make an easy transition to being a confident teacher:

... [it was mostly the] classroom experience because as a tutor you are there for couple of hours a week and a little bit more you are in same school ... you started to get the know how the school operates and in the final year you are practically a teacher at that point ... so having all of that class time I think this has really resonated well with me and has helped me to go into my job in that forever-I mean it was such an easy transition going from all of that class time but still having people support you to be on your own like you'll actually be. (Amber-I)

Time was also seen as contributing factor in gradually building on participants' ability to evolve.

An evidence of the gradual growth from tutor to intern year is reflected in Joe's inquiry report:

My understanding of inquiry has gradually evolved since I began the teacher education program. Three years ago, I had very little knowledge of what inquiry meant or what the inquiry process entailed. I also possessed minimal understanding of the complexity behind intentional reflection. For example, I remember having concerns about my students' learning and considering different teaching strategies. What I did not realize at that time was the importance of reviewing the educational literature to gather information about research-based instruction. Another area that I would consider a weakness at that point in time was my haphazard way of implementing a change in my teaching. Three years ago, I would have thought of something new to try, try it with my students, and conduct a very superficial analysis of whether it had been successful or not.

(Excerpts from Joe's inquiry report)

Ted and Adam also described the limitation that time may out in their current teaching positions. However, the experience in inquiry and doing action research actually helped Ted to tackle time 
limit barriers, especially when it comes to cover most of the CSOs' in his science classes but due to his experience in inquiry-based action research, he attempts to create situations to build on a student's prior knowledge:

... then within the classroom we move out over the time limitations ... We talk outside the classroom ... so we change the learning situation so that the students have more time to explore content in depth ... we introduce the concept that should be like about three days. This means the teaching would be like - let's talk, let's go back to lab to try the experiment. Let's go back and talk [about] what you guys thought ... It's not the teacher teaching but a conversation the teacher is guiding ... the teacher hears when the student is having tough time. (Ted-I)

Citing time as a constraint, Adam sometimes includes strategies like flip classroom to make effective use of class time:

I decided to do a lot of things that put their learning in their hands in classroom experiences. We do one lab experience a week and are on a blocked schedule so students have 90 minute labs just about every week, and then all the other learning experiences are based on focusing on trying to get the students to engage in an active discourse where they are learning solitarily and with each other and there is little of me delivering direct instructions like I don't do any lecturing anymore. We do flip classrooms where students watch videos and take notes at home rather than in the classroom. (Adam-I)

Ted, also shared some of the real world frustration that he faces where he has to work in a certain administrative work culture in schools in which he is currently working:

... unfortunately because of the time constraint teachers feel pressure from administrative leads doing in such and such a way because there is limited freedom. There is a chance of something going wrong and they are very concerned to dangers of something going very wrong. The role of teacher often ends up being more of the person giving them subjects to learn and memorize and hoping that they make connections to their prior knowledge, but because of the time limits or administrative limits at my school I can't do this [always]. That kind of life they take on as first acting like a person giving out the knowledge whereas in the ideal world teacher should be having freedom to implement his teaching curriculum the way he/she wants(Ted-I) 
The kind of positive impact that Benedum Collaborative Program had on participants, that it led some in-service teachers like Rhea and Tami, even consider pursuing doctoral program in the future. Rhea also defines advising within the Benedum Collaborative Program as a very important tool for her development; she had the same advisor for five years. This helped her greatly, especially in terms of scheduling classes, getting into the classes she need, and getting help in required courses. Pre-service teachers showed confidence that the Benedum Collaborative Program is preparing them for the real world, and to go for a teaching career as they are completing their program. All participants find their experience during the Benedum Collaborative Program to be transformative in terms of not only developing pedagogical skills in real teaching situations, but also in the use of inquiry to improve students' learning and growth.

\section{Emerging Themes of Teaching and Learning}

This section answers the research sub-question $1 b$ ): What are the emerging themes of teaching and learning before and during science teachers' participation in the program? This subquestion was tailored to understand how the participants reflect and describe the shifts in their beliefs related to science pedagogy before and during the participation in the program. The participants reflected on their cognitive, intellectual, and behavioral change they believed they went through during their participation in the program. Their participation in the Benedum Collaborative Program helped them to address preconceptions about teaching and learning as they transformed from the student to teacher. In general, two factors were identified: the vague understanding of science pedagogy before taking pedagogy classes and the reality of classroom experience in PDS. The following overarching themes were identified along with subthemes within those themes. 
Teaching as teacher centered vs. student centered. All the participants reported that they entered the program with the belief that a teacher had an active role to play, particularly teaching a science class, and students are passive learners in the classroom following instructions. However, the inquiry-based experiences in the Benedum Collaborative Program helped them shift their perception of teaching toward student centered. Inquiry about students was part of the classroom research-based activity in PDS and it opened their eyes to acknowledge the diverse learning styles of the students and classroom management. While some in-service participants still value the traditional lecture-based course when required, they don't want to follow the "one model fits all" scheme. They believed in using different learning and teaching strategies based on the student-centered approach for student learning which includes not only designing science based inquiry labs but also small group discussion, field activity, and cooperative learning. Not only did participants acknowledge addressing student diversity in terms of differentiated instruction and multiple learning styles, but they also showed more awareness of the socio-cultural influences in understanding their students. They agreed that applying one single teaching strategy does not mean that all students have understood the concept. They believed that as teachers, it is their responsibility to reach out all students in their class, which they wouldn't have thought about their fellow students studying in high school before.

Participants emphasized that teaching also involves classroom research and management so that students should take charge of their learning. Tami elaborated her previous and later perception of teaching after she was exposed to her PDS experience, which included learning classroom management and teaching strategies:

Before joining the program I used to think that teaching is just like preparing the material and ability to explain it. I didn't really think much about it but after joining the program, 
taking all the classes and working with different students in PDS, I realized that teaching is much more than preparing materials and transmitting it to students. I found classroom management a very important factor to consider before teaching, especially if your kids are not paying attention and running all over the place. For me a good teacher should have ability to not only manage the classroom but also invest the time to develop classroom management strategies. (Tami-I)

Joe believes in constructivist approaches towards learning science as he saw his science units based on the constructivist approach and not just based on memorization. He believes that science learning should be seen as building on priory knowledge linking it to new knowledge so that a new individualized concept is created that could be applied to their daily surroundings:

Learning science happens when your mind tries to construct an understanding of what is going on. Learning isn't just memorizing things where giving out list of information but understanding of what you are seeing and what you are hearing and what are you experiencing. When it makes sense in your head you might be able to relate to other things that are already in your mind and relate to your previous learning and try to make sense of all these different things by connecting them in your mind. (Joe-I)

Because Ted had a strong identity of scientist he showed initial resistance to accept that everybody learns differently, but ultimately he realized that soon and considered it an important point when teaching his students:

My preconceived notions were that the way I learn, should also be same for my students...I had to accept and sometimes necessarily not gratefully that not everybody learns the way I learn. Students are different, needs are different ... I would become better by gracefully accepting that in general I would say I accepted most of this . . it was a new concept for me. (Ted-I)

Ted believes that students should be building on prior knowledge to connect to what they already know, allowing students to critically think and challenge themselves and not hold back. As science students, they need to understand "why" and not just "how" and "what." To address students' prior knowledge, a teacher must be able to know students' background knowledge.

Obviously the more you know about your student, then it will be good. Like what kind of learners they are, where they came from, what challenges they are facing etc. This makes 
you prepare as a teacher but say the most basic thing is you need to know what your students already know, the prior knowledge you need to able to connect to because the way your teaching depend on whom you are trying to address. For example, if I have to teach a group of college freshman in chemistry class, I would teach them differently compared to when I am trying to teach chemistry to a group of high school freshman. [I should make sure my lessons are] appropriate to their background experience and knowledge of the subject. That makes a quality teacher. (Ted-I)

Adam also believes in student-based learning where students should be responsible for their own learning and take ownership. Like other teachers, he too believes in implementing CSOs but he tries to make standards and objectives more student friendly so that they understand what's expected of them and what their target is. He believes in setting realistic goals, where students should be able to evaluate where they are and what they need to do. He believes that students should take ownership of their own learning experience where they are doing classroom activities and reflecting on their own; their education should be more important to them. $\mathrm{He}$ always makes sure that his science classes are engaging and student centered:

So the classroom is more about practicing skills and students work together with my guidance-so I hope when people come in my class they see that students know their learning goals, and they see that students know their expectations they hear students talking to each other, and they move around, using their hands and enjoying their learning experience. (Adam-I)

Participants also believed that it is lot easier for students to connect things to prior knowledge and applying making those links help them learn science concepts. Ted gives the analogy of a tree and forest while telling the importance of making connections between science concepts. $\mathrm{He}$ states:

So every time they learn new concept I try to link back to their previous knowledge in my lesson planning. For example, most of students know initially that opposite charges attract and like [charges] repel, and basically at the entry level chemistry most of the concepts we teach links back to that and that's the best way for the students to learn. (Ted-I) 
Participants believed that being aware of students' background and prior knowledge may help teachers create various alternative examples and teaching strategies to address diversity of learners and support them. This may help teachers break information down to a level that students can understand by providing lot of support and examples and hands on examples to help them understand the concept:

some kids they don't need lot of explanation they just need something [explained once] but for lot of my students they need some hands on stuff to really understand science-oh I understand why so why this way or why whatever it may be-So I just try to do a lot of variety to them to keep them interested and to help them learn to make sense to them as an individual. (Amber-I)

Our job is to make sure that everyone is learning and everyone learns differently and so I think learning can happen a lot of different ways and you have to teach a lot of different ways to make sure that they are learning. I mean like a molecular level or brain learning or in general. (Rhea-I)

For example, Ella and Amber found that collaborative work is one strategy that they found useful for the growth of students in science classroom:

My ideal classroom would probably be kids working collaboratively on a project that they have chosen. I would give them option to choose so that they would be working in groups where there will be a mixed ability [of students]. They would be more excited what they are doing so it will be little noisy but not destructive. It would be not off task they working but they are actually interested in what they are doing. (Amber-I)

Most participants believed that they must know about students' prior knowledge in order to design the learning activity, assessment, and teaching strategy. Participants also believed that student assessment should be formative and should be ongoing where students have scope to improve.

I think in a regular classroom situation a teacher who is passionate about learning, his/her students are engaged and there is assessment every 5 minutes. A teacher should motivate her students to learn - the barriers are down its safe, it's okay to shout out the wrong answers. It's okay to make mistakes, it's okay to mess up, it's okay that your experiment didn't come out exact way you wanted to-so let's try it again. (Rhea-I) 
Most participants valued the different learning styles for students and acknowledged that they may not learn the same way as their students learn. They acknowledge the difference in their learning styles and of their students. They find in inquiry-based teaching more productive as they incorporate different teaching strategies to meet various learners' needs. Therefore they appreciate learning more about their students and their learning styles and they always consider this aspect when planning their lesson.

Not only where I am able to explain things through lecture but, I can incorporate hands on activities, I can incorporate inquiry-based activities, and I can incorporate small group work and ask them to work in groups. I can also incorporate technology like, have students working on computers or with iPads and you know when you as a teacher education student, you see that there are so many different ways (Joe-I)

I do enjoy lectures, but that get boring eventually though. But I do know that lot of my kids do learn very through observation and then there are kids who they need to be hands on they need to be touching things and that's why I try to incorporate lot of projects that they are actually doing something and learn whatever they are learning. So I try to figure out how they learn best from the very beginning, and I try to use that to plan my lesson for them. (Amber-I)

Tami discusses the teachers' role to address prior knowledge and challenge the preconceived notions of students, as she herself underwent the changes in her views through her Benedum Collaborative program experience. She gives one example of her high school class:

I think especially in analytical chemistry, they already come in with preconceived notion that chemistry is so hard and my job is to try to breakthrough that notion and bring down to the level so that they understand — on top of the everything else that we do as a number 1 rule as the teacher. (Tami-I)

Tami views teacher as a support system for the students:

Teachers should facilitate the learning and be a support system for the students, get there on their level, and be able to break down the material so that they can understand it. [for them] to be able to explain it a million different ways so that you can try to make sure that everyone in the room understands ... to give them the information they need to give them the opportunities and the labs they need to learn and to be there when they need you - before or after school be there so and to help them through it and (Tami-I) 
Pre-service teachers also value inquiry and research based experience as compared to simply lecture based. They believe that students learn best through inquiry-based teaching besides the structured lesson plan.

I guess learning happens in different ways to different students but I would say learning happens through inquiry and experience in research the instructor can provide many different types of instruction from lecture to labs to discovery learning technology would be available. I think they learn best with inquiry hands on things and activities. (Cory-P)

Teacher's role as facilitator and motivator. Most in-service participants now see the role of science teacher as facilitator rather than someone who is lecturing and asking students to follow certain steps to finish science experiments or hands on activities. They now view teacher as a facilitator who acts more like a guide and resource rather than a preacher and helps students guide their own experience. The following quotes signifies their views:

I want my students to learn through their own experience to question and search for answers. I believe I am more a guide to them. I am not a preacher standing in front of them, delivering information to them. I am not to open up their information to their brain. I do not believe that it's my role to try and do the experiment but help them figure out questions, helping them about answering those questions and helping them synthesis their information. I believe that it's their role to kind of guide their own experience. (Adam-I)

The teacher is more of a facilitator, guy off to the side that allows students to kind of learn at their own pace but also learn things independently so they know to learn and do things without much of teacher's instruction or help and I think one of the ways we can do that by giving them a kind of a head start, may be a background topic and then allowing them to explore the science experiment more deeply and more fully. (Joe-I)

I think in $21^{\text {st }}$ century my role as a teacher is now a facilitator. One of my goals this year is to do more inquiry labs to spend more time in laboratory settings rather than in lecture settings. Now don't get me wrong kids absolutely need to take notes they need some content knowledge from you but I think in 21 century these kids need to do science for learning (Rhea-I)

and the teacher is just a facilitator making sure to be there when they do have questions but I do like the inquiry shift where we are making students responsible for their own learning and more meaningful where more hands on but I guess science teaching so much is because it's so hands on and students can actually see things and top make the learning more meaningful to them (Tami-I) 
Pre-service teachers like Cory and Ella also believe that role of facilitator as an ideal one for science teaching:

The role of teacher would be to facilitate, to give the students a prompt so that students should research on their own before bringing it back together where teacher solidifies their thought and says what's correct and the misunderstanding the student has... a teacher should structure a lesson like that...the role of the student would be an ideal world would be to put in effort and participate and keep in open mind to what teacher is offering and presenting. (Cory-P)

I think teachers are more [of] a facilitator rather than a direct instructor. In my classroom I want to see me like giving the students some kind of projects or some kind of problems they need to solve and to take what they had been learning and trying to solve that and I am there just to explore and I just give them directions. (Ella-P)

Ella recalls that she doesn't want to be like a teacher who she had in high school who just followed PowerPoint presentations. She wants to act like a facilitator giving students enough room to grow themselves through inquiry-based learning:

Science teaching is more of the student led thing. The students need to be able to [get involved] and should be inquiring about something and they should be hands on engaged and they should be just trying to see what works what doesn't works.( Ella-P)

Establishing caring relationships and meaningful dialogue with the students. All

participants emphasized making personal connections with the students, as it can single-handedly make the difference in the student learning in and out of classroom. Participants agree that working in the Benedum Collaborative Program helped them to become better communicators working with diverse students. Some participants have even viewed it crucial for the growth of students. For Amber it is important to know what is going on their lives and where they are coming from:

You need to know what's going on in their life-have they eaten today? Have they any fixed hours when they can sleep. If you have 20 people living in their house they are not able to sleep and they are never going to be taking what they need-you know parents are never home or whatever it is, so first thing I need to figure out is where they coming from. (Amber-I) 
For pre-service teachers like Sylvia, it is the student teacher relationship that is most

important in engaging them in meaningful conversation for both of them to grow:

It is a relationship, so learning is between the students and teacher. You have to work together in order to achieve that learning so that the role of a student is to cooperate with the teacher and to be open tell them how they learn best and realize that it is a two way street. (Sylvia-P)

Sylvia believes in knowing students beyond the classroom:

I do a lot of learning profiles things at the beginning of the semester with new students that can know the hands on, audio, visual and kinesthetic way of learning. I think it's also important to know about the home life, like what type of support they have at home like if they going home and they are taking care of their siblings or if they go home and their parents. Also like how is your day and do you need any homework? Do you need any help? Knowing that what all they do outside the school (Sylvia-P)

Ella too believes that students' socioeconomic background can also influence their interest level in science, something that she didn't realize in her science high school and college science classroom. Ella recalls during her PDS experience how important it is to know students first and then incorporate things in their lesson plan to capture their interest.

You really need to understand their background information like where they come from, what their families are like and what the community is like. I think especially at North Marion which is like in no of nowhere in Fairmont, the students grow up and a lot of them they use to say they want to work in the coal mine like what their parents did. A lot of them see that education is of no use to them as they say-I don't need this as I am going to go work in coal mine. And so I think it's all about knowing your students so that you can really relate the materials to their lives - so I think it's really important to know what their interests are, so that you can kind of make connections (Ella-P)

Rhea considers a science teacher to be passionate in order to relate to the students engaging them in meaningful conversations and motivating them to learn sciences:

I think the role of students is to engage themselves and submerge themselves in the learning, and I think that unless they have a passionate science teacher I don't think that we are going to be actually engaging these student in the sciences. If we cannot motivate students to learn science, our generation will have serious problems. I 100 percent feel 
that a teacher who is exited and passionate about his/her job will be able to grasp the student attention a little more (Rhea-I)

Science instruction as a lecture-based to inquiry-based pedagogy. All participants acknowledged that they joined the Benedum Collaborative Program with pre-conceived notions and beliefs about science pedagogy, mostly learned in their high school and science-content classes taken in the College of Arts and Sciences. Most participants acknowledged they brought an image of a lecture-based science classroom in the Benedum Collaborative Program. They recalled that their high school and science-content courses were based on lectures and hands on activities. The following quotes signify their views:

Even back in my high school there is lot of sitting through lectures, taking notes and once in a while I run a project where I made poster or something like that. Even when I started the program I still had those views while working with those science-content professors. And then when I started to take those courses with science methods professor and other [education professors] who were really showing me the research based best practices, I started to slowly make a transition [to] change [my] approach, and at that point I really got excited about education and I really got excited about kinds of experiences we can provide to students. (Adam-I)

I remember when I was in high school and even in college, the lot of experiments that were given were very cooked book variety, the recipe variety where we were told these ten steps and you do each of them and you are done with the experiment. You kind of proved of something that already has been proven. I think with my science method course we learned more about inquiry-based science. We were able to see that the students construct their own understanding from the experiment that they may be able to develop based on teacher feedback. (Joe-I)

Comparing their high-school science experience, Ella and Rhea do not want students to be passive and go through their teacher's presentation but instead, they want to engage students in hands on learning activity to give them more class time to get involved in the classroom:

I think what made me want to become a teacher was that I never had a really great teacher at high school I never had a teacher that is I am going to telling my students about. I kind of like to change that in my science education. I wanted to be like the fun teacher that everyone like love and kids like can learn something. I don't think science teachers should be in the classroom reading off of PowerPoint. (Ella-P) 
And I really think that learning happens when kids actually do things - not when they listen and not when they take notes - when they are engaged hands on creating experiments - testing out solutions like what works and doesn't work. (Rhea-I)

Participants view science as way of knowing and thinking rather than accepting the content as static knowledge and apply to a specific lab or experiment. They believe that instead of "yes" or "no," teachers should encourage students to think critically based on their prior knowledge.

Joe recalls that one of the important shifts about science-based inquiry happened when he developed an inquiry-based science activity he developed for a lesson plan with his science methods professor, where he encouraged his students to arrange the periodic table based on patterns they saw in the properties of the elements, instead of directly talking about periodic table of elements:

I gave them [students] element cards and those cards that were passed out didn't have elements name on them, all they had were the properties of the element like their reactivity or what other elements they reacted with or how many electrons were in the valence shells and the task of the students was to arrange these cards in order that make sense to them, so that they arrange the cards where they start to see some pattern. I told them use those patterns to arrange those cards in a way that made sense to them. And then I would go around the room and would tell them or give individual feedback like "here's something you might consider doing or do you see that pattern? This is the pattern you might consider and by the activity they arranged the cards so that it looked like the real periodic table...even though they didn't know the name of elements, they made periodic table based on the pattern they saw with the properties of the elementsand that's an inquiry-based activity because instead of telling kids that "here's electronic configuration and here's how the periodic table was formed", I am actually giving them an opportunity to do what scientist did 100 years ago where they saw pattern where scientist saw pattern, based on those pattern they were able to arrange the element in a logical order based on configuration of the electron and I think those types of activities where kids are trying out instead of being told to memorize it - if they construct they own understanding, like seeing a pattern and then getting feedback from the teacher to help them get to where they need to be going, that will allow them to understand the concept much more deeply and help them remember for a longer time as compare to if they were simply told to memorize for the test (Joe-I)

Tami while valuing the traditional lecture-based memory also describes the shift from lecture based to inquiry: 
I still feel like that just like in any other subject, science teaching and learning also requires some amount of memorization for terms but I do feel like the shift into inquiry learning inquiry lab is huge right now (Tami-I)

Pre-service teachers reported that they feel the transition from their previous ideas of teaching that they brought in the program and are still evolving as a teacher. They realize that teaching requires much more than transmitting information to the students and is adaptive in nature. The sentiments are echoed in the following statement:

It's definitely shaping me up as a teacher that I want to be. Before joining the program I had these pre-conceived ideas about a teacher that just stands upon there and lectures the materials but I have learned to be more patient and that is more involved with the teaching. Before I came to college, I thought that it [science teaching] is lot easier than it is where you kind of like create lessons on what you want to teach. I didn't think about all the planning that goes into it or all the things you take into account like students and their prior knowledge and how are you going to assess them. I know lot of my science experience has been like lecture based in high school we didn't do lot of labs. It's more like that the teacher lectured and we took notes (Cory-P)

As I have gone through the program I have grown and adapted to work through [different teaching] situations and become less overwhelming. Most of [my learning experiences] came my field experience in the classroom or observation of my mentor teacher (SylviaP)

\section{Science as a fixed set of knowledge and activities vs. a relationship to social issues.}

Almost all participants had the notion of science as hands on learning activity when they started the program but now they all see science as something connected to society and as a tool to improve the lives of the students. Their view of scientific literacy does not mean transferring knowledge based on memorization but to make sure that science is for all no matter what and should be channelized to serve students interest. Students should be viewing science as something that can motivate people to take part as responsible citizens in the society. For Joe, science should not be just a localized phenomenon, but students should be able to see a bigger 
picture and it should be a global phenomenon. It should be related to everyday life as stated by Joe.

Joe knows the importance of understanding prior knowledge of students and connecting to their existing knowledge structures by connecting science. This is also reflected in Joe's action research project which was based on making science topics more relevant to the real life situation, helping students connect with the content by involving them in activities and discussions related to current issues in science. This experience has helped him design his lesson plans:

Once I understand their interest and hobbies I can design my lesson and incorporate some of the things that they are interested in, For example if I am teaching physics and if they are interested in football or soccer, I can talk about projectile motion, I can talk in terms of two dimensional motion in terms of a ball in a court or like a ball and a ball in a field. Or I know for some of my students told me that they were interested in medicine and they interested in becoming doctors so I would put some questions related to medicines in my chemistry lesson. (Joe-I)

Rhea recalled that she was never taught to see science as something related to society and

the environment, and her view of looking at science was more confined to hands on activities:

I think once you bring the real science in the classroom it allows them to see the issues and to do it and I think that one difference between me and them I did not get much of that experience in high school but I am trying to incorporate it into my classroom today . . . I think there were very few teachers in my school who allowed me to take risk and take chances and allowed me to actually engage in science--they were fantastic science teachers but I did not see much inquiry when I was younger and these kids absolutely need inquiry lab because as I said before they are going to be solving science problems that we have today (Rhea-I)

Rhea now relates to her high school students in such a way that they can relate science with the society so that they have future responsibilities in them:

I tell my kids on a daily basis how the science topic is related to some current events in society. I often remind them that "listen when I was of your age I didn't have an iPhone, I didn't have internet on palm of my hand, I could not text my friend-somebody at some point has to come up with that and I always trusted them. It's your generation who is going to be taking caring of me, you will be playing a role in creating new medical 
technology, and you are going to be creating new energy solutions that we desperately need here in America and around the world (Rhea)

Ella does not see science as a fixed set of knowledge anymore but a set of knowledge that

is bound to change and therefore she should ready to adapt as new theories come in:

As new discoveries is being made, I learned in my education classes that helped me see that science is always changing. I think you really have to be accepting for change accepting of change when you are an educator because everything always changes. And that's one thing that was really good. I am really good at being flexible. I accept change and I love to adapt things with changing time. It was ok for me that my views were revised. (Ella-P)

Science should be more discovery learning and investigative learning like using a hypothesis. I believe that critical thinking is really important, so being in the program has definitely taught us those hand-on models (Cory-P)

Sylvia too, values the importance of connecting science contents to everyday phenomena:

The field experience in the program definitely shifted my view about teaching about science teaching. I find it important and challenging to include modern or things that are happening now in the world into my lessons. (Sylvia-P)

Sylvia always felt that a safe environment is necessary for both teachers and students to grow.

Like most of the participants, she feels that safety is not just related to doing science labs but also creating an environment where students feel safe to have dialogue with teacher:

I think that learning happens when students feel safe and comfortable. A science teacher must create a learning environment that is appropriate for all students to learn and I think learning happens best with lots of hands on and models especially in science. Things like modeling has helped me teach topics which can't be seen with eyes like structure of atom etc. (Sylvia-P)

Teacher as a know-it-all person vs. life-long learner. Most participants recalled how their teachers had skilled sets of knowledge and a guide during their school days. Before coming to the Benedum Collaborative Program they had this notion about education that once you graduate you are done as a scholar, but due to the professional experience which included the kind of uncertainties they come through by doing inquiry-based classroom research, they find 
themselves motivated to constantly reinvent themselves to be a better educator. Adam explains

how his views about a learner changed after joining his experiences in Benedum Collaborative

Program:

Before I went into the education program I was just in college because college is what I suppose to do; therefore, I had this notion that your learning stops after college. But due to my experiences in the Benedum Collaborative program, the type of people that I worked with, the experiences that I gained they made me change my perspectives and want to be better at what I do. Because of my program, my education has not stopped at the end of college because of what they taught me, what they instilled in me. That really changed me into a lifelong learner. I know now that I need to always continue to be work, and I think what I gained with type of people I worked in my education program. (AdamI)

Rhea still recalls the golden words of her education faculty about constantly reinventing herself

as a teacher and she finds it very true as a full time teacher in:

The Benedum Collaborative deepened my appreciation of becoming a teacher and wanting to do better. Each year I wanted to do more. One of my [education] professors said to me, "Rhea, a good educator does not teach the same thing exactly every year," and they are right. I always thought [during] my internship that I am working too hard but then I ways go back to what my prof said it's not that I am working more hard but I am becoming more skilled in my craft and understanding that each year, each semester, in each period I have to change my teaching method just a little bit because every student is different, every student learns differently, and every student has different pace when they learn. (Rhea-I)

Tami never realized that teaching is not just passing out some knowledge to students but

involves dedication as a teacher which involves alertness and sometimes certain sacrifice too:

My mom is a teacher, and until you become a teacher you don't realize how much time it takes to plan and grade ... to take the time meet with your students before and after school . . . to give up your lunch sometimes as a student teacher — so I guess the time that it takes you don't realize until after going through it. (Tami-I)

Joe even goes one step further and calls the role of both teachers and students lifelong learners.

He believes that both teachers and students should always be open to new ideas:

The student needs to know that the teacher doesn't know it all and also the teacher is also learning all the time. Teachers can definitely and should be able to learn from their own 
students. I think students need to realize that we are all teachers and we are all lifelong learners. From the moment we are born we are observing the world around and trying to make a sense of it and we should have this natural curiosity this natural interest in knowing how things work and why it works and I think the kids see that in their teachers. The teachers are also learning things and are also keeping up with their education and they should be always open to new ideas. If students see themselves as lifelong learners they will be encouraged to learn and they will be encouraged to ask questions and do more research on their own if they are curious on a particular topic. I think it will benefit both teachers and students when students realize that no matter what they will be learning and you can always find people and resources that would help them investigate the questions and the curiosity that they have. (Joe-I)

Pre-service teachers also emphasize for continuous improvement in teaching, which made them ready to improve their teaching. While Cory was surprised to see how much paper work teacher has to do in the teaching career, Ella while comparing her high-school experiences to her PDS experience, realized that a teacher should always be ready to learn and improve according to changing times:

... teachers that I had in high school, I felt like that their always stuck in their old ways . .. it [experience in PDS] also got me to see that everything is always changing and you really have adapt according to the changing tome and situations. You need to keep up with the times, you need to keep up with how students are learning so that you can help get your students to do the best they can. (Ella-P)

Teacher as role model with a good work ethic. Most participants viewed their high school and middle school science teachers as their role models but now their definition of role model has changed. Earlier their definition of role model was based on their high school and college content science teachers whom they saw as individuals who build interest in science and involve them in hands on activities. Now the participants' definition of role model goes beyond as someone who just creates science lesson plan and hands on activities. Instead, they now view themselves as role models for their students based on what they taught from their education 
professors or their PDS mentor teachers that they worked with during their clinical based

experiences. As Joe states,

Teachers kind of have a special duty to teach students about social wellbeing, the social and mental aspect of their wellbeing, in terms of showing them integrity, honesty, showing ethical practices... that way students have at least role models they see eight hours a day. So what that means is they see in a person with a good work ethic. It is not only like as someone who helps them learn science skills or knowledge of science concepts but also be just to be there as a role model. I see teachers as some of the most important role model we have in society to teach students about respect, to teach students about responsibility, honesty and how we treat others. I think all these qualities are really important in our society. (Joe-I)

Adam recalled how he worked at a NASA resource center during his internship

experience developing lesson plans and working with teachers, so now he thinks that it is teacher responsibility to involve everyone to produce a better society. Therefore, he views himself as a more responsible person and values collaborative teaching and research:

Teachers don't have to be alone in that process to instill a better education, and everybody should take ownership of not only our classes but education as a whole. That includes our classroom, our school, our county, our state and everywhere. We all should be working to better education for all students. (Adam-I)

Participants viewed teachers as a responsible hard working citizens and also emphasized

the importance of collaborative nature when working in and as a community:

Before joining the program I think I just didn't view teachers as people who have to integrate so much work into their job. I thought it was much simpler than this, but now I realize there were so many things you need to deal with. (Sylvia-P)

I still recall that the internship that I was given to work with the NASA educator resource center where I was partnered to develop my own program but also to work on educating other teachers. I think this is also something that really helped me realize education is a great collaborative process. Teachers don't have to be on their own when we should be working together to provide all our students the best educational experience. (Adam-I)

The participants' view clearly showed that the experience within the Benedum

Collaborative Program gave them a sense of transformation in terms of expanded identity in- 
terms of the continuous evaluation of their work as a teacher and also in-terms of moving beyond the role of science teacher to consider themselves as role models and responsible citizens.

\section{Conclusion}

This chapter provided a snapshot of the experiences that the participants found meaningful during their participation in the Benedum Collaborative Program. They also described how the components of Benedum Collaborative Program influenced their experiences and understanding of teaching and learning and their development as a teacher. It was also interesting to see the ways they described and interpreted their experiences especially in terms of their interaction and relationships with their education faculty and PDSs teacher and how that had profound effect on their identity as teacher. The themes of teaching and learning were found consistent with the organizational framework of Benedum Collaborative Program which includes diversity, inquiry, and technology as important strands. The emergent themes and sub-themes of teaching and learning were aligned with the INTASC and Characteristics of Novice Teachers (CNT) principles in terms of: a) Increased awareness of diverse learners and different approaches for instruction and assessments (INTASC 2, 3, 4, 8 and CNT \# 4, 9); b) Understanding of individual and group motivation and communication to foster active inquiry and supportive interaction to meet curriculum goals (INTASC \# 5, 6, 7 and CNT \#2, 4, 6, 7); and c) Reflected practitioner and promote learning to the larger community of society (INTASC \# 9,10 and CNT \# 1, 3)

One thing that clearly shows from the result is that the organizational framework did have the influence on the participants' way of thinking and educational experience. Next chapter will provide a detailed discussion about the findings in this chapter and implications of the study. 


\section{CHAPTER 5}

\section{Discussions}

\section{Introduction}

My role as a researcher and my background and interpretation played an important role in formulating discussions provided in this chapter. Instead of focusing only on pre-service teachers, I tried to provide a voice to in-service teachers who form two-thirds of my participants, to value their perception about what they thought about their experiences during the participation in the program. An advantage of including in-service teachers is that some of them also related their experiences in the Benedum Collaborative Five-Year Teacher Education Program to their current teaching practices that they found meaningful. This research also tried to find out how inservice teachers and pre-service secondary science teachers reflect on their educational journeys in the program. And in that process, how they viewed their development within the program especially in terms of the kind of prior experiences they brought into the program, their perception of the of science and pedagogy courses they took, and the kind of relationship and experiences they found meaningful with the faculty, host teachers, and peers as they evolved during the program. This qualitative interpretative research was an attempt to understand their lived experiences as they reflect on their journey during their participation in the program. The aim was also to find how they perceived and described the components of teacher education at West Virginia University.

One of the limitations of doing this qualitative research is that it is contextual as it has been conducted in a five-year education program located in a public land-grant university. Another limitation was that not all participants were ready to open up to explain each and every 
experience that was meaningful to them. Before I started the interview, some participants expressed their concern on how much detailed they should be in their explanation and there were certain occasion when their response was very precise without any explanation. Even though there were prompts included in my open ended semi-structured questionnaire, some of the preservice participants were still very reserved in opening up their feelings or opinions. However, most of the in-service participants provided rich and detailed description about their experiences in Benedum Collaborative Five-Year Teacher Education Program which helped the researcher understand the kind of experiences they have gone through in three cultures of their teacher education program, namely: Culture of Science, Culture of Education, and Culture of PDSs. The second limitation was that not all the participants provided the written work in the form of lesson plans and journal entries.

Three pre-service participants reported they were confident that their current experiences will eventually grow better as they proceed to complete the program. Since six of the nine participants were in-service teachers who graduated from the program and were practicing teachers at the time of this study, they already had crossed all milestones of the program. Based on the emergent themes in the findings, they reflected a greater confidence as a science teacher in their current practice. Participants were able to go back and recall the kind of learning situations or experiences that not only helped them gain skills but also supported the perceived shifts/ongoing shifts in their beliefs about science pedagogy. The confidence shown by the six in-service participants in their current teaching practice due to their development and skills gained in the program, reflects the success of the program towards teacher retention initiatives found in teacher education literature (Darling-Hammond et al., 2002; Davis et al., 2006; Kagan, 1992; Wideen et al., 1992; Rodriguez, 1998; Rushton, 2000; Tschannen-Moran et al., 1998). 
This chapter is divided into four main sections: Discussion of the Research Findings, Implications, Future Research and Returning Back to my Personal Context. The findings are also discussed in the light of literature review as discussed in chapter 2.

\section{Discussion of the Findings}

Teacher education plays an important role in not only addressing teachers' prior beliefs but also influence their ways of thinking. This includes the educational experiences and choices provided to them within the framework of the program as they socialized with their professors, host teachers, advisors, and peers. The research findings highlighted the experiences and the ways participants interpreted and described those experiences that they found meaningful during their participation in the program. The program goals, strands, policies, structures, and elements played an important role in driving the participants toward the outcome of the program.

According to Beck and Cowan (1996), the value structures (ways of thinking) do not shift all of a sudden or within a short span of time. According to spiral dynamics, the shift in value structure (belief system or ways of thinking) happens when a life situation demands. This demand contains certain conditions like potential to change, inconsistency between beliefs, identification of the barriers, and neutralizing or reframing them and providing insight and support during the process (Beck and Cowan, 1996). The participants emphasized that the experiences provided to them not only challenged their previous beliefs but also helped them acquire skills and grow as teacher. Measuring the exact shift or transformation in pedagogical and personal beliefs is complex in a developmental program like a five-year teacher education. Instead of relying on a quantitative instrument, I relied on qualitative explanation to get an in-depth essence of their experience. 
The purpose of this research was not to inform the "extent" they changed their value structure and how it is affecting their practice in terms of student learning. It was more focused about knowing how the participants interpret their development during their participation in the program that ultimately reflects on their value structures intertwined with their experiences. The participants also did inform about the kind of experiences they found meaningful that influenced their identities as science teachers and their choice of practices (Davis et al.; 2006; Kagan 1992; Eick and Reed, 2002; Sadler, 2002).

The reflection and inquiry strand of the program helped the participants review their learning experiences as they sought answers to their research questions. The emergent themes related to teaching and learning as expressed by the participants were found to be consistent with the three strands of the Benedum Collaborative Five-Year Teacher education program- diversity, inquiry, and technology. They were also found consistent with the characteristics of novice teachers (CNT). The main issues that I found worth discussing in the findings were: the "awareness of student diversity in learning sciences" and the "influence of the dialogical relationships" to inform their growth and learning within the program. This awareness of student learning was not just limited to socioeconomic, racial, and learning diversity but also to the students with special-needs and English as Second Language (ESL). What I found unique is that how the secondary science teachers reflected their willingness to work with these students as a part of their responsibility to make "science for all" a reality. From the dialogical pedagogy approach, the teacher development should be seen through what Freire defines as the development of "critical consciousness" where students' learning involves not just receiving some socially prescribed knowledge but a deep " awareness of both socio-cultural reality that shape their lives and of their capacity to transform that reality"(Friere, 2000, p.27). And this 
leads to a praxis which is a "continuing process of action, critical reflection, and dialogue" (Stevens-Long et al. 2012). Therefore education can be empowering when seen as life-long learning with formative relationship between teacher and students, students and their learning, and students and society. The most powerful shift that participants discussed was the role of teacher-student relationship in teaching science, and learning about students' interests to adapt lesson plan, as they realized that the way they learn may not be the same as their students. Participants also talked about the experiences that created a contradiction in their thought process, as evidenced in their narratives. A dialogical and truthful relationship with science method professor and host teachers combined with real life experiences in their PDS helped them accept their beliefs to construct new belief system, and ways of thinking (value structures). In most of the cases the participants' previous value structures (or beliefs) were found inconsistent after watching the role of their science methods teachers, education faculty, and PDS host teachers.

Participants also recalled events that lead to meaningful experiences with students and how their pedagogy classes, such as classroom management and special education, combined with their PDS experience, helped them realize the classroom reality. Contrary to some studies (Shen 1997; Quartz and TEP Research Group; Kagan 1992; Wideen et al. 1998) where teachers find disconnect between courses and practice, all the in-service participants reported that they found the elements of the program, especially the combination of pedagogy and field experiences very interconnected that was helpful in their current practice. Participants reported that the experiences in their PDS has actually helped them implement the classroom management techniques and has given them experience to make decisions in various classroom situations/uncertainties that arise. For example, Joe talked about how his experiences in PDS 
helped him to manage disruptive classroom behavior in his present school where he was currently teaching. The Benedum Collaborative Five-Year Teacher Education Program provided the experiences, professional development opportunities (like WVSTA conferences), theory to practice connection, long-term interventions in the form of inquiry-based seminar sessions, and extended field experiences which are considered as essential for an effective teacher education program (Darling Hammond et al. 2002).

\section{Influence of Academic Cultures on Pedagogical Beliefs and Identity}

This study highlighted the perception of in-service and pre-service secondary science teachers about their experiences in the three cultures (college of science, college of education and professional development schools) and the role of five year program in shaping their perception about science pedagogy. The emergent themes from the findings also informed how the teachers beliefs (or value structures or ways of thinking) about pedagogy and identity is influenced by the kind of experiences in academic cultures that they were a part of. Such academic experiences include the types of ways they interact with the culture and mingle with it. The experiences in the culture influence their learning and thinking and how they operate in the culture. This is revealed in the participants' narrative of their experiences. All participants were initially in pre-science and engineering majors for the first few semesters before entering the program. The narrative of the experiences of the participants reflected the influence of the academic cultures in shaping their perceived beliefs and identity related to science and science pedagogy. The participants did identify themselves with the group of individuals in the cultures of science, education, and PDS. And therefore the relationship they shared with the members of that culture also influenced/influences the way they perceived themselves in that culture. In science culture, most of them either had the scientist identity and developed the relations as 
scientists; however, some of them did not perceive any relationship with the science community. While the culture of science did provide them the knowledge of scientific concepts and lab work, making them identify with the culture of science where students' learning-differences and inquiry-based science were not addressed. All participants did not see any connection between the science content and diversity of students and learning styles. In terms of spiral dynamics, I can assert that based on the descriptors provided by the participants, the science culture represents the authoritarian value structure.

On the other hand, they felt a sense of teacher community in the culture of education. The professional development in education included not only working closely with the education faculty but also presenting and participating in national and state conferences and working closely with their science-methods professor and other education faculty. The support and professional development opportunities provided to science teachers in the program helped them grow as a professional teacher. Participants also described the barriers and challenges during their journey. Many participants found that they got the sense of community while participating in the "collaborative" nature of the program. Most participants agreed that with dialogical relationship, inquiry-based reflective practices, and professional development support helped them not only revise their previous concepts of science pedagogy but also apply them in real-life classroom settings. The strong statements of in-service participants are some of the evidences that the program is effective because as reflected in the emergent themes of this research findings, most of them described how they are implementing those concepts in their current classes. The findings show that all participants worked more closely with education professors and saw more theory to practice connection in pedagogy classes like science methods courses, 
special education courses, classroom management, inquiry seminars, lesson plan design, and technology integration.

Working closely with their PDS host teacher made the participants consider meaningful relationships more valuable, as it influenced their thinking to make student learning as their first priority and showed more concern for them, connecting with them, knowing about them, and probing their prior knowledge before teaching. Based on the descriptors provided by the participants, I can assert that collaborative culture of education and PDS represents post-modern and integrative value structure. The literature review expresses that secondary science teachers need to know the diverse needs of learners (Davis et al., 2006; Larkin, 2010; Sadler 2006; Rodriguez, 1998) which is also an important strand of Benedum Collaborative Five-Year Teacher Education Program. Participants reported that when they were exposed to the diverse students in PDS, special education and non-English speaking students, they became more informed about the various learners that they wouldn't have imagined learning sciences. Some participants even showed the responsibility to make sure science literacy should be for everyone including students with special needs. The culture of PDS provided diverse educational contexts to participants to help them grow, and expand their identity as a leader who is connected to wider community and sees him/herself responsible for science literacy for everyone. PDSs were located in the mixture of semi-urban and rural areas and participants reported that working with various students from various socio-economic-cultural backgrounds helped them expand their views on the role of the learner in science education. Participants saw as their duty to inform students about science and make lesson objectives to meet a learner's needs. According to Rodrigues (1998), one of the primary goals of secondary science teacher education should be preparing teachers for diverse learners based on the ideological stance of social justice : "to 
work respectfully and effectively with children from diverse backgrounds(i.e. from diverse socioeconomic status, cultures, ethnicities, abilities, sexual orientations, family units and so on)" (p. 593). All the participants described the diversity of learners as their biggest awareness, which is also consistent with previous studies done on pre-service secondary science teachers where they valued this the most toward successful teaching (Rodriguez, 1998; Sadler, 2006; Larkin 2010).

This research also informs that dominant cultures do play important role in influencing the value structures and practices of the individuals. Some in-service participants like Ted, Joe and Adam also talked about the kind of limitation that they sometimes have to face in their current teaching positions, where they have to consider the school structure influencing their decision on how to teach a science class and how much content needed to be covered. This may lead them to go back to their authoritarian value structure that they faced as the students during their high-school and culture of science that they once were part of. They also showed frustration that they are sometimes told to cover the science contents at the superficial level which they may not agree to. For example, in case of Ted, even though he thinks in terms of postmodern value structure but sometime he may have to operate in authoritarian value structure in his current teaching position. This was evident with the Ted's narrative that sometimes district school curriculum and time factor influences his decision to apply science inquiry to a certain extent.

But at the same time the in-service participants expressed the confidence in dealing with such situations rather than frustration because they learned to deal with such situations in the structured field experiences that prevented them from getting praxis shock once they started teaching (Fletcher, 2006; Kagan, 1992; Rushton, 2000; Suranna, 2005; Wideen et al., 1998). Most of them attributed this to the meaningful dialogue and working relationships with 
cooperating host teachers while working in a real classroom scenario. This gave them confidence to meet the uncertainties in the classroom, so that sometimes even if they are required to go back to the authoritative structure if the situation demands, they can deal with the situation to handle their classroom. For example, Adam used flipped classroom to address the time constraints in his science classroom. The classroom management, lesson planning, parent teacher conferences, etc. are some other positive sides that the research participants found helpful in dealing with such situations.

Almost all the participants reported that they were not coming from schools with diverse student population but the exposure to different PDS schools helped them realize the importance of multiculturalism in their teaching and learning. They sometimes faced difficulties in expanding their value structures that they were part of. However, science methods course, inquiry-based seminars, and other pedagogy courses helped them saw science teaching as an inquiry-based learning activity and address students' prior knowledge. In-service participants see it as a required criteria for teaching and have adopted this in their current teaching practice. This was also evident from their written works which took account of the students' learner differences in teaching activities and assessments. The written works provided by the participants in the form of the lesson plans validates the point. It was only through the experiences in the "collaborative culture" of the College of Education and Human Services and PDS that most participants realized that their life may not be same as their students' lives. Therefore they valued the fact that they must know about students' lives and establish a connection with them. The inquiry strand combined with the meaningful coursework in science content and pedagogy courses, helped them develop as a science teacher. 
Sometimes the identity of scientist is so strong that it becomes hard to make the shift happen. It taught me one thing that the cultures within the institutions may make you stuck at on one level but also can help you shift in your ways of thinking if given the opportunity or experiences to enhance the shift. While the science content is still important there needs to be collaboration to understand a better view of combining both the science and education cultures as stated by some participants like Joe, Ted and Adam. For example, Ted was not able to get an initial approval for his action research project, but due to continuous support and his openness to learn made him successfully implement his project. Ted gave credit to his struggle in implementing action research that ultimately resulted in a growth in confidence in his present role as a teacher to conduct inquiry based classrooms. According to spiral dynamics, whenever there is conflict in value structures, negotiations are made to shift to the new value structure. All participants agreed that when faced with dilemmas, they were given constructive feedback from the education faculty and PDS host teachers to work on the situation jointly. Findings suggest that education faculty and host teachers have significant influence on pre-service and in-service teachers' decision on what they do/are doing in their classroom. This is due to the experiences and choices provided to the students during their socialization in the teacher education program. Participants mentioned that science method course, inquiry seminars and other education courses related to classroom management, helped them know not only students diversity but also their own understanding of science pedagogy.

Participants also talked about the shifts in their ways of thinking as they transformed from student to teacher in the program. The shift may be structural developmental stages like spiral dynamics which includes both individual as well as social transformation, viewed as higher order of consciousness. Here one can move from one stage to another, toward more 
inclusive and complex ways of thinking, but can come back to the original stage when required. In-service teachers like Joe and Ted gave examples of some of their recent classroom situations where they faced some familiar dilemmas exposed to them previously as pre-service teachers in their PDS and how their decision making skill that they learned during that time, came out to be useful.

Also, while some in-service participants viewed their science content coursework as beneficial, most participants reported that they did not perceive the advanced science courses helpful in learning pedagogy and making connections to their teachings and teacher development (Fletcher, 2006; Kohlhaas Labuda, 2002; Davis et al., 2006) . Some in-service participants like Joe and Adam suggested that if both science and education faculty can work collaboratively, teachers can actually see the content directly be applied in a teaching setting. For example, they recommended uniting the cultures of science and education so that they can learn content and pedagogy side by side. While the finding in this study provide evidence of the successful collaboration between the culture of education and PDS, more collaborative efforts to connect the culture of science to the collaborative culture may be beneficial (Kohlhaas Labuda, 2002; Sadler, 2006; Davis et al, 2006).

\section{Influence of Structured Field Experiences on the Perception of Teaching Preparedness}

Strong statements of growth in the sense of teacher preparedness were related to the confidence of teaching and handling the real-world classroom situation influenced by collaborative culture during the structured field experiences. This also made the research participants aware of greater emotional need of children, as evident by the emergent themes in 
the findings. All participants wanted to be a good science teacher and to make an impact on student learning but little did they know about how to teach students in meaningful ways.

The Benedum Collborative Five-Year Teacher Education Program is integrated with a balance of content and pedagogy with structured clinical experiences with inquiry as an important strand within the collaborative culture, which helped the participants develop habit of mind to constantly raise questions about teaching practices and improving them. Other strands like diversity and technology helped the participants not only gain awareness of learners and context but also the confidence in combining the technology with their content pedagogy. All the participants gave credit to the structured inquiry reflections distributed throughout their three years of clinical field experiences as valuable contributors of their perceived growth as teachers. While the culture of science does develop a strict set of scientific knowledge and verification of those knowledge in the form of hands on activities and lab experience, the collaborative culture of education and PDS did provide them nurturing environment to grow and reflect on their pedagogical learning.

Another important theme that emerged from the findings was they ways the participants perceived themselves as teachers after their participation in the program. Most participants perceived themselves as a role model for their students with increased confidence of implement student-centered inquiry based classroom as compared to their previous views of a science teacher transmitting science knowledge and directing hands on lab activities. As discussed in the literature review, studies have shown that teachers' sense of self efficacy is not only related to the perception of the learning opportunities that help them gain teaching skills but also the sense of how well they feel prepared (Darling-Hammond et al., 2002; Davis et al. 2006; Fletcher, 2006; Rock and Levin, 2002; Rushton 2002). In spite of having the passion to become a 
science teacher, all the participants reported that they initially doubted themselves when they actually started student-teaching and described the kind of uncertainties before starting their field experiences. But due to structured three year clinical field experiences, combined with the nurturing environment, they all asserted that confidence was developed over time. The constructive criticism and feedback given by the education professors, small group facilitators and their PDS mentor teacher helped them create dialogical relationship which nurtured their pedagogical understanding about inquiry stance which is stranded throughout the program. One thing that applies in dialogical relationship is the praxis. Therefore whatever they learned they applied in their current teaching practice. Participants credited the helpful nature of their PDS host teachers to understand the issues related to classroom management and strategies to address them. For example, evidence of strong growth in self- efficacy from in-service teachers like Rhea is reflected when she compared her fellow teacher from another program and found herself more confident in apply action research in her classroom with as compared to her colleague. She credited her program structure as the main reason for her ability to deal with the classroom realities and implementing inquiry-based teaching strategies. In-service teachers also attributed their confidence and awareness to the PDS experience that they had during their participation in the program, and the strong relationship they shared with the PDS host teachers and education faculty. All in-service participants acknowledged that being in PDS consistently was the most important thing in the program that helped them improve not only their teaching skills but helped them develop confidence over the time. The clinical field experience along with their experiences in the culture of science and education, helped them not only develop their classroom management strategies and student awareness but also directly exposed to the culture of school as they went through rigorous training in the program. 
Hence, it can be asserted, that the realistic classroom exposure and preparation within the framework of collaborative culture in the Benedum Collaborative Five-Year Teacher Education Program, were viewed very positively by the research participants in this study. Additionally, the emergent themes in the findings also informs that five-year teacher education program, with structured field experiences, contributed towards growth in teaching confidence as told by the participants. All the in-service participants were working as professional teachers at the time of this research study. Participants reported that they were informed and prepared for the realities of classrooms. The emergent themes in the findings reflected an increased confidence in dealing with issues related to classroom management, student behavior, and capability to take judgments in complex situations happening inside the classroom. All pre-service participants acknowledged an increased awareness and confidence in their teaching and thinking ability to understand education as a whole.

Consistent with the literature review, all participants found their structured student teaching experience as the most meaningful learning experience in the program. The growth in the sense of teacher preparedness was overall attributed to a combination of balanced science and pedagogy courses, science methods course, and structured inquiry-based seminars along with the long term collaborative efforts with PDS host teachers and education faculty. This was found consistent with the previous studies done on pre-service secondary science teachers (Sadler, 2006; Kohlhaas Labuda, 2006; Larkin, 2010; Davis et al., 2006) and the program structure of Benedum Five-Year Teacher Education Program which is based on the strands of inquiry, diversity and technology.

\section{Implications of This Research}


1. This research was an attempt to include in-service teachers to voice their opinion on a five year teacher education program. Most research on teacher education program are done keeping pre-service teachers in mind and in-service voices are not included (SnowGerono, 2009; Mason, 2009; Toll et al., 2004). However, in-service teacher and preservice teachers can provide a wide range of useful information related to the program reform policy. The dynamics of their experiences can inform reform policy not only for the current program renewal and improvement, but also to the other teacher education programs. Qualitative data provided a rich description of experiences with feelings and emotions which value the authentic feelings and perceptions of participants.

2. This research informs about the kind of experiences participants find meaningful in their teacher education program and provided an insight and further documentation of what past and current literature has already shown. What this research also suggests is that some of the themes that can be used for a possible quantitative study like the kind of courses, challenges and barriers that teachers consider important in a teacher education program. For example, some participants reported that they found only those pedagogical courses useful where they saw connection with the practice. This raises a possibility for a quantitative or mixed method research to see what aspect of pedagogy curriculum teachers find relevant and whether it can contribute to the curriculum of the teacher education program.

3. Some participants reported that they did not see any relevance in the college science content curriculum and the curriculum they teach in their schools. This raises a question if there should be more involvement of science faculty in College of Arts and Sciences to collaborate with education faculty and PDS. Can there be a secondary science curriculum 
specific to science subjects (like Physics, Chemistry, Biology, Geology etc.) that can be more relevant to the subjects that teachers teach in their schools? In spite of the differences of experiences in the two cultures (science and education), more collaboration may be needed to bridge the gap of those two cultures just like the collaboration between the culture of education and culture of PDS.

4. Another important issue that may be relevant is to engage host teachers of participating PDSs in professional development/continuous education in the teacher education program. Most of the descriptors provided by participants about PDS host teachers were favorable to their learning and growth. However not all the descriptors were found favorable. For example, some participants also talked about instances when they struggled with their host teachers who seemed unengaged and were following "outdated ways of teaching" and didn't match up with the pedagogy skills they learned in their science methods course. Therefore additional training for some PDS host teachers working with pre-service secondary science teachers to implement inquiry-based lesson plans may be beneficial (Sadler, 2007).

5. All participants considered science methods and inquiry seminars with action research as the most important factors in implementing inquiry-based science classroom. They also informed that those experiences were helpful in gaining them confidence to implement action inquiry research in their own classroom. In retrospect I learned from this research that observing the participants what they have said in journal and interviews, could have enriched the data or research. Because I didn't observe them implementing their lesson plan, this may be one of the limitation of this research. However, it will be very helpful to 
connect the relationship between their views on planning action research and actually implementing it and the possible barriers (if any) in the implementation.

6. Personally, the experiences in this research will help me improve my teaching as future practitioner. As a facilitator of technology seminar courses EDUC 311 and 312, I have worked with pre-service teachers in the technology integration efforts in their PDSs. I have also taught $E D U C-400$ (an advance course in technology integration in pedagogy) which is based on the technology strand of the Benedum Collaborative Five-Year Teacher Education Program and is taken by Tutor Year of the clinical field experience. This course is related through technology strand of the program and gives a platform to use the technology in their PDS class. This research will also serve as a base for my future researcher in the area of science teacher education and student development.

\section{Future Research}

1. This study only involved limited participants to inform their experiences in relations to the program elements in this study. However more dimensions can be added if an additional study is conducted that involves science and education faculty and PDS host teachers about their experiences working with pre-service secondary science teachers.

2. Not all participants viewed the content and pedagogy courses equally effective or necessary for their teacher development. Therefore a mixed methods research can be done to understand why some science content and pedagogy courses are more meaningful to pre-service secondary science teachers and why some are not.

3. How do the practicing in-service teacher see relationship between their beliefs about implementing inquiry in class that they learned in their program and the problems they 
face as the practicing teacher? This may be an interesting topic of research which is not covered in- depth in this research as the focus is more on their experiences in the Benedum Collaborative Five-Year Teacher Education Program.

4. A comparative study of science teachers' experiences in other five year teacher education programs that have PDS collaborative in place.

5. A comparative study of teacher's growth in Four and Five-year teacher education program.

\section{Returning Back to My Personal Context}

When I look at the experiences as defined by some of my research participants I find it spectacularly similar to my own life experiences. Just like most research participants in this study, I decided to change my career from being an experimental scientist to a "science educator" and I too was not met with very encouraging initial response by my near and dear ones. I recall my own undergraduate science classes for my training in science and the belief in my academic science culture was same as described by Joe for science professors who teach large science classes. I found that I come from a culture of science where no pedagogical knowledge is required and the only criteria for becoming a science faculty is to have publish some research papers and have an advanced degree. My exposure to the culture of education happened after I was admitted to the doctoral program, where I took classes related to pedagogy classes and developmental theory. I didn't take long for me to experience the conflict in my value structures during my class participation where my beliefs were challenged about education. It made me realized my vague understanding about education and transformed my pedagogical beliefs as I engaged in continued dialogue with my professors. But this also depended on the 
kind of professional support I received in my doctoral program and the kind of interaction and meaningful dialogue I had in my program.

Just like my research participants, I too had to cross the milestones in my own doctoral program and in that process I saw a growth in me as an educator. This ultimately helped me to realize the importance of inquiry and reflection which I implemented in my own advising and teaching orientation classes for undecided-major students. My doctoral educational experience helped me as a practitioner while advising and teaching my students. The interactions that I had with my own doctoral advisor helped me inspired to be more empathetic toward the students that I advised during my work experience as an academic advisor. I may be racially or ethnically different from the research participants in this study but as I tried to understand their journey, I felt connected with them. This included the similar and not so similar experiences gone through by them. And this lead a growth in me both as an educator and human being.

The participants did not regard the stereotype of views like "science teaching as not lucrative career" and brought a passion in this program, hoping that they all will succeed. All participants viewed science only in-terms of personal context and they wanted to become science teachers as they found science teaching interesting. However, as they proceeded in their program, they realized that science teaching is not just creating lesson plans and transmitting scientific knowledge to the students but also to understand the nature of students learning, student diversity and the sense of social responsibility as a teacher (Wideen et al., 1998; Davis et al., 2006; Rodrigues, 1998; Sadler, 2006). This shows that when encouraged into dialogical relationship in a collaborative setting, where meaningful conversation may take place, especially in the context of science education, then science is seen as a human phenomenon. 


\section{References}

Agostinho, S. (2004). Naturalistic inquiry in e-learning research. International Journal of Qualitative Methods, 4(1), Retrieved from http://www.ualberta.ca/ iiqm/backissues/4_1/pdf/agostinho.pdf

Akerson, V. L., Morrison, J. A., \& McDuffie, A. R. (2006). One course is not enough: Preservice elementary teachers' retention of improved views of the nature of science. Journal of Research in Science Teaching, 43, 194-213.

Alvesson, M., \& Skoldberg, K. (2004). Reflexive Methodology. Thousand Oaks, CA: SAGE Publications.

Alvord, L. A. \& Van Pelt, E. C.(2000). The Scalpel and the Silver Bear. New York, NY: Bantam Books.

Anderson, L. M., \& Stillman, J. A. (2013). Student teaching's contribution to preservice teacher development: A review of research focused on the preparation of yeachers for urban and high-needs contexts. Review of Educational Research, 83(1), 3-69.

Andrew, M.D.(1990). Differences between graduates of 4-year and 5-year teacher preparation programs. Journal of Teacher Education, 11(2), 45-51

Appleton, K., \& Kindt, I. (2002). Beginning elementary teachers' development as teachers of science. Journal of Science Teacher Education, 13(1), 43-61.

Arbaugh, F., Lloyd, G .M., Knight, S. L., Edmondson, J., Nolan, J., Whitney, \& McDonald A. E. (2013). Teacher Learning and Perceptions Across the Professional Continuum. Journal of Teacher Education, 64(1), 6-7.

Aurobindo, S. (1990) The Life Divine. Twin Lakes, WI: Lotus Press 
Azar, A. (2010). In-service and pre-service secondary science teachers' self-efficacy beliefs about science teaching. Educational Research and Reviews, 5(4), 175-188.

Backhus, D. A., \& Thompson, K. W. (2006). Addressing the nature of science in preservice science teacher preparation programs: Science educator perceptions. Journal of Science Teacher Education, 17, 65-81.

Bandura, A. (1997). Self-efficacy: The exercise of control. New York, NY: W. H. Freeman.

Beck, D. E., \& Cowan, C. C. (1996). Spiral dynamics: Mastering values, leadership, and change. Malden, MA: Blackwell Publishing.

Benedum Collaborative Five-Year Teacher Education Program Student Handbook (2014). Retrieved from http://slate.wvu.edu/r/download/195051

Brickhouse, N. W., \& Potter, J. T. (2001). Young women's scientific identity formation in an urban context. Journal of Research in Science Teaching , 38(8), 965-980.

Brown, J. R. (1996). The I in Science: Training to Utilize Subjectivity in Research. Oslo, Norway: Scandinavian University Press.

Callejo, D. M. (2008). Teacher education and research: Imagining teacher education between past and future. American Educational History Journal, 19-40.

Coladarci, T. (1992). Teachers' Sense of Efficacy and Commitment to Teaching. The Journal of Experimental Education, 60(4), 323-337.

Darling-Hammond, L., Chung, R., \& Frelow, F. (2002). Variation in teacher preparation: How well do different pathways prepare teachers to teach? Journal of Teacher Education, 53(4), 286-302.

Darling-Hammond, L (2008). Knowledge for Teaching: What do We Know? In Marilyn 
Cochran-Smith, Sharon Feiman-Nemser, \& D. John McIntyre (eds.), Handbook of Research on Teacher Education, 3rd edition, pp. 1316-1323. NY: Routledge, 2008.

Davis, E. A., Petish, D., \& Smithey, J. (2006). Challenges New Science Teachers Face. Review of Educational Research, 76(4), 607-651.

Dewey, J. (1963). Experience and Education. New York, NY: Collier Books.

Driel, J. H., Beijaard, D., \& Verloop, N. (2001). Professional development and reform in science education: The role of teachers' practical knowledge. Journal of Research in Science Education, 38(2), 137-158.

Eick, C. J., \& Reed, C. J. (2002). What Makes an Inquiry-Oriented Science Teacher? The Influence of Learning Histories on Student Teacher Role Identity and Practice. Science Education, 86(3), 401-416.

Enyedy, N., Goldberg, J., \& Welsh, K. M. (2006). Complex dilemmas of identity and practice. Science Education, 90(1), 68-93.

Ferguson, R. (2008). If multicultural science education standards existed, what would they look like? Journal of Science Teacher Education, 19, 547-564.

Fletcher, S. S. (2006). Exploring the beliefs and practices of five preservice secondary science teachers from recruitment through induction in a university preparation program: A longitudinal study. The University of Texas at Austin. ProQuest Dissertations and Theses, http://search.proquest.com/docview/304978592?accountid=2837

Fletcher, S. S., \& Luft, J. A. (2011). Early career secondary science teachers: A longitudinal study of beliefs in relation to field experiences. Science Teacher Education, 1124-1146.

Freire, P. (2000). Pedagogy of the Oppressed. New York: The Continuum International Publishing Group Inc. 
Gadamer, H. G. (1998). Truth and method (2nd ed.). New York, NY: Continuum. (Original work published 1960.)

Geertz, C. (1973) The Interpretation of Cultures. New York, NY: Basic Books.

Giroux, H. A. (1988). Teachers as Intellectuals: Toward a Critical Pedagogy of Learning.Westport, CT: Bergin and Garvey Publishers.

Godfrey, E., \& Srivastava, N. (2009, May). Advising as Teaching: Helping Undecided Students in the Classroom. Poster session presented at the annual meeting of the National Academic Advising (NACADA), SanAntonio, TX.

Goodland, J.I.(1990). Teachers for our nation's schools. San Francisco,CA:Josey-Bass

Greene, M. (1984). Cognition, consciousness and curriculum (curriculum theorizing: An emergent form of curriculum studies in the United States). Curriculum Perspectives, 4(1), 69-84

Greene, M. (1997). Curriculum and consciousness. In D. J. Flinders \& S. J. Thornton (Eds.), The Curriculum Studies Reader (pp. 137-149). New York, NY: Routledge.

Hamre, B., \& Oyler, C. (2004). Preparing teachers for inclusive classrooms: Learning from a collaborative inquiry grooup. Journal of Teacher Education, 55(2), 154-163.

Hancock, E. S., \& Gallard, A. J. (2004). Preservice science teachers' beliefs about teaching and learning: The influence of k-12 field experiences. Journal of Science Teacher Education, 15(4), 281-291.

Helms, J. V. (1998). Science—and me: Subject matter and identity in secondary school science teachers. Journal of Research in Science Teaching, 35(7), 811-834.

History of the PK/20 collaborative. (2012). Retrieved from http://benedumcollaborative.wvu.edu/about/history 
Holland, D., Lachicotte Jr, W., Skinner, D., \& Cain, C. (1998). Identity and agency in cultural worlds. Cambridge, MA: Harvard University Press.

Holmes Group (1986). Tomorrow’s Teachers. East Lansing. MI: Holmes Group

Hong, J., \& Greene, B. (2011). Hopes and fears for science teaching: The possible selves of preservice teachers in a science education program. Journal of Science Teacher Education, 22, 491-512.

Iannone, R. (1997). The missing community voice in the phenomenological perspective of Curriculum. Education, 117(3), 356-360.

Kagan, D. M. (1992). Professional growth among preservice. Review of Educational Research, 62(2), 129-169.

Keeley, P. (2008). Science education-The times they are changing. Journal of College Science Teaching, 38(1), 10-11.

Keopuhiwa, T., Srivastava, N., Oonge, H., \& Maundu, I. (2012). Hear me out! The use of identity, space, and voice in an online classroom. Curriculum and Teaching Dialogue, 65-78.

Knight, S. L., Lloyd, G., Arbaugh, F., Edmondson, J., Nolan, J., McDonald, S. P., \& Whitney, A. E. (2012). Getting our own house in order: From brick makers to builders. Journal of Teacher Education, 63(1), 5-9.

Kohlhaas Labuda, K. (2002). Teachers' voices: A comparison of two secondary science teacher preparation programs. Texas A\&M University. ProQuest Dissertations and Theses, http://search.proquest.com/docview/305438184? accountid=2837

Kuhn, T. H. (1996). The Structure of Scientific Revolutions. Chicago, IL: University Of Chicago Press. 
Larkin, D. (2010). Learning the pedagogical implications of student diversity: The lived experience of preservice teachers learning to teach secondary science in diverse classrooms. The University of Wisconsin - Madison. ProQuest Dissertations and Theses, http://search.proquest.com/docview/756022892?accountid=2837

Laverty, S. M. (2003). Hermeneutic phenomenology and phenomenology: A comparison of historical and methodological considerations. International Journal of Qualitative Methods, 2(3), 21-35.

Leonard, C. (2011, January 10). Changing the way we socialize doctoral students. The Chronicle of Higher Education. Retrieved from http://chronicle.com/article/Changing-the-WayWe-Socialize/125892/

Levin, B. B., \& Rock, T. C. (2003). The effects of collaborative action research on preservice and experienced teacher partners in professional development schools. Journal of Teacher Education, 54(2), 135-149.

Levine, M. (1992). Professional practice school: Linking teacher education and school reform. New York: Teachers College Press

Lincoln, Y. S., \& Guba, E. G. (1985). Naturalistic Inquiry. Beverly Hills, CA: SAGE Publications.

Luehmann, A. L. (2007). Identity development as a lens to science teacher preparation. Science Education, 91, 822-839.

Lumpe, A. T., Haney, J. J., \& Czerniak, C. M. (2000). Assessing teachers' beliefs about their science teaching context. Journal of Research in Science Teaching, 37(3), 275-292. 
Mason, K. O. (2009). Teacher involvement in preservice teacher education. The University of Wisconsin - Madison. ProQuest Dissertations and Theses, http://search.proquest.com/docview/305032787? accountid=2837

McLaren, P., \& Leonard, P. (Eds.). (1993). Paulo Freire: A Critical Encounter. New York, NY: Routledge

Meijer, P. C., Graaf, G., \& Meirink, J. (2011). Key experiences in student teachers’ development. Teachers and Teaching: Theory and Practice, 17(1), 115-129.

Midgley, C., Feldlaufer, H., \& Eccles, J. S. (1989). Change in teacher efficacy and student selfand task-related beliefs in mathematics during the transition to junior high school. Journal of Educational Psychology, 81(2), 247-258.

Mogalakwe, M. (2006). The Use of Documentary Research Methods in Social Research. African Sociological Review, 10(1), 221-230.

Monet, J. A., \& Etkina, E. (2008). Fostering self-reflection and meaningful learning: Earth science professional development for middle school science teachers. Journal of Science Teacher Education, 455-475.

Mulready, A. M. (2005). The role of a five year teacher education program in supporting retention in an urban setting up to and during the critical third to fifth year attrition period. The University of Connecticut. ProQuest Dissertations and Theses, http://search.proquest.com/docview/305013186?accountid=2837

National Council for the Accreditation of Teacher Education [NCATE]. (2001). Standards for professional development schools. National Council for the Accreditation of Teacher Education. Retrieved August, 2013 from http://www.ncate.org/documents/pdsStandards.pdf. 
National Research Council. (1996). National Science Education Standards. Washington, DC: National Academy Press.

National Research Council. (2001). Educating Teachers of Science, Mathematics, and Technology. Washington, DC: National Academy Press.

National Science Teachers Association. (2000). Retrieved from http://www.nsta.org/about/positions/natureofscience.aspx

National Science Teachers Association. (2003). Standards for science teacher preparation. Retrieved from http://www.nsta.org/main/pdfs/NSTAstandards2003.pdf.

Nespor, J . (1987). The role of beliefs in the practice of teaching. Journal of Curriculum Studies, 19, 317-328.

Opfer, V. D., \& David, P. (2011). Conceptualizing teacher professional learning. Review of Educational Research, 81(3), 376-407.

Ozmon, H. A., \& Craver, S.M. (2008). Philosophic Foundations of Education. Columbus, OH: Merrill Publishing.

Pajares, M. F. (1992). Teacher's beliefs and educational research: Cleaning up a messy construct. Review of Educational Research, 62(3), 307-332.

Palmer, P. J. (1993). To Know As We Are Known: A Spirituality of Education. San Francisco, CA: Harper \& Row.

Patton, M. (2002). Qualitative Research and Evaluation Methods. Thousand Oaks, CA : Sage Publications. 
Pease, J. S. (2008). Preservice teachers' pedagogical belief development. University of Virginia). ProQuest Dissertations and Theses, http://search.proquest.com/docview/304473116?accountid=2837

Quartz, K. H., \& Group, T. R. (2003). Too angry to leave: Supporting new teachers committment to transform urban schools. Journal of Teacher Education, 54(2), 99-111.

Rock, T. C., \& Levin, B. B. (2002). Collaborative action research projects: Enhancing preservice teacher development in professional development school. Teacher Education Quarterly, 29(1), 7-21.

Rodriguez, A. J. (1998). Strategies for counterresistance: Toward sociotransformative constructivism and learning to teach science for diversity and for understanding. Journal of Research in Science Education, 35(6), 589-622.

Rosado, C. (2004). Building your leadership team: Value systems, memetics, and educationaspiral dynamics approach. Retrieved from http://www.EdChange.org/multicultural/papers/rosado leadership.pdf

Rushton, S. P. (2000). Student teacher efficacy in inner-city schools. The Urban Review, 32(4), 365-383.

Sadler, T. D. (2006). "I won't last three weeks": Preservice science teachers reflect on their student-teaching experiences. Journal of Science Teacher Education, 217-241.

Savran, A., \& Cakiroglu, J. (2003). Differences between elementary and secondary pre-service teachers' perceived efficacy belies and their classroom Management Beliefs. The Turkish Online Journal of Educational Technology, 2(4), 15-30.

Scott, D. K. (2007). Spirituality in higher education. Retrieved from http://www.kosmosjournal.org/kjo/articles/articlessub2/spirituality-in-higher-ed.shtml 
Selmer, S. J. (2008). The human experience: Changing perspectives in math education. West Virginia University. ProQuest Dissertations and Theses, http://search.proquest.com/docview/304446921 ?accountid=2837

Sewell, W. H. (1999). The concept(s) of culture. In V. E. Bonnell \& L. Hunt (Eds.), Beyond the cultural turn: New directions in the study of society and culture (pp. 35-61). Berkeley, CA: University of California Press.

Shen, J. (1997). How to reduce teacher attrition in public schools: Policy implications from a national study. Phi Delta Kappa International, 76(1), 33-39.

Slattery, P. (2006). Curriculum Development in the Postmodern Era. New York, NY: Taylor and Francis Group.

Snow, C. P. (1993). The Two Cultures. New York, NY: Cambridge University Press.

Snow-Gerono, J. L. (2009). Voices less silenced: What do veteran teachers value in schooluniversity partnerships and initial teacher preparation? The Teacher Educator, 248-267.

Steel, S., and Hoffman, N.E. (1997). The Benedum collaborative: The story of an educational reform effort. In N.E. Hoffman, W.M. Reed,\& G.S. Rosenbluth(Eds.), Lessons from restructuring experiences: Stories of change in professional development schools (pp.5174). Albany, NY: State University of New York Press.

Stevens-Long, J., Schapiro, S. A., \& McClintocK, C. (2012). Passionate scholars: Transformative learning in doctoral education. Adult Education Quarterly, 62(2), 180198.

Suranna, K. J. (2000). The nature of teacher leadership: A case study of elementary school teachers from a five-year teacher education program. The University of 
Connecticut. ProQuest Dissertations and Theses, http://search.proquest.com/docview/304596972?accountid=2837

Talanquer, V., Morgan, D., Maeyer, J., \& Young, K. (2007). Linking general education and science teacher preparation. Journal of College Science Teaching, 18-22.

Teitel, L. (1999). Looking Toward the Future by Understanding the Past: The Historical Context of Professional Development Schools. Peabody Journal of Education, 74 (3\&4), 6-20.

Thomas, D. R. (2003). A general inductive approach for qualitative data analysis. Retrieved http://www.frankumstein.com/PDF/Psychology/Inductive\%20Content\%20Analysis.pdf

Tierney, W. G. (1988). Organizational culture in higher education: Defining the essentials. The Journal of Higher Education, 59 (1), 2-21.

Toll, C.A., Neirstheimer, S.L.,Lenski, S.D.,\& Kolloff, P.B.(2004). Washing our students clean:Internal conflicts in response to preservice teachers' beliefs and practices. Journal of Teacher Education,55(2),164-176

Tsai, C. C. (1999). Laboratory exercises help me memorize the scientific truths: A study of eight graders' scientific epistemological views and learning in laboratory activities. Science Education, 83, 654-674.

Tschannen-Moran, M., Hoy, A. W., \& Hoy, W. K. (1998). Teacher Efficacy: Its meaninig and and measure. Review of Educational Research, 68(2), 202-248.

Wang, J. R., Kao, H. L., \& Lin, S. W. (2010). Preservice teachers' initial concenptions about assessment of science learning: The coherence with their views of learning science. Teaching and Teacher Education, 26, 522-529.

Wideen, M., Mayer-Smith, J., \& Moon, B. (1998). A critical analysis of the research on learning to teach: Making the case for an ecological perspective on inquiry. Review of 
Educational Research, 68(2), 130-178.

Zeidler, D. L. (2002). Dancing with maggots and saints: Visions for subject matter knowledge, pedagogical knowledge, and pedagogical content knowledge in science teacher education reform. Journal of Science Teacher Education, 13(1), 27-42.

Zembylas, M. (2002). Constructing genealogies of teachers' emotions in science teaching. Journal of Research in Science Teaching, 39(1), 79-103.

Zembylas, M., \& Barker, H. B. (2002). Preservice teacher attitudes and emotions: Individual spaces, community conversations and transformations. Research in Science Education, $32,329-351$.

Zitzewitz, P. W., Moyer, R. H., Otto, C. A., \& Everett, S.A. (2010). Building a scientist-science educator collaboration: Establishing the inquiry institute. Journal of College Science Teaching, 39, 24-27. 
APPENDICES 
Dear Participant,

\section{APPENDIX A \\ Recruitment Letter}

My name is Nitin Srivastava and I am conducting a research study under the supervision of Dr. Patricia Obenauf, a professor in the College of Education and Human Services at West Virginia University. The purpose of this research study is to help understand the lived experiences of students who graduated from or are enrolled in Benedum Program for science teacher certification at West Virginia University. More specifically, this study is aimed to find how meaning is made through reflection of the educational experiences during the participation in the program.

I would like to invite you to participate in an interview as part of this study. The interview will be recorded (via audio recorder) in order to accurately represent what you say. The interview should last for no more than 60 minutes. Only I will have access to these documents and audiotapes. The documents and interviews will be coded so that no personal identifying information is visible on them. I will keep the documents, interview transcripts, and audiotapes in a locked file cabinet and I will destroy those two years after the completion of this research.

Before choosing to participate in the study I want to make sure you understand the following:

- You must be 18 years of age or older to participate.

- Your participation is entirely voluntary, you can choose to stop the interview at any time and you do not have to answer any question you do not want to answer.

- Your responses will be kept as confidential as legally possible. Your name will not be attached to notes from this interview or to transcribed data, and the audio will be erased once transcription is complete. At no time will your name be revealed during reporting.

- Your class standing, grades, or job status will not be affected if you decide either not to participate or to withdraw.

- Besides volunteering your time to participate in this interview, there are no more than minimal risks for you to participate in the study.

- West Virginia's University’s Institutional Review Board acknowledgement of this project is on file.

Please email me, confirming your willingness to participate in the research study.

Name

Telephone

We can set up a time for the interview, which will take place in the Allen Hall or over the phone. Thank you again for your willingness to participate in this study.

Sincerely,

Nitin Srivastava

Patricia Obenauf, Ed.D.

304-276-4668

Nitin.Srivastava@mail.wvu.edu

304-293-4376

Patricia.obenauf@mail.wvu.edu

\section{APPENDIX B}




\section{Interview Questions}

1. Please tell me about your early educational experiences?

Possible exploratory prompts:

- Where are you from?

- What is your family background?

- What kind of schools you attended?

- What was the early science related educational experiences that stand out in your memories (you can include middle and high school)

- What relationships with science teachers stand out in your memories?

- Anything else you like to share about yourself?

2. Please tell me about your post-secondary experiences.

Possible exploratory prompts:

- What made you decide to choose West Virginia University?

- Was there any barrier(s) you may have experienced in your pursuit of higher education?

- (If the response is "yes") how did you overcome such barrier(s)?

- What were the influences that motivated to become a science teacher?

- Did you consider any other career option? Please explain.

- What did your friends and family think about your decision of becoming teacher?

3. How would you describe your overall experience in taking science content classes?

Possible exploratory prompts:

- How do you think your science content classes prepared you to teach in school?

- How do you describe your relationship with science content professors?

- How do you describe your relationship with fellow science content students?

- Please share specific case(s) of learning experience that stand out in your memories.

4. How would you describe your overall experience in taking education classes?

Possible exploratory prompts:

- How do you think your education classes prepared you to teach in school?

How do you describe your relationship with science education professors?

- How do you describe your relationship with fellow education students?

- Please share specific case(s) of learning experience that stand out in your memories.

5. How do you think your field experience/student teaching experience benefitted you?

Possible exploratory prompts: 
- How do you describe your relationship with the host teacher?

- Please share specific case(s) of learning experience that stand out in your memories.

- How would you describe your feeling before joining the field experience/ student teaching?

6. What are your views about science teaching and learning?

Possible exploratory prompts:

- How does learning happen?

- What is the role of teacher?

- What is the role of a student?

- What is important to know about the students when you teach them?

- How would an ideal classroom learning situation look like?

- Please describe any differences or similarities between how you and your students learn?

7. How would you compare your views about science teaching and learning before and after joining the program?

Possible exploratory prompts:

- What experiences during the program prompted the shift in your old views about science teaching and learning? Please elaborate.

- How did you feel when your views were revised?

- Were there any experiences outside your program that prompted the shift in your old views about science teaching and learning? Please elaborate.

8. How would you rate overall experience in the program?

Possible exploratory prompts:

- If you have to design your own science teacher-education program what would it look like?

- How it will be different or same as compared to your present program that you are/were part of?

- How your experiences at WVU have shaped or changed who you are?

9. Do you wish to voluntarily share any Lesson plan/Journal entries of the field experiences/student teaching during/after your participation in the program 
APPENDIX C

Clinical Experiences and Associated Teacher Education Courses

\begin{tabular}{|c|c|c|}
\hline \multicolumn{2}{|r|}{ Fall } & \multirow{2}{*}{$\begin{array}{l}\text { Spring } \\
\text { Volunteer Experience (continued) }\end{array}$} \\
\hline Year 1 & $\begin{array}{l}\text { Volunteer Experience (60 hrs completed in year } \\
1 \text { and/or } 2) \\
\text { Elementary \& Secondary } \\
\text { EDUC 100: Education Colloquium }\end{array}$ & \\
\hline Year 2 & $\begin{array}{l}\text { Volunteer Experience (continued) } \\
\text { SPED 304: Special Ed. in Contemp. Society }\end{array}$ & $\begin{array}{l}\text { Elementary \& Secondary } \\
\text { EDUC 200: Professional Inquiry }\end{array}$ \\
\hline $\begin{array}{l}\text { Year } 3 \\
\text { TUTORS }\end{array}$ & $\begin{array}{l}\text { EDUC 311: Practicum 1/Technology } \\
\text { Applications (2 hours/wk) } \\
\text { Elementary \& Secondary } \\
\text { EDUC 301: Learning I }\end{array}$ & $\begin{array}{l}\text { EDUC 312: Practicum 2/Technology Applications } \\
\text { (2 hours/wk) } \\
\text { Elementary \& Secondary } \\
\text { EDUC 400: Instructional Design \& Evaluation } \\
\text { Secondary Only } \\
\text { C\&I 425: Approaches to Teaching Literature } \\
\text { (or taken in year 4) }\end{array}$ \\
\hline $\begin{array}{l}\text { Year } 4 \\
\text { PARTICIPANTS }\end{array}$ & 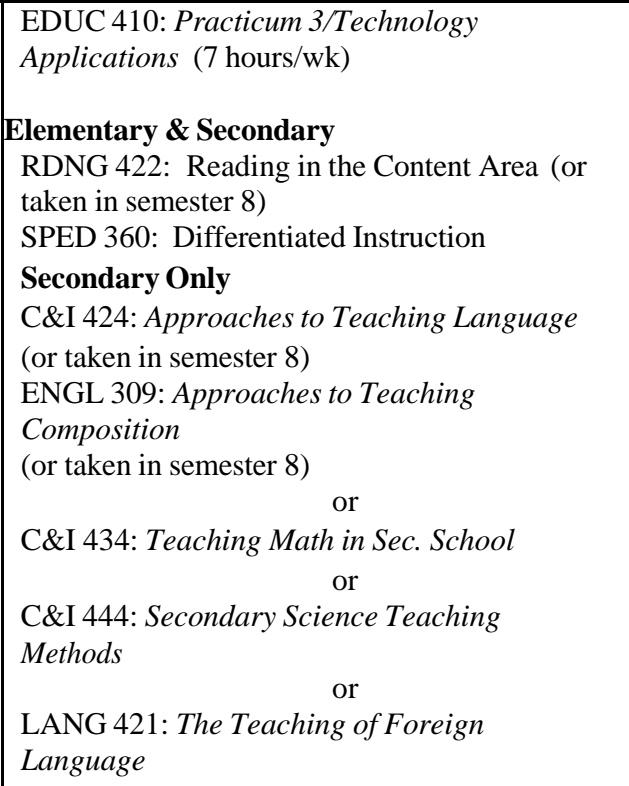 & $\begin{array}{l}\text { EDUC 411: Practicum 4/Technology Applications } \\
\text { (12 hours/wk) } \\
\text { Elementary \& Secondary } \\
\text { EDUC 401: Managing \& Organizing Learning } \\
\text { Environments } \\
\text { (Note: Sped majors take SPED } 403 \text { in lieu of } \\
\text { EDUC 401) } \\
\text { RDNG 422: Reading in the Content Area (or } \\
\text { taken in semester 7) } \\
\text { Secondary English/Language Arts Only } \\
\text { C\&I 324: Teaching Language Arts in Secondary } \\
\text { Schools } \\
\text { C\&I 424: Approaches to Teaching Language } \\
\text { (or taken in semester 7) } \\
\text { C\&I 425: Approaches to Teaching Literature } \\
\text { (or taken in year 3) } \\
\text { ENGL 309: Approaches to Teaching Composition } \\
\text { (or taken in semester 7) }\end{array}$ \\
\hline $\begin{array}{l}\text { Year 5 } \\
\text { INTERNS }\end{array}$ & $\begin{array}{l}\text { EDUC 612: Professional } \\
\text { Internship/TechnologyApplications } \\
\text { (Full-Time) } \\
\text { Elementary \& Secondary } \\
\text { EDUC 600: Teacher As Researcher }\end{array}$ & $\begin{array}{l}\text { EDUC 687: Instructional Practicum/Technology } \\
\text { Applications } \\
\text { (135 contracted hours) } \\
\text { Elementary \& Secondary } \\
\text { EDUC 601: Context of Education } \\
\text { EDUC 602: Professional Identity: Teacher As } \\
\text { Leader } \\
2 \text { Graduate Electives }\end{array}$ \\
\hline
\end{tabular}




\begin{abstract}
APPENDIX D
$\underline{\text { Characteristics of Novice Teachers as defined by the Benedum Collaborative Program }}$
\end{abstract}

1. We believe that the novice teacher should have a commitment to and skills for life-long learning.

2. We believe that the novice teacher should be an effective communicator

3. We believe that the novice teacher should recognize that teaching is a professional, moral, and ethical enterprise, should understand moral issues and ethical practices in educational environments, and should have developed ethical frameworks which facilitate effective teaching.

4. We believe that the novice teacher should be a facilitator of learning for all students.

5. We believe that the novice teacher should have in-depth knowledge of content.

6. We believe that the novice teacher should have in-depth knowledge of pedagogy.

7. We believe that the novice teacher should have in-depth knowledge of content and pedagogy.

8. We believe that the novice teacher should be a reflective practitioner.

9. We believe that the novice teacher should be aware of and have respect for human diversity.

10. We believe that the novice teacher should be liberally educated. 


\section{APPENDIX E}

Eight Developmental Zones/Value Structures Defined By Color-Coding

BEIGE (Archaic/Survival ). This value structure involves "staying alive through innate sensory equipment" (Beck \& Cowan, 1996, p. 41). Basic theme is "Do what you must to stay alive" (Roemischer, 2002). Examples: extremely poor/homeless people on streets.

PURPLE (Animistic/Clannish “Us”): This value structure involves "Blood, relationships and mysticism in a magical and scary world" (Beck \& Cowan, 1996, p. 41). Pre-modern thinking dominate here. A sense of attachment to particular group/tribe or places is heightened. Basic theme is "Keep the spirit happy and their tribe's nest warm and safe" (Roemischer, 2002).

RED (Egocentric ): This value structure involves individuals who "enforce power over self, others, and nature through exploitive independence" (Beck \& Cowan, 1996, p. 41). The emphasis is more towards "egocentric self". Basic theme is "Be what you are and do what you want regardless" (Roemischer, 2002).

BLUE (Authoritarian/Absolustic/Traditional): This value structure involves "absolute belief in one right way and obedience to authority" (Beck \& Cowan, 1996, p. 41). In this meme, people accept the authoritarian power and the need to be controlled. Basic theme is "Life has meaning, direction and purpose with predetermined outcomes" (Roemischer, 2002).

ORANGE (Rational/Scientific/Materialistic): This value structure involves "possibility thinking based on making things better for self" (Beck \& Cowan, 1996, p. 41). It is more based on advancements, rational reasoning and scientific approach and methods and believes in competing to get results. Modern thinking is dominated in this value structure. Basic theme is "Act in your self-interest by playing the game to win" (Roemischer, 2002).

GREEN (Pluralistic/Sociocentric): This is the final level of the first tier of the value structure where postmodern thinking dominates. The consensual, non-sectarian approach and a sense of belonging is given prominence here. The value structure involves individuals who insist that "well-being of people and consensus get highest priority" (Beck \& Cowan, 1996, p. 41). Basic theme is "Seek peace within the inner self and explore with others, the caring dimensions of the community" (Roemischer, 2002).

YELLOW (Integrative): This value structure involves, "flexible adaptation to change through connected, big-picture views" (Beck \& Cowan, 1996, p. 41). Basic theme is "Live fully and responsibly as what you are and learn to become" (Roemischer, 2002). This value structure accepts the chaotic nature of life and the complexities of life and other value structures and transcending in nature.

TORQUOSE (Globalist): This value structure involves "attention to whole-Earth dynamics and macro-level actions" (Beck \& Cowan, 1996, p. 41). This is the higher and more spiritual stage of consciousness where thinking is in terms of global community. Basic theme is "Experience the wholeness of existence through mind and spirit" (Roemischer, 2002). 


\section{APPENDIX F}

Value structures and their Associated Learning and Teaching Styles Source: http://www.EdChange.org/multicultural/papers/rosado leadership.

\begin{tabular}{llll} 
VMEME & Values & Learning style & Teaching style \\
\hline
\end{tabular}

Tier 2

\begin{tabular}{clll}
\multicolumn{1}{c}{ CORAL } & Undetermined & Undetermined & Understanding \\
$\begin{array}{c}\text { TORQUOISE } \\
\text { (globalist, renewalist) }\end{array}$ & $\begin{array}{l}\text { Lives for wisdom, self-distinct } \\
\text { whole, everything is connected, } \\
\text { holism }\end{array}$ & $\begin{array}{l}\text { Experiential } \\
\text { (participate with senses) }\end{array}$ & $\begin{array}{l}\text { Holistic } \\
\text { (open doors) }\end{array}$ \\
& $\begin{array}{l}\text { Lives for mutuality, } \\
\text { enlightened self-interest, } \\
\text { flexible, creative }\end{array}$ & $\begin{array}{l}\text { Informational } \\
\text { (freedom to be/discover) }\end{array}$ & $\begin{array}{l}\text { Integrative (seek connections, } \\
\text { diverse) }\end{array}$
\end{tabular}

Tier 1

\section{GREEN}

(relativistic, sociocentric)

ORANGE

(materialist, achiever)

BLUE

(traditional)

RED

(my powerful self)

\section{BEIGE (survivalist)}

\section{Lives for harmony,}

world-centric,

egalitarian, empathy, authentic

Lives for gain, liberated,

competitive, materialistic,

consumerism

Lives for later, law and order, ethnocentric outlook, one-right-way

(use trial/error, competitive)

Lives for now, aggression, impulsive, egocentric, exploitation, power, glory

Lives for survival, safety, protection
Observational

(watch, feel and learn)

Expectancy
(to succeed in objectives)

Experimental

Avoidant

(so as to not be punished)

Affiliative

(foster belonging)

Authoritarian

(impose order, punish mistakes fairly)

Conditioned (operant

through reinforcement)

Reinforcement (empower individuals, tough love)

Not applicable
Not applicable 